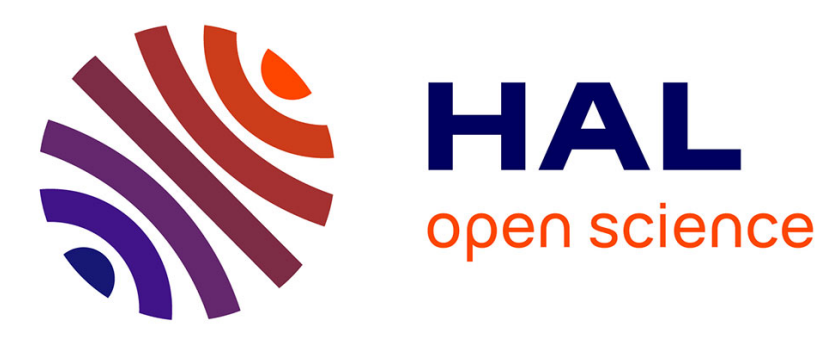

\title{
La société locale vue à travers la statuaire domestique du Hunan
}

Alain Arrault

\section{To cite this version:}

Alain Arrault. La société locale vue à travers la statuaire domestique du Hunan. Cahiers d'ExtrêmeAsie, 2012, 19, pp.47-132. halshs-00959725

\section{HAL Id: halshs-00959725 \\ https://shs.hal.science/halshs-00959725}

Submitted on 15 Mar 2014

HAL is a multi-disciplinary open access archive for the deposit and dissemination of scientific research documents, whether they are published or not. The documents may come from teaching and research institutions in France or abroad, or from public or private research centers.
L'archive ouverte pluridisciplinaire HAL, est destinée au dépôt et à la diffusion de documents scientifiques de niveau recherche, publiés ou non, émanant des établissements d'enseignement et de recherche français ou étrangers, des laboratoires publics ou privés. 


\title{
LA SOCIÉTÉ LOCALE VUE À TRAVERS LA STATUAIRE DOMESTIQUE DU HUNAN
}

\author{
Alain ArRAULT
}

\begin{abstract}
The religious statuary of Hunan provides a rich documentary source on domestic cults. While such statuary can be viewed as the culmination of the long history of the religious image in China, on which a lot of work remains to be done, it nevertheless shows much dissimilarity with that tradition. The most important of those dissimilarities is that the statuettes feature a certificate of consecration, a veritable certificate of civil status which reflects a concrete image of familial religious practices, and adds to the already substantial amount of information on the subject of communitarian cults published in a number of works during the last few decades. Unsurprisingly, but nevertheless instructively, family altars since the end of the Ming dynasty feature not only statuettes of national and local divinities, but also major ancestors and masters of lineage and, above all, close ancestors and masters, this last factor constituting a specificity about which we have little information available. The aim of this article is thus to focus on statues of ancestors and masters with a view to presenting and analyzing the phenomenon and sketching a table of religious practices in Hunan, both diachronically thanks to the "civil status certificates" and bistorical sources including genealogies, and synchronically using contemporary surveys conducted in the field. This reversal of perspective based on the family nucleus calls into question the nature of the organization of clans and local society, and puts an end to all attempts to apply a global approach to Chinese society.
\end{abstract}

\section{Introduction}

Le catalogage informatique de trois collections de statuettes provenant de la province du Hunan, plus précisément de la partie centrale de cette province, nous a permis de dégager un certain nombre de traits caractéristiques de cette statuaire. Il s'agit sans ambiguïté aucune de statuettes religieuses, par conséquent objets de culte. Ce culte est domestique, l'aspect communautaire, alliant des fidèles hétéronymes, ne dépassant pas en nombre d'occurrences - toutes catégories cultuelles confondues (culte aux divinités, aux divinités locales, aux ancêtres, aux parents et aux maitres) - le i \% du total des pièces recensées. En soi, même si cette statuaire ne recouvre qu'une région du sud de la Chine, elle dévoile un type de culte rarement visible, les cultes autour d'un temple, rassemblant une communauté, étant à ce jour les mieux documentés. Par ailleurs, le domus dont il est question ne concerne dans la grande majorité des cas que la famille et non la famille élargie, et encore moins le clan : nous sommes en présence de trois générations de fidèles : le père, le plus souvent associé avec la mère, les enfants, fils et filles, les gendres et brus, les petits enfants. Autrement dit, nous sommes au fondement même de la société chinoise

Cabiers d'Extrême-Asie 19 (2010) : 47-132

(C) École française d'Extrême-Orient, Paris, 2012 Do not circulate without permission of the editor / Ne pas diffuser sans autorisation de l'éditeur 
traditionnelle, et d'une grande partie des sociétés humaines avant que celles-ci, suivant des rythmes propres, ne reposent sur une structure familiale réduite à deux générations (parents - enfants). Certaines études récentes montrent que c'est dans cette forme de sociabilité que prévalaient de manière plus active et efficace les règles de solidarité et d'entraide, de légitimité et de succession, que l'on a abusivement, et parfois exclusivement, attribuées au clan. Il n'est ici naturellement pas question de nier tout rôle au clan, qui sans aucun doute fut grand, ni de nier l'existence de liens sociaux au delà de la famille restreinte, mais grâce à cette statuaire et sa documentation, de revenir sur le noyau primordial de la société chinoise que des documents foisonnants tels que les généalogies, les monographies de temples, la description de fêtes religieuses, etc., ont eu tendance - et pour cause - à occulter. Il s'agit donc d'une complémentarité et d'un changement de perspective qui s'appuient sur un nouveau type de sources, les certificats de consécration inclus dans une cache située dans le dos des statuettes. La nature religieuse de ces données ne peut constituer un argument d'exceptionnalité, de contre-exemple à une version « laïcisée » où la famille existerait sous des formes autres (économique, juridique, etc.), tant la famille chinoise est indissociable de ses composantes religieuses, au sens large de religion, intervenant non seulement dans les moments cruciaux de la vie (naissance, mariage, mort), mais aussi dans les moments plus quotidiens de l'existence : les statuettes dont il est question sont installées sur un autel, situé dans la pièce principale, au cœur de la maison.

Nous n'aborderons dans cet essai que les statuettes dédiées aux ancêtres et aux maitres, laissant de côté celles qui concernent les divinités, et ceci pour deux raisons : I) ces dernières ont été déjà présentées et analysées dans des études précédentes ${ }^{1}$; 2) même si nous trouvons, comme nous le verrons, des exemples des premières dans d'autres régions de la Chine, ce culte particulier recouvre au Hunan des proportions inégalées ailleurs et présente des caractéristiques inédites, notamment dans son extension, qui englobe non seulement les grands ancêtres, mais aussi les proches parents ; non seulement les maitres de lignage, les patrons de guilde, mais aussi les maitres d'initiation directs.

\section{Statues d'ancêtres et de maîtres dans la province du Hunan}

Les analyses qui suivent reposent, comme nous l'avons signalé dans notre introduction, sur le catalogage informatique de trois collections de statuettes provenant du Hunan. Deux collections sont privées : elles appartiennent à Patrice Fava $(\mathrm{PF})$ et Yan Xinyuan 顏新元 (YXY) ; la troisième, propriété du Musée du Hunan (MH), est de ce fait «publique ». Elles comprennent respectivement 9 II, 1362 et 870 pièces.

I. Voir Alain Arrault, "Analytic Essay on the Domestic Statuary of Central Hunan. The Cult to Divinities, Parents and Masters," Journal of Chinese Religions, 36 (2008), p. 4-9 ; Alain Arrault et Michela Bussotti, "Statuettes religieuses et certificats de consécration en Chine du Sud », Arts asiatiques, 63 (2008), p. 37-38.

2. Les numéros de catalogage sont les suivants : «T » suivi de quatre chiffres pour la collection $\mathrm{PF}$;

(C) École française d'Extrême-Orient, Paris, 2012

Do not circulate without permission of the editor / Ne pas diffuser sans autorisation de l'éditeur 
Tableau 1 : Analyse quantitative des données des statuettes

\begin{tabular}{|c|c|c|c|}
\hline $\begin{array}{l}\text { Nom de } \\
\text { la collection }\end{array}$ & Nombre total de statues & $\begin{array}{l}\text { Nombre de certificats } \\
\text { de consécration }\end{array}$ & $\begin{array}{l}\text { Nombre de statues sans certificat } \\
\text { et avec inscriptions }\end{array}$ \\
\hline YXY & 1362 & 362 & 32 \\
\hline PF & 911 & 826 & 11 \\
\hline MH & 870 & 103 & 84 \\
\hline Total & 3143 & 1291 & 127 \\
\hline
\end{tabular}

Insérés lors de la consécration dans une cache située dans le dos de la statuette, les documents écrits, appelés localement yizbi 意旨 (littéralement « Notre Volonté », que nous traduisons librement par «certificat de consécration»), permettent dans la plupart des cas de les identifier, de les localiser et de les dater's. De surcroît, les noms des commanditaires et des sculpteurs sont mentionnés 4 . Il s'agit par conséquent d'une véritable fiche d'état civil des statues, terme qu'il faut prendre à la lettre et qui confère à ces certificats une nature d'archive, avec toute la richesse mais aussi les défauts que présente ce genre de documentation : il offre des faits concrets et bruts, qui ne nécessitent pas de métadiscours pour les comprendre. Pris séparément, ces yizbi ne disent pratiquement rien, - du moins pas plus que ce qu'ils donnent à voir ; ce n'est qu'en les prenant dans leur ensemble, qu'en recoupant les informations qu'ils distillent, - ce qu'autorise justement une banque de données informatisées -, que nous pouvons en extraire des données significatives et en déduire des analyses religieuses et sociologiques pertinentes. Dans ce cas, la quantité devient un critère décisif : plus le nombre de documents est grand, plus il permet d'affiner nos conclusions.

Mais toutes les statues ne sont pas "pleines » : certaines ont été ouvertes et vidées de leur contenu, soit par inadvertance, soit délibérément. Dans ce dernier cas de figure, c'est le fait du propriétaire, qui vend (ou jette) une statuette en prenant soin de la dé-consacrer, un rite se concluant par l'ouverture de la cache et le vidage de son contenu - qui peut éventuellement être réutilisé pour une nouvelle statue ; ou le fait de l'antiquaire, qui prive ainsi l'objet d'une datation certaine, se laissant toute liberté de proposer à ses clients une datation la plus reculée possible et, partant, un prix plus élevé. Les statues vidées ne sont pas pour autant toutes dépourvues d'informations : il arrive en effet que soient inscrits sur elles leur nom, le nom du graveur, la date de consécration. Le tableau i ci-dessus présente le détail en chiffres des certificats et des pièces avec inscriptions.

La documentation de la collection PF est de loin la plus riche en pourcentage ; celle de la collection YXY occupe environ $25 \%$ du total des pièces, celle de la col-

« Y » suivi de chiffres pour la collection YXY ; du type de ooI7/C:915, où les quatre premiers chiffres sont un numéro de catalogage et le reste un numéro d'inventaire, pour la collection $\mathrm{MH}$.

3. Pour plus de détails sur la répartition temporelle et géographique des statuettes, voir Alain Arrault, art. cit., p. 4-9 ; Alain Arrault et Michela Bussotti, art. cit., p. 37-38.

4. Pour ce qui concerne les sculpteurs, voir dans ce numéro l'article de Michela Bussotti. 
lection $\mathrm{MH}$ un peu plus de Io \%, ces deux dernières ayant néanmoins un nombre de pièces avec inscriptions relativement important. La comparaison des trois collections quant à leur contenu, dépendant de la manière et du lieu où elles ont été constituées, offre d'heureuses complémentarités : si la collection PF comprend un nombre important de statuettes d'obédience "taoïste ", celle de $\mathrm{MH}$ est remarquable par la prééminence de statuettes " bouddhiques »'. Quant à celle de YXY, d'origine plus modeste, elle présente la particularité de rassembler des pièces certes généralement plus petites et frustres mais également plus « populaires », notamment des statues de chasseurs quasiment absentes dans les deux autres collections.

Les pièces des deux collections $\mathrm{PF}$ et $\mathrm{MH}$ couvrent une période allant du début du XvII ${ }^{e}$ siècle jusqu'aux années 90 du siècle dernier, avec une proportion importante répartie sur le $\mathrm{XIX}^{\mathrm{e}}$ et le début du xxe siècle 6 . Celles de la collection YXY se concentrent par contre en grande majorité sur le $\mathrm{XX}^{\mathrm{e}}$ siècle ( $\mathrm{I} 80$ pièces sur les 249 datées avec certitude), du début du siècle aux années 9o, la caractérisant ainsi comme "plus récente ». Si les statuettes des collections $\mathrm{PF}$ et $\mathrm{MH}$ occupent géographiquement le coeur de la région dite de Meishan 梅山, notamment les districts d'Anhua 安化 et de Xinhua 新化, il en va autrement pour celles de la collection YXY, qui proviennent plutôt de la partie orientale de cette région, dans les districts de Ningxiang 寧湘 et Xiangxiang 湘榔. Il va sans dire qu'en dehors de ces grandes caractéristiques de différenciation, le détail apporte également son lot de disparités complémentaires. Autrement dit, la confrontation de ces collections efface partiellement les orientations subjectives des collectionneurs, ainsi que les aléas inhérents au choix, pour faire apparaitre un tableau plus objectif de cette statuaire.

\section{A) Statues d'ancêtres}

Si au discours iconoclaste concernant la représentation des ancêtres s'est superposé en réalité l'existence de portraits, que ce soit ceux des empereurs et leur suite, ou ceux de gens plus ordinaires, au moins à partir de la fin des Ming, de statues d'ancêtres dont la présence est attestée au tournant du XviII ${ }^{e}$ siècle dans le sud de la Chine?, c'est bien parce que l'ambiguïté du culte aux ancêtres, de ses principes et règles, n'a jamais été levée. L'exemple du Hunan ne constitue donc pas une étrangeté absolue, si ce n'est qu'il déroge par le nombre considérable d'icônes ancestrales, réparties sur une période de plus de trois siècles. Au fond, il confirme résolument sur certains points une pratique qui serait passée de la lumière à l'ombre. Mais sur certains autres, il relève pourtant de l'exception et de l'exceptionnel, comme nous allons le voir.

5. Voir Arrault, art. cit., p. Io-I6, et Arrault et Bussotti, art. cit., p. 39-42.

6. Voir Arrault, ibid., p. 7, et Arrault et Bussotti, ibid., p. 38.

7. Voir Li Guangdi 李光地 (1642-1718), Rongcun yulu xuji 榕村語錄續集, juan I2, dans Siku weishou jikan 四庫未收輯刊, siji 作輯, Beijing, Beijing chubanshe 北京出版社, 1997, vol. 2I, p. 90-9I.

(C) École française d'Extrême-Orient, Paris, 2012

Do not circulate without permission of the editor / Ne pas diffuser sans autorisation de l'éditeur 


\section{De lointains et proches ancêtres}

Les statuettes dédiées aux ancêtres dans les données à notre disposition sont déterminées par l'appellation que les rédacteurs des certificats ont accolée à leur nom, une appellation confirmée sur un premier niveau par un nom de famille commun à celui des commanditaires, puis parfois par les appellations de « fils», "petits-fils», " arrière-petits-fils », " descendants » qui précèdent la liste des commanditaires eux-mêmes. Sur cette base, une comptabilité rigoureuse fournit le nombre de I46 statuettes sur les trois collections, un total certes non négligeable mais qui ne représente qu'un dixième environ des statuettes munies de certificats ou recouvertes d'inscriptions (I4I8 = I29I + I27) (voir le Tableau I ci-dessus). La série de termes exprimant la relation familiale indique clairement que l'éventail se déploie très largement, puisqu'il fait se rejoindre le premier ancêtre avec le fils du cousin germain. Si nous procédons par tranches générationnelles (voir Tableau 2 ci-dessous), la catégorie "père » (ligne numérotée 7) domine largement toutes les autres, viennent ensuite les mères (ligne 8), les oncles (ligne io) et les grands parents (ligne 5), suivis de très près par les grands ancêtres (lignes $\mathrm{I}, 2,3$ ). Les trisaïeux et bisaïeux (ligne 4), les beaux-parents (ligne 9), les grands oncles et tantes (ligne 6), et les frères (ligne II) ferment la marche. La belle-sour (ligne I2) et le fils de cousin (ligne I3), qui font figure d'exception, démontrent $a$ contrario que la liste n'est pas close et $a$ priori extensible à volonté.

Le culte englobe par conséquent les ancêtres très lointains jusqu'aux parents les plus proches. Parmi la catégorie "grands ancêtres », il est remarquable qu'un seul «premier ancêtre » (shizu 始祖) soit recensé. Il serait né sous le règne de Shunzong 順宗 (r. 805) des Tang et mort sous celui de Wenzong 文宗 (r. 826-840), si ce n'était que les dates avancées en fonction des règnes de ces deux empereurs sont fantaisistes (T 0474), un phénomène que l'on observe souvent lorsqu'il s'agit des premiers ancêtres dans les généalogies, ce qui pour autant ne retire évidemment rien à leur statut : une date aussi reculée ne peut que correspondre à un «fondateur ».

Les dates des taizu 太祖 vont de la dynastie des Yuan, au commencement des Ming jusqu'au tout début de la dynastie des Mandchous, avec dans tous les cas des consécrations effectuées par des descendants plusieurs siècles plus tard, à la fin du XIX ${ }^{\mathrm{e}}$, au début du XXe siècle (T 0459, T0295, T0284), soit bien au-dessus des sept générations - le nombre de générations d'ancêtres admis seulement pour l'empereur — au-delà desquelles les ancêtres rejoignent la « masse ancestrale » et ne sont plus objets de culte, une règle qui ne semble pas observée dans les citang 祠堂 à l'époque des Qing. Ceux que nous avons inclus parmi les « ancêtres » (gu $x i a n z u$ 故顯祖, $g u z u$ 故祖, lao waizu 老外祖) l'ont été en quelque sorte par défaut : nous ne disposons pas des dates précises de leur naissance et mort, mais ils nous semblent se situer entre les grands ancêtres et les trisaïeux et bisaïeux, à un moment où le vocabulaire des liens de parenté n'existe plus, mais qui précède de peu celui des arrière-arrière-grands-parents et des arrière-grands-parents, respectivement désignés sous les vocables de gaozu 高祖 et zengzu 曾祖.

Comme nous pouvions nous y attendre, la branche paternelle l'emporte en nombre sur la branche maternelle : il est bien connu qu'en Chine la patrilinéarité 
Tableau 2 : Type de relations familiales pour les statuettes dédiées aux ancêtres

\begin{tabular}{|c|c|c|c|c|}
\hline & $\begin{array}{l}\text { Appellation } \\
\text { en chinois }\end{array}$ & $\begin{array}{l}\text { Appellation } \\
\text { en français }\end{array}$ & Nombre & $\begin{array}{c}\text { Total par catégorie de } \\
\text { parenté }\end{array}$ \\
\hline 1 & 始祖 & Premier ancêtre & 1 & \multirow{6}{*}{13} \\
\hline 2 & 太祖 & Grand ancêtre & 7 & \\
\hline 2 & 太公 & Grand ancêtre & 2 & \\
\hline 3 & 故顯祖 & Ancêtre & 1 & \\
\hline 3 & 故祖 & Ancêtre & 1 & \\
\hline 3 & 老外祖 & Ancêtre du côté maternelle & 1 & \\
\hline 4 & 故太高 & Arrière-arrière-grand-père paternel & 1 & \multirow{4}{*}{6} \\
\hline 4 & 曾祖 & Arrière-grand-père paternel & 2 & \\
\hline 4 & 祖妣 & Arrière-grand-mère paternelle & 2 & \\
\hline 4 & 曾祖妣 & Arrière-grand-mère paternelle & 1 & \\
\hline 5 & 祖考 & Grand-père paternel & 8 & \multirow{6}{*}{15} \\
\hline 5 & 祖父 & Grand-père paternel & 2 & \\
\hline 5 & 登曹祖父 & Grand-père paternel & 1 & \\
\hline 5 & 祖公 & Grand-père paternel & 1 & \\
\hline 5 & 老祖公 & Grand-père paternel & 1 & \\
\hline 5 & 祖母 & Grand-mère paternelle & 2 & \\
\hline 6 & 堂伯祖 & Grand oncle paternel & 1 & \multirow{3}{*}{3} \\
\hline 6 & 姑婆 & Grand-tante paternelle & 1 & \\
\hline 6 & 家堂姑婆 & Grand-tante paternelle & 1 & \\
\hline 7 & 父親 & Père & 28 & \multirow{10}{*}{70} \\
\hline 7 & 先考 & Père & 20 & \\
\hline 7 & 顯考 & Père & 7 & \\
\hline 7 & 父 & Père & 7 & \\
\hline 7 & 故先考 & Père & 3 & \\
\hline 7 & 先父 & Père & 1 & \\
\hline 7 & 清故先考 & Père & 1 & \\
\hline 7 & 父親符水 & Père & 1 & \\
\hline 7 & 父親靈神 & Père & 1 & \\
\hline 7 & 仙逝顕考[父]親 & Père & 1 & \\
\hline 8 & 母 & Mère & 4 & \multirow{7}{*}{15} \\
\hline 8 & 母親 & Mère & 4 & \\
\hline 8 & 先妣(母親) & Mère & 3 & \\
\hline 8 & 堂母 & Mère & 1 & \\
\hline 8 & 老母 & Mère & 1 & \\
\hline 8 & 故母 & Mère & 1 & \\
\hline 8 & 慈母 & Mère & 1 & \\
\hline 9 & 岳父 & Beau-père & 2 & \multirow{4}{*}{5} \\
\hline 9 & 岳翁 & Beau-père & 1 & \\
\hline 9 & 岳丈 & Beau-père & 1 & \\
\hline 9 & 岳母 & Belle-mère & 1 & \\
\hline
\end{tabular}




\begin{tabular}{|c|c|c|c|c|}
\hline 10 & 伯父 & Oncle paternel & 6 & \multirow{6}{*}{14} \\
\hline 10 & 叔祖 & Oncle paternel & 1 & \\
\hline 10 & 叔父 & Oncle paternel & 3 & \\
\hline 10 & manque & Oncle & 1 & \\
\hline 10 & 叔外祖 & Oncle maternel ? & 1 & \\
\hline 10 & 伯母 & Tante (épouse du frère aîné du père) & 2 & \\
\hline 11 & 胞兄 & Frère aîné & 1 & \multirow{3}{*}{3} \\
\hline 11 & 故兄 & Frère aîné & 1 & \\
\hline 11 & 長兄 & Frère aîné & 1 & \\
\hline 12 & 嬏母 & Belle-sœur & 1 & 1 \\
\hline 13 & 堂姪 & Fils de cousin & 1 & 1 \\
\hline \multicolumn{3}{|c|}{ Total } & & 146 \\
\hline
\end{tabular}

prévaut sur la matrilinéarité, que ce soit d'un point de vue coutumier, législatif ou plus concrètement économique. Les femmes mariées sortent de leur famille d'origine, désignée globalement par le terme d' «extérieure » (wai 外); les filles ne sont ainsi généralement pas nommées dans les généalogies familiales, sauf en terme de nombre, et les femmes mariées sont uniquement désignées par leur nom de jeune fille : par exemple, madame $X$, née $Y$, a eu les garçons Untel, Untel... et trois filles. La statuaire du Hunan laisse pourtant une place, bien que dans des proportions moindres, aux femmes du côté patrilinéaire : des statues sont en effet dédiées à des arrière-grands-mères, grand-tantes et même belles-sœurs ; elle prend aussi en compte non seulement la mère, honorablement représentée, mais aussi le lignage autour d'elle : il y a un ancêtre du côté maternelle (lao waizu), des beaux-parents et un oncle maternel. Par ailleurs, les filles, et parfois même les petites-filles, désignées par leur prénom, sont assez fréquemment associées au culte dans la liste des commanditaires. En d'autres termes, la famille restreinte opère selon une logique qui n'est pas celle du clan.

\section{Des ancêtres initiés}

À partir des Qing, le portrait d'ancêtre, le plus souvent peint, représente fréquemment un couple, un homme et une femme assis dans une pose hiératique sur un siège, les mains sur les genoux, habillés d'atours chatoyants, l'homme coiffé d'un chapeau mandarinal et et les deux faisant face au spectateur, impassible. Le duo a tout l'air de divinités, si ce n'était les traits du visage qui offrent non pas une figure lisse et impersonnelle, mais celui de personnes particulières. Dans cette individualisation, le visage est pourtant sublimé en partie pour répondre aux canons de la physiognomonie : il ne peut être que prometteur d'une longue descendance, brillante et riche. Certaines statues d'ancêtres adoptant la pose classique répondent plus ou moins à ces critères : voici un grand-père, sculpté sur un siège sans accoudoir, sa main gauche est posée sur son genou et l'autre tient ce qui semble être un éventail ; sa tunique fermée avec quatre boutons et son chapeau rond correspondent à un accoutrement plutôt populaire (T 0699, voir fig. I). Une grand-mère, portant une longue robe d'où 
Fig. 1 : Grand-père Li Qi [zhi] 李起 [志], 1941, T 0699.

Cliché Zhang Chaoyin.
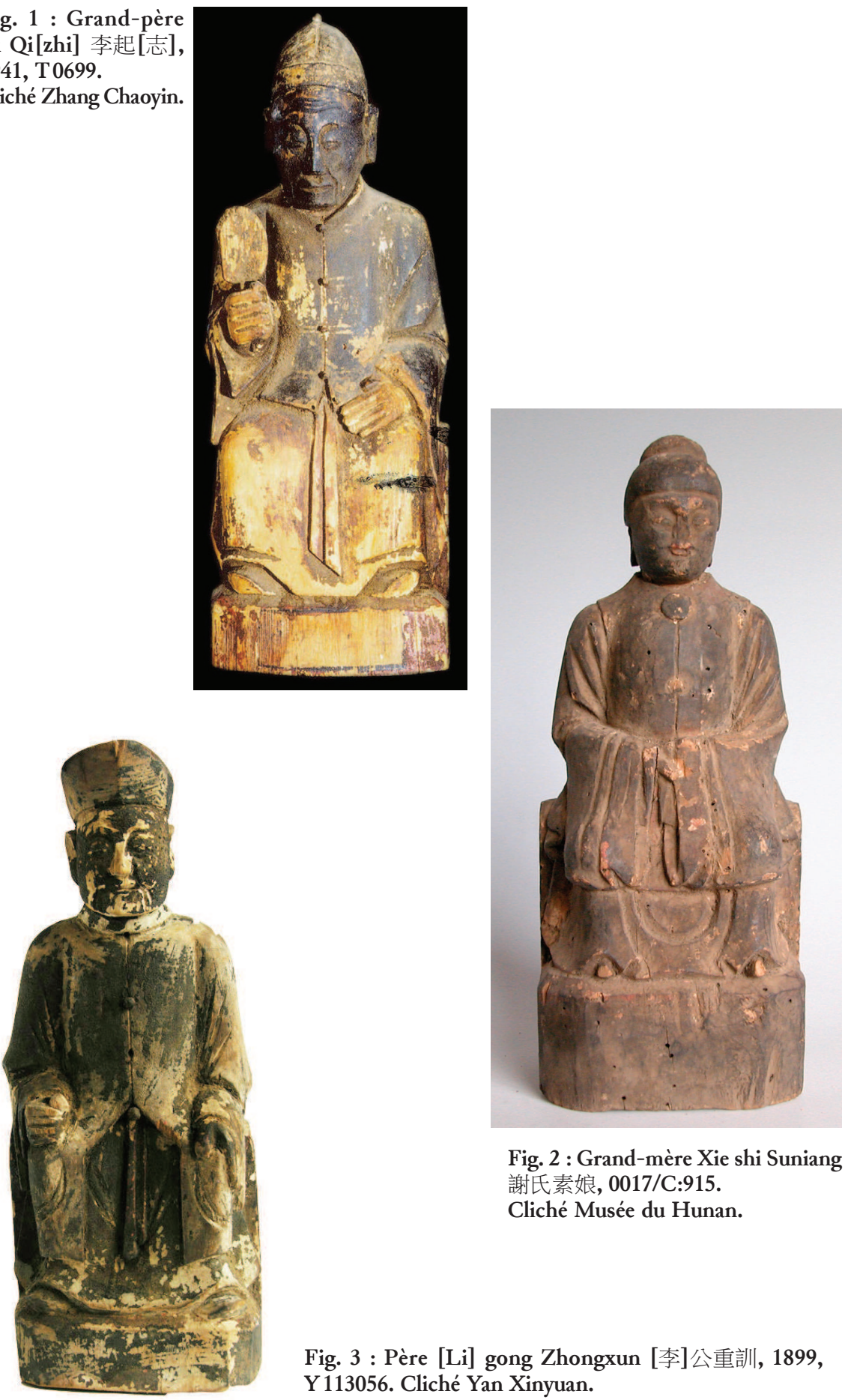

Fig. 3 : Père [Li] gong Zhongxun [李]公重訓, 1899, Y113056. Cliché Yan Xinyuan.

(c) École française d'Extrême-Orient, Paris, 2012

Do not circulate without permission of the editor / Ne pas diffuser sans autorisation de l'éditeur 
pointent des petits pieds, les mains jointes dans ses larges manches, est également en position assise. Son visage est plein, surmonté d'une coiffure ronde (oor7/C:915, voir fig. 2). Un père présente des caractéristiques identiques à la statue du grand-père, même type de vêtement, une coiffure certes un peu plus carrée, mais à première vue rien qui ne soit détonnant, et pourtant... La main gauche est comme toujours sagement posée sur le genou, mais celle de droite est comme un poing fermé sur la cuisse : cette main tenait à l'origine un ustensile (YII3056, voir fig. 3). Cet indice nous conduit vers un autre type d'ancêtre.

En effet, la majorité des statuettes d'ancêtres tiennent des instruments qui ne sont pas insignifiants : il s'agit le plus souvent d'un bol dans la main gauche et d'un bâton de commandement dans la main droite, ou encore de blocs divinatoire, d'un livre, autant d'ustensiles qui relèvent de la liturgie. Le bol contient de l'eau lustrale pour purifier une aire sacrée ; le bâton a pour fonction de ponctuer le rite d'invocation des divinités qui doivent répondre aux ordres de l'officiant, etc. Certaines statues se tiennent debout, la main droite faisant le geste de tenir quelque chose à hauteur de poitrine : ce sont des chasseurs qui ont perdu leur fusil (Y I5OI2, voir fig. iI). Lorsque l'aspect extérieur ne signale pas une fonction religieuse particulière, les certificats de consécration nous livrent les noms d'ordination (zouming 奏名), de fonction (zbiming 職名), de maîtres d'exorcisme (faming 法名), de taoïste (daoming 道名), de bouddhiste (shiming 釋名) de personnages représentés de manière neutre. Parfois, c'est en lisant plus avant les certificats que nous découvrons des qualités particulières : telle arrière-grand-mère, sous des abords innocents, est en fait invoquée sous le nom de lao xianren 老仙人 (vénérable immortelle) pour protéger une naissance à venir (To607). En d'autres termes, les ancêtres dont il est question sont en réalité des personnes qui ont été initiées et ordonnées, le plus fréquemment en maittres exorcistes (fashi 法師, ou localement appelés shigong 師公, les maitres), mais il peut aussi s'agir de métiers comme ceux de sage-femme, de chasseur, de guérisseur, qui supposent une initiation et l'exercice d'un pouvoir rituel et symbolique. Ce ne sont donc pas des « laïcs », éventuellement munis de titres de fonctionnaire, mais des hiérarques relevant de la sphère du religieux. Quelques exemples suffiront à illustrer ce point.

\section{a) Statues de grands ancêtres}

Au plus haut de la hiérarchie des ancêtres dominent les jiazhu 家主, les maîtres de famille, en regard des maîtres des lieux (dizbu 地主) qui sont l'objet de culte non pas seulement d'une famille, mais de plusieurs, jouant ainsi le rôle de protecteur d'un lieu, d'un ou plusieurs villages, parfois d'un district. De ce fait, le maitre de famille doit en principe être vénéré par des descendants. Perdu dans la nuit des temps, ce maître est normalement perçu comme un fondateur, à l'instar d'un shizu 始祖, mais rien ne prouve qu'il ne soit pas en fait un personnage remarqué et célébré pour ses talents d'ordre spirituel, un personnage qui peut se conjuguer au masculin comme 
au féminin ${ }^{8}$. À cause de cette ambiguité — ancestralité ou charisme religieux —, il n'est pas aisé de les situer sur la ligne du temps, aussi ne les avons-nous pas recensés dans notre tableau, sachant par ailleurs que les collections de référence ne fournissent curieusement que peu d'exemples formellement identifiés et qu'il a fallu aller plus loin que les appellations pour en trouver. Nous présenterons ensuite quelques exemples de "grands ancêtres » (taizu 太祖).

Maître de famille. Laozu Shisi lang gong 老祖十四郎公 (le vieil ancêtre Quatorzième seigneur), ToI26, consacré en I9II (voir fig. 4). Le commanditaire principal est une femme née Zou 鄒, accompagnée de son fils, de sa bru, de son petit-fils et de sa petite-fille. On nous apprend que ce seigneur est :

Un célèbre lettré des Song. Il examina les montagnes pour les défricher et en expulser les renards. C'est à Fuzhou 撫州 [Jiangxi 江西] qu'il s'initia aux rites d'exorcisme, il occupa un rang dans le corps des immortels. Son efficacité est puissante, ses réponses (à nos demandes) sont manifestes ; il réside comme maitre de famille, toute l'année nous lui rendons hommage et le célébrons...

宋代名儒, 觀 $[$ ]䦣荒, 狐狸是驅, 撫州學法, 身列仙軀, [威]靈顯應, 家主是居, 值年朝賀 $\cdots$

Le lang 郎 dont est affublé cet ancêtre est d'ordinaire réservé à ceux qui occupent le sommet de la hiérarchie religieuse.

Maître de famille. Benjia dizhu gonggong Yuan jun Fashan 本家地主公公袁君法閃 (maitre des lieux de la famille, le sieur Yuan Fashan), To5ıI, consacré en 1926 (voir fig. 5). L'appellation de sieur Yuan, vénéré par des Yuan, dit explicitement qu'il est à la fois le maitre de famille et le maitre des lieux, un ancêtre et une divinité locale.

Maître de famille. Jiazhu Wang jun Fameng 家主王君法露 (maître de famille, le seigneur Wang Fameng), T oo8I, date de consécration incomplète (voir fig. 6). Les commanditaires sont à nouveau conduits par une femme Kang 康, née Zeng 曾, avec ses deux fils. Il est intéressant de noter que c'est une dame Kang qui rend un culte à un Wang, une incohérence qui s'explique par le fait que des familles pouvaient prendre comme maitre de famille celui d'une famille localement influente et dont elles étaient dans la plupart des cas affiliées.

Grand ancêtre. Rentian de dao taizu Wu jun Yongdao 人天得道太祖吳君永道 (grand ancêtre qui des hommes et du Ciel obtint le Dao, le seigneur Wu Yongdao), né en I485, ToI46, consacré en 1799 (voir fig. 7). Sieur Wu, avec son casque de guerrier, une longue barbe, une cuirasse ornée d'une tête d'animal, le pied gauche levé pour mimer le mouvement, est l'un des rares héros à avoir bénéficié d'une biographie assez détaillée dans le certificat :

8. Voir Su Yejiang 蘇業江, «Shang Meishan Manwang chongbai »上梅山蠻王崇拜, dans Chen Zi'ai 陳子艾, Hua Lan 華瀾 (Alain Arrault), éd., “Xiangzhong zongjiao yu xiangtu shehui” diaocha baogao ji “湘中宗教與鄉土社會”調查報告集, 2 vol., actes du colloque du même nom, Loudi 婁底一 Shuiche 水車, 24-29 juin 2006, Beijing, Zongjiao wenhua chubanshe 宗教文化出版社, sous presse.

(C) École française d'Extrême-Orient, Paris, 2012

Do not circulate without permission of the editor / Ne pas diffuser sans autorisation de l'éditeur 


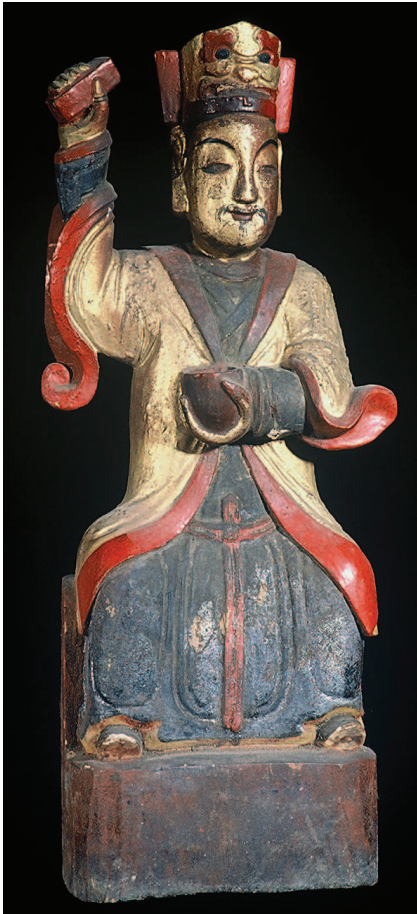

Fig. 4 : Le vieil ancêtre Quatorzième seigneur 老 祖十四郎公, 1911, T 0126. Cliché Zhang Chaoyin.

Fig. 5 : Maître des lieux de la famille, le sieur Yuan Fashan 本家地主公公袁君法閃, 1926, T0511. Cliché Zhang Chaoyin.
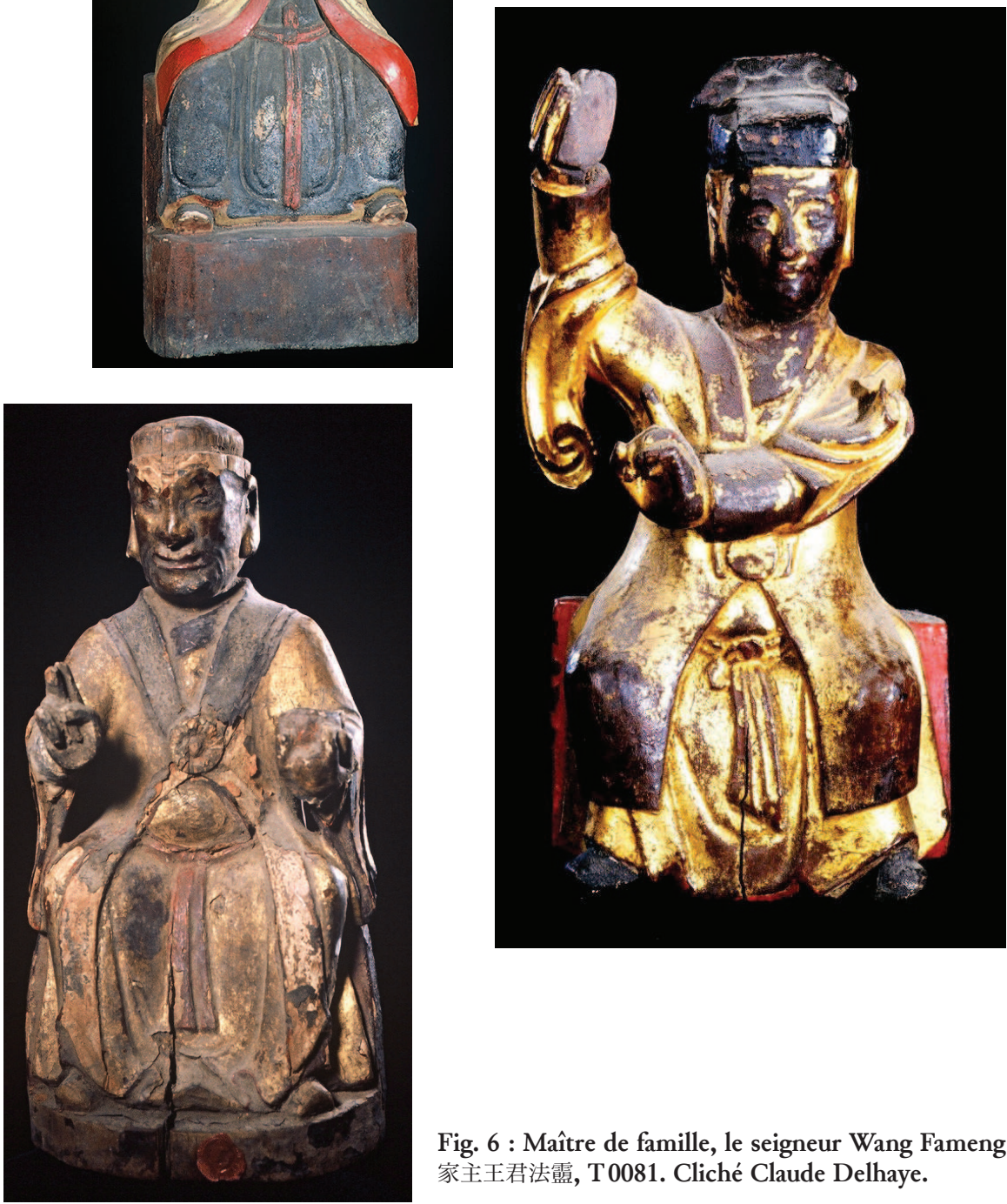

Fig. 6 : Maître de famille, le seigneur Wang Fameng 家主王君法需, T0081. Cliché Claude Delhaye. 
Dès son enfance, il lut des livres et apprit les rites./9 $\mathrm{Il}$ prit pour épouses les deux dames Kuang 匡 et Li 李./ Pendant l'ère Zhengde 正德 (I526-I52I), à cause de désordres causés par des rebelles,/ quatre-vingt brigands attaquèrent le village/ et pillèrent un des membres du clan des Wu, Wu Zhongxu 吳忠序./ Un rapport fidèle en fut fait au seigneur du yang 陽 公 (Wu Yongdao), qui ne put le supporter./ Il fit ses adieux à son saint père et à sa sainte mère,/ ainsi qu’à ses deux épouses Kuang et Li./ Il conduisit Wu Mao 吳毛 [ou les Wu et les Mao], ainsi que cinq groupes d'autodéfense./ Avec Deng Xin 鄧新 et Zhang Jie 張 傑 en avant-garde,/ il leva des troupes et poursuivit les bandits jusqu'à Shuangjiangkou 雙江口 [dans le district de Ningxiang ?]./ Au lieu dit Zhumei 朱梅, il organisa la bataille comme investi de la puissance divine ;/ pendant trois batailles de suite, il montra l'étoffe d'un général héroïque,/ monté sur son cheval blanc, il allait toujours de l'avant./ Mais à Ma'ou 馬地 un carreau d'arbalète lui provoqua des meurtrissures./ Il s'en revint blessé et passa des années/ dans un groupe d'autodéfense, résidant dans le district d'Anhua./ Les hommes et les femmes du district louaient ses mérites,/ la préfecture locale [ ] le recommanda pour entrer dans le Hall impérial des clochettes d'or,/ un décret impérial lui conféra une investiture et la consécration d'un pavillon de temple./ A Ma'ou, on lui éleva un temple des Sujets fidèles./ Au moment des sacrifices au dieu du Sol, au printemps et en automne, on exhibait son portrait./ Pour appeler le vent et la pluie, les diminuer ou les augmenter, il répondait ;/ pour s'emparer des brigands et attraper les voleurs, il était sans pitié./ Quand les gens avaient des problèmes, ils venaient l'implorer ;/ pour sauver des garçons et des filles, il manifestait une grande efficience./ Moi, le disciple, devant l'autel je l'implore sincèrement,/ pour que le grand seigneur descende en personne,/ le très compatissant, très consentant, très saint, très charitable, ô Wu Yongdao, investi très grand bodhisattva!

自幼讀書知禮義, 娶妻匡李二夫人, 正德年間因賊亂, 八十強人過硐冲, 打劫族下吳忠序, 信 報陽公不肯容, 辭別圣公并圣母, 又辭匡李二夫人, 帶領吳毛并五保, 鄧新張傑做先鋒, 起兵 赶至雙江口, 朱梅棑陣顕神通, 連戰三陣英雄將, 身騎白馬往前行, 馬圤矢机遭暗害, 帶傷回 轉受年經, 保甲住居安化縣, 縣裡男女奏其功, 本府口奏金銮殿, 圣旨加封立廟亭, 馬牭立起 忠臣廟, 春秋社祭表其容, 呼風喚雨加減應, 拏賊捕盜不容情, 凡人有事來相請, [救]男救女 顕威灵, 弟子(坛)前虔奉請, 爲願太公親降灵, 大悲大願大圣大慈, 敕封吳永道菩薩摩荷沙.

Grand ancêtre. Taizu Xiao jun Daoxing 太祖蕭君道興 (grand ancêtre, le seigneur Xiao Daoxing), né en I652, To284, consacré en I862 (voir fig. 8). Cette statue a été commanditée par "le disciple qui met en branle les troupes" (xingbing dizi 行 兵弟子), un certain Xiao Dehua 蕭德化, dont le nom d'ordination est Daling 大靈. Son « palais [de naissance] personnel rencontrant cet automne des calamités et des nuisances, on demanda secours aux divinités en interrogeant les blocs divinatoires et c'est ainsi que le grand ancêtre seigneur Xiao Daoxing manifesta sa puissance » 自于本秋身宮災厄, 求神問等, 乃是太祖蕭君道興顕道. C'est donc par la procédure classique d'un appel aux divinités par blocs divinatoires et parfois par médiumnie que l'ancêtre est sollicité ou qu'il se manifeste spontanément de lui-même pour délivrer de maux divers.

Grand ancêtre. Sishi zu Zeng jun hui Zhonglun xing Shisi langgong 四世祖 曾君諱仲綸行十四郎公 (ancêtre à la quatrième génération Zeng, de nom personnel

9. Ce texte est composé de phrases de sept caractères, dont la césure dans le texte français est indiquée par un «/». 


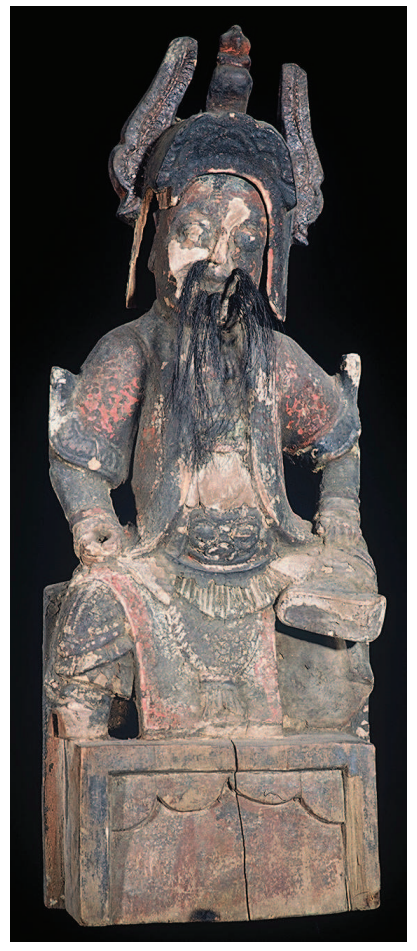

Fig. 7 : Grand ancêtre qui des hommes et du Ciel obtint le Dao, le seigneur Wu Yongdao 人天得道太祖吳君永道 (1485 - ?), T 0146. Cliché Zhang Chaoyin.

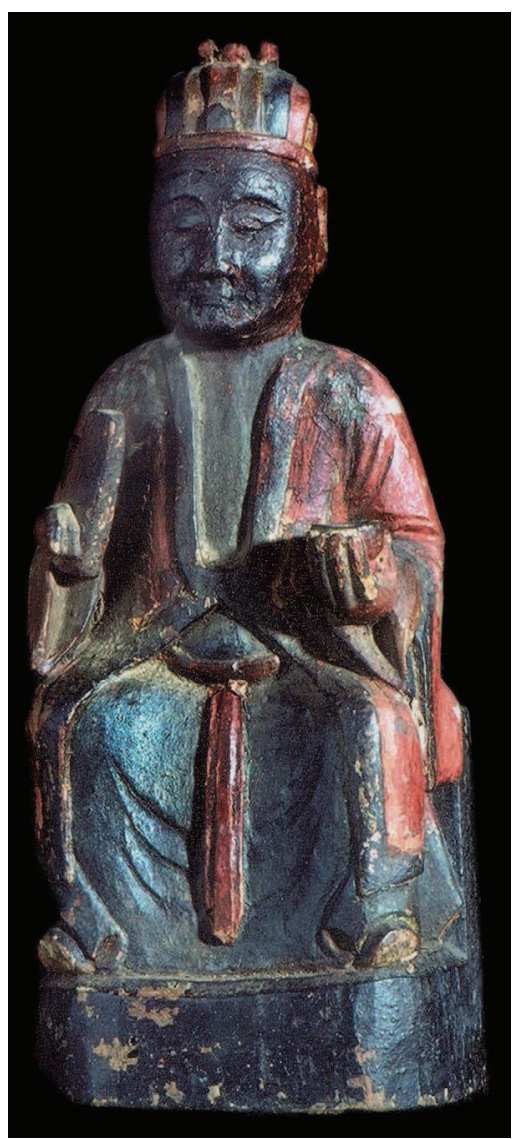

Fig. 8 : Grand ancêtre, le seigneur Xiao Daoxing 太祖蕭君道興 $(1652$ - ?), T 0284 . Cliché Zhang Chaoyin.

Fig. 9 : Ancêtre à la quatrième génération Zeng, de nom personnel (tabou) Zhonglun, cumulant le titre de Quatorzième seigneur 四世祖曾君諱仲綸行十四郎公, 1915, T0148. Cliché Zhang Chaoyin. 
(tabou) Zhonglun, cumulant le titre de Quatorzième seigneur), Tor48, consacré en I9I5 (voir fig. 9). C'est l'épouse Zeng 曾, née Zhou 周, qui conduit le culte, avec son fils, sa bru et sa petite fille. On demande pour chacun d'entre eux une protection particulière de la part du Quatorzième seigneur : longévité et bonne santé pour la mère, une belle destinée pour les enfants du fils et de sa femme, l'élimination des passes dangereuses de l'enfance pour la petite-fille afin qu'elle soit facile à élever jusqu'à ce qu'elle devienne adulte. Hormis le fait que cet ancêtre réponde avec diligence aux demandes de pluie ou de beau temps, d'expulsion des maléfices et de guérison des maladies, nous apprenons que :

Actuellement la dynastie est particulièrement remarquable, à plus forte raison notre ancêtre qui a le bien-être [de tous] à cœur, qui a transmis la doctrine familiale du Souverain de l'origine de nos ancêtres, que de lui viennent nos origines, qu'il médita la véritable transmission du Dao et de sa vertu du vieux Seigneur, raisons pour lesquelles les gens de trois cantons de notre district le vénèrent tous et que, dans la branche de notre clan, chacun a profité de sa bienfaisance...

今朝尤烈, 况老祖利濟爲懷, 承先祖元皇家教, 淵源有自, 思老君道德真傳, 所以一邑三鄉,

人人共仰, 而我同宗一脈, 個個沾恩…

Le lieu où s'est accompli ce culte est à quelques détails près identique à celui concernant le Quatorzième seigneur que nous avons présenté précédemment ${ }^{10}$, avec deux dates de consécration situées au début de la période républicaine (I9II et I9I5). Cette coïncidence ne peut être le fruit du hasard, et il y a fort à parier que ces deux Quatorzième seigneurs sont une même et seule personne : un maitre de famille de l'époque des Song, fondateur, civilisateur et initié, qui ferait donc partie en réalité de la quatrième génération des Zeng, initiateur de la religion familiale du Souverain de l'origine et vénérés par tous localement" ${ }^{\mathrm{II}}$.

D'autres sources confirment et complètent cette hypothèse. D’après la généalogie des Zeng, Zeng Zhonglun appartient effectivement à la quatrième génération des Zeng qui ont émigré du Jiangxi au Hunan au début des Song. Zeng Taiyu 曾泰諭, fonctionnaire des Zhou postérieurs 後周 (951-960), est exilé dans le Sud en 959. En 998, avec ses trois fils, Yanqiang 延衳, Yanfu 延福 et Yanshou 延壽, parti du district de Ji'an 吉安 dans le Jiangxi, il s'installe dans la région de Meishan. Après la mort de Taiyu, Yanshou déménage dans les environs de Weishan 維山, situé à environ $20 \mathrm{~km}$ au sud de la ville de Xinhua. Yanshou a eu quatre fils, dont le second, Wenlu 文祿, est le père de Zhonglun. Zhonglun est né en IO23, la date de sa mort est inconnue ${ }^{12}$.

IO. Les deux adresses sont les suivantes : 湖南省寶慶府新化縣大陽[上]八都[上]維山林屋青山 水口廟 [王]社 (ToI26) et 湖南省寶慶新化縣大陽上八都下維山青山水口廟王祠下土地分烟 (ToI48).

II. Il est à remarquer que la commanditaire du premier Quatorzième seigneur n'est mentionnée que par son nom de jeune fille (Zou 㱀), il n'est donc pas impossible qu'elle soit elle aussi mariée à un Zeng. Il existe une troisième statue dédiée à un Zeng jun Shisi lang 曾君十四郎, et bien que le certificat de consécration soit très endommagé, les quelques indices lisibles indiquent la même adresse, mais il ne subsiste des commanditaires que le prénom de deux fils (Tozı6).

I2. Cf. Hu Nenggai 胡能改, Meishan kebu: Xinbua xingshi tanyuan: 梅山客户:新化姓氏探源, Xinhua, Guoji Yan Huang wenhua chubanshe 國際炎黃文化出版社, 200I, p. 59 ; Hunan tushu guan 湖南圖書館, ed., Hunan shizu yuanliu 湖南氏族源流, Changsha 長沙, Yuelu shushe 岳麓書 社, 2006, p. I023. Les deux généalogies citées par ce dernier ouvrage datent des années I930. 
Un lointain descendant de Zhonglun, au milieu du XIX ${ }^{\mathrm{e}}$ siècle, lui a consacré une courte biographie apologétique. Rappelant l'ascendance de Zeng Zhonglun ainsi que son titre de Quatorzième seigneur, appelé pour l'occasion par son surnom de Wang Yan 王言, l'auteur présente les faits et gestes de son ancêtre, qu' «il a entendu dire de la bouche des anciens ». À la fin des Song du Nord, Zhonglun a passé l'examen local de bachelier (xiucai 秀才). Grand lecteur, il était surtout très affuté dans le domaine de la topologie (dili 地理), du yin et du yang (陰陽) et de la divination (rizhe 日者). Il résidait dans le village de Guanshan 關山, au milieu des barbares du Sud, ethnies non chinoises (manliao 蠻獠). Après l'arrivée de Zhang Dun 章嵉 (I035-IIO5) qui « sinisa » la région à la fin du XI ${ }^{\mathrm{e}}$ siècle, Zhonglun chassa les bêtes sauvages et défricha, et put ainsi faire de son village « un lieu de lumière ». Mais les mânes des «barbares » sur les monts et dans les forêts causaient des malheurs, alors Zhonglun imita les « exorcistes chargé de chasser les mauvais esprits » (fang xiang $s h i$ 方相氏), il expulsa les pestilences, écarta les nuisances et l'endroit devint paisible. On raconte que Zhonglun, avec son épouse, fut enterré entre les monts Mitian 蜜田 et Yantang 嚴塘, dont il aurait dit : "Etre enterré à Mitian procurera des milliers de (descendants) mâles ; être enterré à Yantang procurera des milliers de sapèques » 葬蜜田發千丁, 葬嚴塘發千金. 《Ainsi l'esprit lumineux de notre seigneur, passés cinq ou six cents années, on l'invoque et il répond, on l'appelle et il se manifeste » 然則 公之靈爽, 至今五六百年求之即應, 感之即通 ${ }^{13}$.

Les généalogies attestent donc le caractère charismatique et la dimension religieuse de Zeng Zhonglun. Les sources religieuses, dont on ne sait si elles ont suivi ou précédé les écrits familiaux, vont naturellement dans le même sens. Datée de 1935, la monographie du mont Wenjin 文斤山, situé dans le district de Xinshao 新邵, est l'une de ces sources. Wen Jin 文斤, qui a donné son nom à ce mont, est un personnage de la fin du IV ${ }^{\mathrm{e}}$ siècle. Fonctionnaire puis ermite sur cette colline, il est à l'origine du belvédère de l'immortel Wen (Wenxian guan 文仙觀) ${ }^{\text {I4 }}$. Les fondateurs, Tan Guanmiao 譚觀妙 et Zhang Jinghua 張景華, eurent un disciple en la personne de Wang Guilin 王桂林, qui eut à son tour trois grands disciples, dont le grand-père de Zeng Zhonglun, Zeng Rushou 曾如壽 (alias Zeng Yanshou). Si l'on en croit cette monographie, ce lignage se dissémina dans toute la région et fut, génération après génération, le fondateur d'une centaine de belvédères dans les districts de Shaoyang 邵陽, Xinhua, etc. Zeng Rushou, qui aurait enfreint la règle du célibat prônée par le lignage, " retourna à la vie profane pour pratiquer la doctrine »(fansu xingjiao 返俗行教), étudia pendant huit années sur le Longhu shan 龍虎山, haut lieu du taoïsme de l'Un orthodoxe (Zhengyi 正一) dans la province du Jiangxi, et fonda - ou résida — dans le célèbre temple Yuxu gong 玉虛宮 à Xinhua ${ }^{15}$. La monographie ne mentionne pas son petit-fils, Zhonglun, mais une

13. Zeng Yufang 曾毓芳, “Wang Yan gong shulüe 》王言公述略, dans Zeng shi wuxiu Xiang pu zhengbian 曾氏五修祥譜正編, 《Wenlu fang 》 文祿房, juan 4, Duqin tang 篤親堂, 1857, s. p.

I4. Au sujet du Wenxian guan, voir également l'article de James Robson dans ce volume.

15. Voir Wenjin daojiao sanxiu zongpu 文斤道教三修宗譜, s. 1., 1935, un imprimé conservé par Liu Weishun 劉偉順 (Shaoyang 邵陽) et Zeng Di 曾迪 (Loudi 婁底). Cette monographie a connu trois versions, la première en I746, la seconde en i868 et la dernière en I935. Au sujet de 
« annonce » extraite d'un livre de rituel appartenant à un maitre exorciste de Weishan 維山 ${ }^{16}$ le présente ainsi :

L’Annonce précieuse du Quatorzième seigneur

Le vieil ancêtre sieur Zeng, de nom tabou Zhonglun

Manifeste sa grande efficacité en chevauchant un cheval blanc.

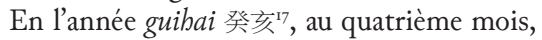

C'est à l'heure $w u$ 午 (IIh-Izh) du onzième jour que son corps authentique descendit (sur terre).

Dans sa tendre enfance, il manifesta à l'égard des autres sagesse et perspicacité,

Il avait une connaissance profonde de la topologie et de l'astronomie.

Il reçut autrefois de Yanshou 延壽 la transmission de la doctrine du souverain de l'Origine,

Puis alla à Fuzhou 撫州 vénérer le Vieux seigneur.

Il obtint du Vieux seigneur d'authentiques et merveilleuses formules secrètes,

Et il eut constamment à cour le secours d'autrui et le profit de tous les êtres.

Les invocations pour la pluie et les implorations pour le beau temps recevaient toutes des réponses éclatantes,

Expulser les nuisances et guérir les maladies sauvaient les gens ordinaires.

A trente-six sui 歲, il monta dans le monde des immortels,

En l'année $w u x u$ 戊戌 ${ }^{18}$, le neuvième mois, il quitta la poussière du monde,

A l'heure wei 未 ( $13 \mathrm{~h}-\mathrm{I} 5 \mathrm{~h})^{19}$ du premier jour, il rejoignit le palais céleste,

Au milieu des neuf nuées, il est devenu divinité.

$[\ldots]$

十四郎寶誥

老祖曾公諱仲綸, 騎坐白馬顯威靈。

癸亥年間四月養, 十一午刻降真身。

自幼為人多敏捷, 深知地理識天文,

昔傳延壽元皇教, 又在撫州拜老君。

得授老君真妙訣, 濟人利物有恒心。

禱雨祈睛皆顯應, 驅邪治病救凡民。

三十六歲登仙界, 戊戌九月謝紅塵,

初一末[未]刻歸天府, 九霄之內為神。

$[\cdots \cdots \cdot]$

cette monographie, de l'histoire du mont Wenjin et des généalogies religieuses attenantes, on lira avec profit l'article de Liu Weishun, «Xinshao xian Wenxian guan diaochao baogao » 新邵 縣文仙觀調査報告, et celui de Zeng Di 曾迪, «Xinhua xian daojiao yuanliu ji Julan gong leijiao chanshi » 新化縣道教源流暨聚嵐宮雷醮閐事, dans Chen et Hua (Arrault), éd., op. cit., sous presse.

I6. Cette annonce provient d'un manuscrit conservé par Zeng Zhucai 曾柱才, maitre exorciste résidant dans le village Sidu 四都 du canton de Weishan 維山 dans le district de Xinhua. Ce texte, ainsi que celui de "Wang Yan gong shulüe », nous ont été communiqués par Zeng Di, que nous remercions ici vivement.

17. L'année de naissance de Zhonglun, I023, est effectivement une année marquée du binôme sexagésimal guibai.

I8. Ce qui correspond à l'année io58.

19. Le texte original comporte l'expression moke 末刻 (dernière heure ?), probablement une erreur pour weike (l'heure wei de $\mathrm{I} 3 \mathrm{~h}$ à $\mathrm{I} 5 \mathrm{~h}$ ). 
Les documents inclus dans les statuettes, les généalogies, la monographie du mont Wenjin et un livre de rituel sont concordants. Nous sommes au début de la dynastie des Song, il s'agit d'une famille émigrée dans un premier temps du Nord de la Chine, puis de la province du Jiangxi vers la province du Hunan ; une famille qui est liée à la fois avec les pratiques religieuses locales et le taoïsme du Longhu shan. Cependant, toutes ces sources sont très tardives, au mieux datées du $\mathrm{XIX}^{\mathrm{e}}$ siècle, aucune n'est contemporaine. Il faut donc admettre la fidélité mémorielle de ces textes par delà les siècles et, pour qu'ils soient reliés entre eux, considérer comme un fait intangible que le Zeng Yanshou des généalogies est le Zeng Rushou de la monographie du mont Wenjin. Dans les premières, les dates de Yanshou sont 984 et I057, et la date de naissance de son petit-fils Zhonglun I023, autrement dit il faudrait accepter qu'en moins de 40 ans se sont constituées trois générations. La biographie de Rushou comportent des éléments très proches de celle de son petitfils : tous les deux se sont rendus dans le Jiangxi afin d'étudier le taoïsme, leur date de mort coïncide à une année près (I057 et I058). Le premier est lié à l'édification d'un temple et d'une lignée religieuse importante dans le district de Xinhua, le second est une divinité vénérée localement, nous pourrions ainsi nous demander si en vérité les biographies des deux personnages n'ont pas été mélangées pour former une double face : un charisme local et une revendication d'orthodoxie nationale ${ }^{20}$.

\section{b) Statues d'ancêtres proches}

Nous entrons avec cette catégorie parmi les ancêtres dont le rang ne remonte pas au-delà de quatre générations au-dessus des donateurs, ce qui ordinairement constitue la règle quant aux nombres d'ancêtres qui peuvent recevoir un culte dans les familles roturières et qui, a priori, relèvent encore du patrimoine mémoriel de la famille : il est possible de conserver de ces ancêtres, au moins pour les trisaïeux, une mémoire plus vive de leurs faits et gestes, que l'on se raconte et que l'on transmet aux descendants. Nous cheminerons ensuite progressivement dans le temps pour présenter des ancêtres d'une grande proximité, les parents et même une belle-sœur.

Arrière-grand-père. Zengzu Zhenfu gong 曾祖振料公 (arrière-grand-père sieur Zhenfu), or73/C:1650, consacré en I824 (voir fig. Io). Les donateurs, Wang Zulun 王祖綸 et sa femme Liu 劉, nom de dame Septième-tante 七姑, se présentent sans ambiguïté comme les descendants à la troisième génération et ils sont, fait peu courant, épaulés par des témoins de leur culte : les parents et les frères de Wang Zulun. La raison de ce culte apparait assez nettement : les donateurs sont un couple sans enfant et les souhaits émis tournent autour de la descendance, de l'enfant à venir qu'il doit être facile de faire grandir, etc. Autrement dit c'est un enfant, de préférence un garçon, qu'ils attendent de leur ancêtre. Un arrière-grand-père qui

20. Zeng Di nous a signalé deux autres statuettes du Quatorzième seigneur, conservées par des Zeng dans les provinces du Hubei et du Yunnan.

(C) École française d'Extrême-Orient, Paris, 2012 Do not circulate without permission of the editor / Ne pas diffuser sans autorisation de l'éditeur 


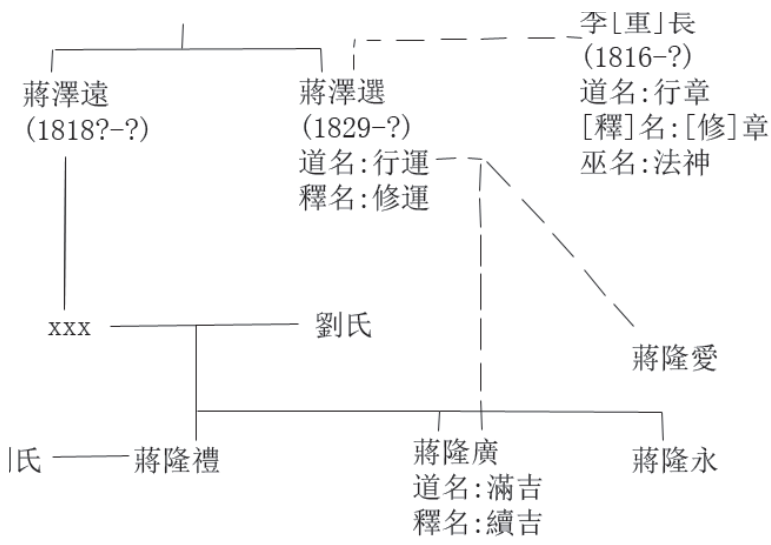

Légende : - : lien de parenté ; - - : relation de maître à disciple Schéma des relations de parenté et de maîtrise dans la famille des Jiang.

n'est pas dans la position habituelle : il se tient debout, une main sur les hanches, l'autre - amputée pour moitié - est levée au niveau de la poitrine, ajoutés à cela sa coiffure et son accoutrement rustiques, autant d'éléments qui trahissent une statue de chasseur. On notera par ailleurs la mention du nom du sculpteur (danqing 丹青, l'artisan de la couleur), un fait habituel sur ces certificats, suivi de celui d'un maître exorciste, Wang Faxiu 王法秀, une notation rare : ce maitre aurait-il procédé à la consécration de la statue?

Grand-père. Zukao Tang gong Shangguo daren zouming Fayu 祖考湯公上國 大人奏名法玉 (grand-père sieur grand homme Tang Shangguo, nom d'ordination Fayu) (I870-1927), Y I5OI2, consacré en 1945 (voir fig. II). Comme la précédente, cette statue est celle d'un chasseur, mais pieds nus. Sa main droite levée au niveau de la poitrine tenait clairement un fusil dont la crosse reposait sur le sol. C'est bien son petit-fils 孫男, Yuqiu 雨秋, qui lui rend un culte.

Grand-père. Zukao Jiang gong Zeyuan 祖考蔣公澤遠 (grand-père sieur Jiang Zeyuan) (I8I8 ? - ?), Y II22009, consacré en I9IO (voir fig. I2). Les trois « fidèles petits-fils» (xinsun 信孫) Jiang Longli 蔣隆禮, Jiang Longguang 蔣隆廣, Jiang Longyong 蔣隆永, qui sont à l'origine de ce culte, se sont également réunis pour dédier

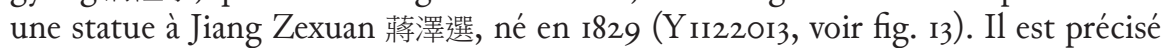
que ce Jiang a pour nom public Xuanzhi 巽之, nom taoïste Xingyun 行運, et nom bouddhiste Xiuyun 修運, et dont l'appellation est ainsi tournée : «grand-père qui a obtenu le Dao du Ciel antérieur ». Au premier abord, nous serions donc face à une fratrie avec deux grands-pères! En fait, le commanditaire principal pour la statue de Jiang Zexuan est l'un des trois frères, Longguang, qui s'appelle « disciple » et non «petit-fils», et qui mentionne également pour son propre compte un nom de taoïste, Manji 滿吉, et de bouddhiste, Xuji 續吉 : ce serait donc par excès de langage,

(C) École française d'Extrême-Orient, Paris, 2012

Do not circulate without permission of the editor / Ne pas diffuser sans autorisation de l'éditeur 


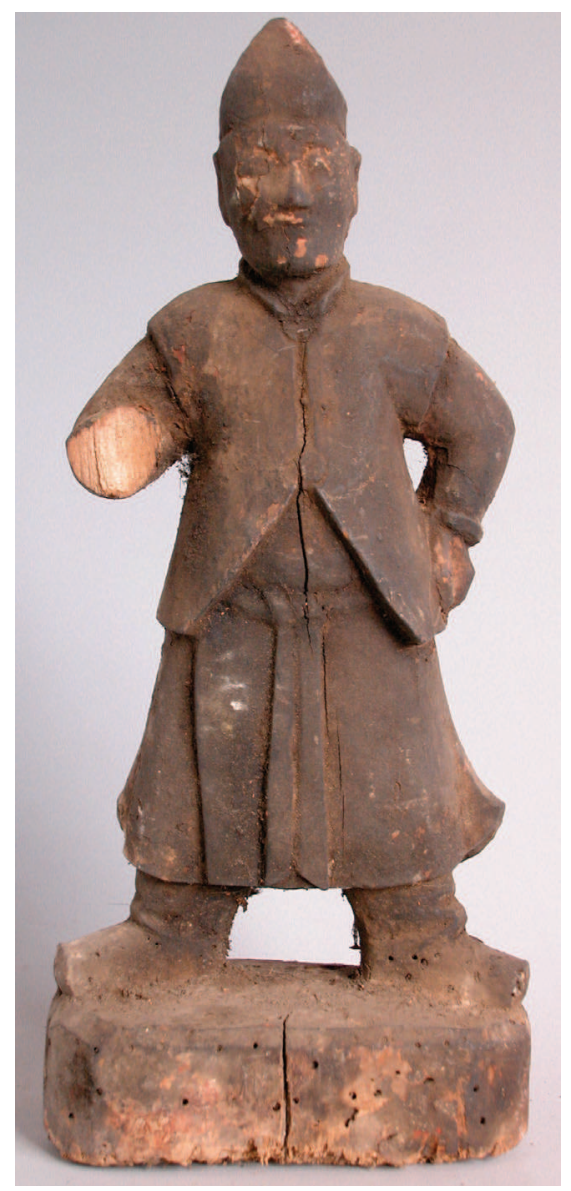

Fig. 10 : Arrière-grand-père sieur Zhenfu 曾祖 振䊇公, 1824, 0173/C:1650.

Cliché Musée du Hunan.

Fig. 11 : Grand-père sieur grand homme Tang Shangguo, nom d'ordination Fayu 祖 考湯公上國大人奏名法玉 (1870-1927), 1945, Y 15012. Cliché Yan Xinyuan.

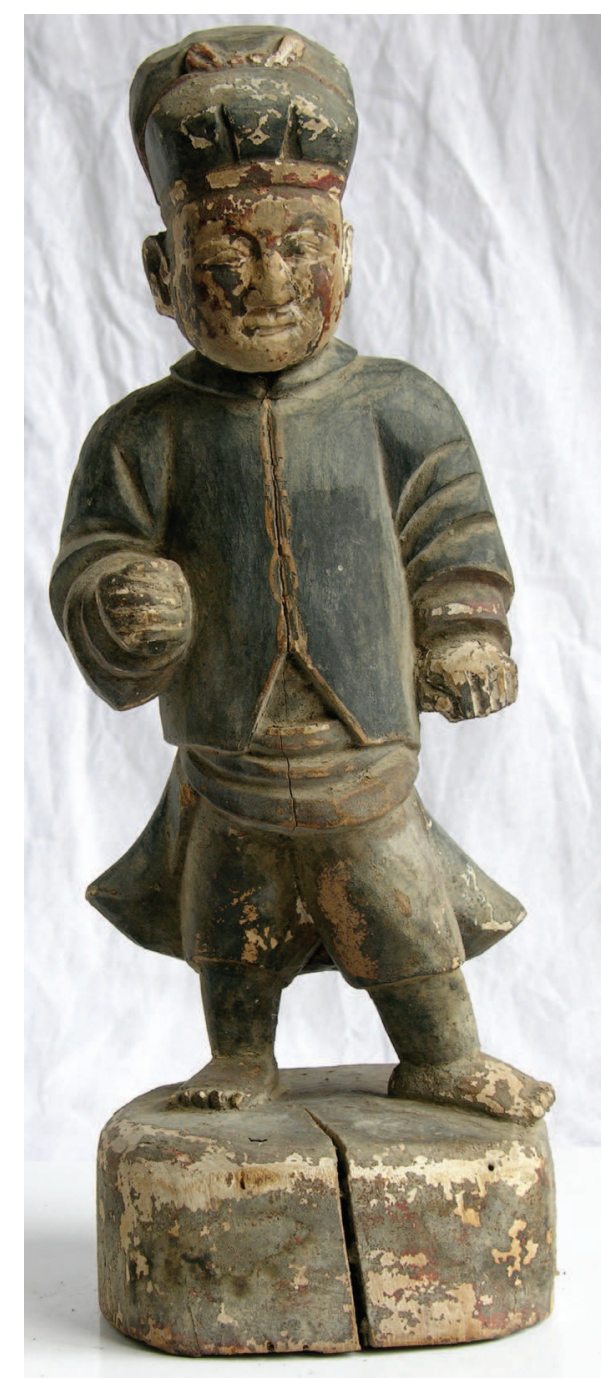

(C) École française d'Extrême-Orient, Paris, 2012 Do not circulate without permission of the editor / Ne pas diffuser sans autorisation de l'editeur 
ou plutôt comme un disciple qui voit dans son maittre un père, que Longguang désigne affectueusement son grand-oncle comme son grand-père ${ }^{21}$.

Ce grand-oncle a fait faire en tant que disciple, avec la femme de son neveu née Liu 劉 (probablement la mère des trois frères) et son frère Zeyuan, une statue

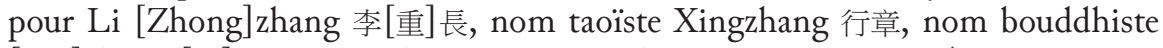
[Xiu]zhang [修]章 et nom de "sorcier » Fashen 法神, né en I816 (YII22OI2, voir fig. I4). Un Jiang qui doit être de la même génération - un cousin ? - que les trois Jiang, puisqu'il porte le même caractère générationnel Long (voir le schéma résumant les différentes relations ci-dessous), un certain Jiang Long'ai 蔣隆愛 a, en tant que disciple, consacré à son tour une statue à Jiang Zexuan ${ }^{22}$. Signalons enfin une troisième statue dont l'inscription sur le socle indique qu'elle est dédiée à Jiang Xingyun, alias Jiang Zexuan (Y II220I5, voir fig. 15) 23, qui comparée iconographiquement avec les autres statues donnera un aperçu sur la notion de portrait - une singularité - et les éléments d'uniformisation de la statuaire.

Que ce soit Li, Jiang Zexuan ou Jiang Longguang, ils ont donc tous reçu une double ordination, taoïste et bouddhiste, voire une triple ordination pour le premier qui a également un nom de "sorcier ", c'est-à-dire dans ce contexte celui de maître exorciste (fashi). Dans la plupart des cas, l'ordination bouddhiste est pour ainsi dire incomplète : aucun d'eux n'a adopté la tonsure, ni quitté sa famille, ni prononcé des voeux de célibat, ils sont en quelque sorte des bouddhistes laïcs, une situation fréquente dans le Hunan : ils n'ont lors de leur apprentissage que reçu quelques livres bouddhiques, dont en particulier le Guanyin jing 觀音經, le Sütra de la déesse de la Miséricorde. Le nom taoïste pour lequel ils ont dû s'initier plus sérieusement à la doctrine pose pourtant ici des problèmes, ne serait-ce que du point de vue du lignage. Le nom générationnel de Jiang Zeyuan est le même que celui qu'il dit être son maitre - Xing 行 - alors qu'il devrait en tant que disciple être d'une génération en dessous. Son petit-neveu, Longguang, porte celui de Man 滿. Ces deux caractères, xing et man, sont issus du poème générationnel de l'ordre des Quanzhen 全真 (les Parfaits), plus précisément de la branche Quanzhen de Longmen 龍門24. Bien que l'ordre Quanzhen ait eu tendance au contact des régions méridionales à se rapprocher des pratiques des taoïstes locaux, qui ne sont pas célibataires et vivent dans

2I. À moins que Longguang ait été adopté par son grand-oncle. Les deux hypothèses maître égal grand-père et l'adoption — ne sont absolument pas contradictoires. L'adoption n'étant pas dans ce cas complète - Longguang sait de qui il est familialement le petit-fils - , il a donc deux grands-pères. Le saut de génération s'expliquerait par le fait que le père, qui serait le fils de Jiang Zeyuan, totalement absent des listes de donateurs, alors que sa femme est mentionnée, serait décédé précocement.

22. La statue Y II22I42 porte sur son socle le nom de Li gong [ ]yue 李公[]月, le certificat aurait donc été inséré dans une autre statue.

23. Il n'existe pas de certificat dans cette statuette.

24. Voir le poème intitulé « Taishang Hunyuan Qiu zu zhenren baidai pai » 太上混元邱祖 真人百代派 (La branche aux cent générations du parfait patriarche Qiu, de la très haute origine chaotique), reproduit un peu partout, et que nous avons trouvé dans un manuscrit hunanais du maître contemporain Qin Guorong 秦國榮, intitulé Daopai banci 道派班次 (Ordre de succession des branches taoïstes), mss., s. 1., I998. 
Fig. 12 : Grand-père sieur Jiang Zeyuan 祖考蔣公澤遠 (1818 ? - ?), 1910, Y 1122009. Cliché Yan Xinyuan.
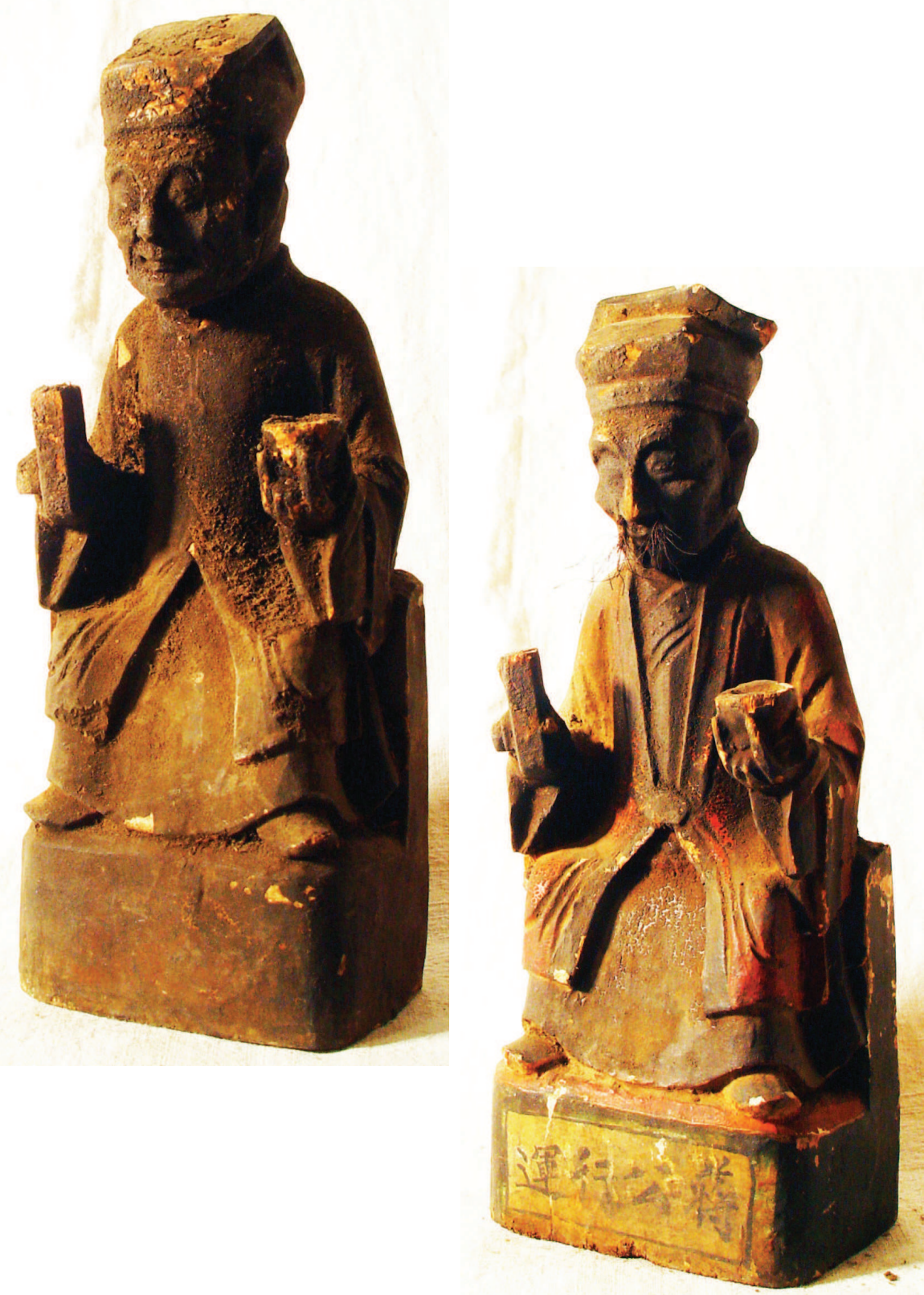

Fig. 13 : Grand-père qui obtint le Dao du Ciel antérieur, sieur Jiang Zexuan, nom public Xuanzhi, nom taö̈ste Xingyun, nom bouddhiste Xiuyun 先天得道祖考蔣公諱澤選字巽之道名行運釋 名修運先生 (1829 - ?), 1897, Y 1122013. Cliché Yan Xinyuan. 
Fig. 14 : Celui qui obtint le Dao du Ciel antérieur, monsieur Li [Zhong] zhang, nom public [Yuan] shan, nom taö̈ste Xingzhang, nom [bouddhiste] [Xiu]zhang, nom de sorcier Fashen 先天[得]道李[重]長字[元]善道名行章口名[修章巫名法神 [ ][生] (1816 - ?), 1890 ?, Y 1122012. Cliché Yan Xinyuan.

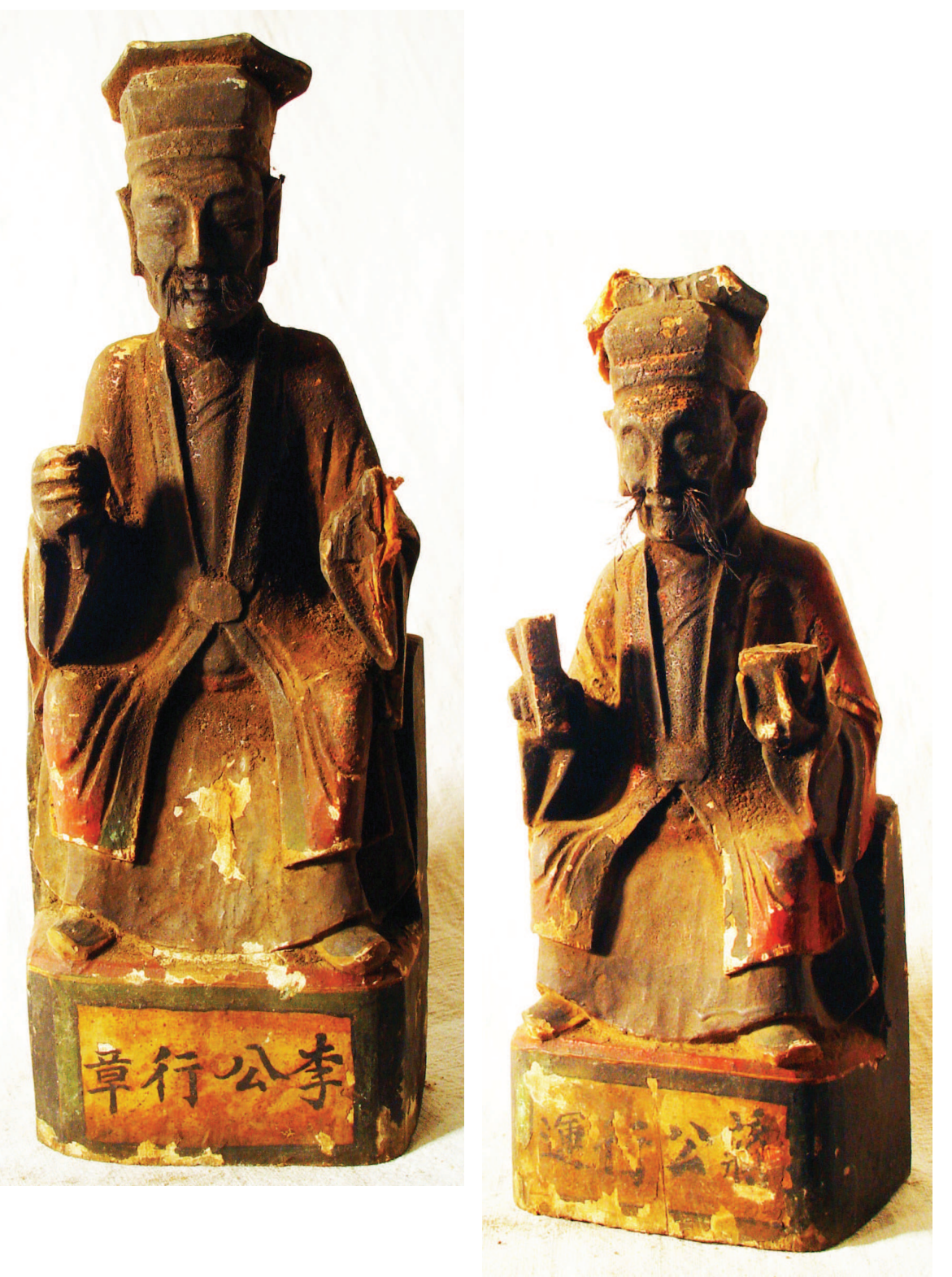

Fig. 15 : Sieur [Jiang] Xingyun [蔣]公行運, Y1122015. Cliché Yan Xinyuan.

(C) École française d'Extrême-Orient, Paris, 2012

Do not circulate without permission of the editor / Ne pas diffuser sans autorisation de l'éditeur 
la société, il est évident qu'il s'agit d'un simple emprunt à un ordre, sans véritable transmission. Semble-t-il à la mode à l'époque des Qing, cet emprunt est d'autant plus superfétatoire que les deux caractères en question se situent à la quatre-vingt et unième et quatre-vingt-deuxième place dans le poème, ce qui ferait remonter l'origine de la branche de Longmen à plus de 1600 ans en arrière ${ }^{25}$ !

Tante, grand-tante. Jielie Liuniang gushi 節烈六娘姑氏 (Tante fidèle Sixièmedame), Tioo6 (voir fig. I6). Cette statuette a eu deux consécrations, écrites sur la même feuille : la première exécutée en 1682 a été faite par Ouyang Heng 歐陽亨 qui se présente, en dépit de l'appellation de "tante », comme petit-fils ; la seconde en 1798. C'est pour Ouyang Heng qui souffrait de malaria qu'on a "demandé à un maitre de la faire descendre afin qu'apparaisse son corps de lumière et qu'elle manifeste son efficience pour rendre la famille prospère 》請師傅降云節烈六娘姑氏, 欲討光身, 显灵旺家. La seconde consécration ne parle plus de Sixième-dame mais d'une 《 grand-tante » (gupo 姑婆), née sous l'ère Chenghua 成化 (I465-I487) - ce qui ferait de Ouyang Heng non pas un petit-fils mais un descendant plus lointain, les appellations «tante » et " grand-tante » étant souvent employées dans un sens à la fois familier et honorifique. Elle se serait mariée avec un Yuan 袁, un mauvais mari bossu qui se serait enfui, l'amenant à revenir chez elle où elle aurait psalmodié, toute sa vie durant, le Sanguan jing 三官經 ${ }^{26}$, ce qui signifie qu'elle ne se serait pas remariée, restant fidèle et chaste d'où son titre de jielie 節烈, femme fidèle exemplaire, un titre très fréquemment conféré à l'époque des Qing aux veuves chastes, auquel s'ajoute dans ce cas la dimension religieuse de la sainteté.

Père. Xianshi xiankao [fu] qin Zeng Fuling 仙逝頻考[父]親曾復靈 (père Zeng Fuling, disparu en immortel), Too88, consacré en I895 (voir fig. I7). Cette consécration a été faite en particulier pour Zeng Qingluo 曾慶洛, dont les « yeux n'avaient plus de lumière », en dépit d'« un appel aux divinités, qui resta sans réponse, et de l'absorption de médicaments, qui se révéla inefficace » 因慶洛眼不光, 求神無應, 服 藥無郊(效). L'invocation d'un proche ancêtre représente donc un ultime recours pour se soigner.

25. L'ordre « orthodoxe » Quanzhen au XviI ${ }^{\mathrm{e}}$ siècle en est à sa septième-huitième génération de patriarches. Mais il est vrai que l'ordre se scinda en différentes branches selon les régions. Par exemple, le vingt-troisième patriarche, Zhang Zongrui 張宗睿, fonda la branche de Huoshan 霍 山 dans le nord à la fin du XIX ${ }^{e}$ siècle, tandis que le huitième patriarche, Xu Shoucheng 徐守誠 (I632-1692), fonda dans la région méridionale du Jiangxi la branche Jingming 淨明. Actuellement, d'autres lignages du Hunan ne revendiquent cependant que dix-huit ou dix-neuf générations selon le poème générationnel.

26. Le Sanguan jing, sūtra des trois fonctionnaires, ou des trois origines (sanyuan 三元), en charge du Ciel, de la Terre et de l'Eau, dont l'invocation garantit protection et délivrance. Il est fréquemment psalmodié au début de tous les services lors du rituel d'ouverture de l'aire sacrée (kaitan 開壇). 
Fig. 16 : Tante fidèle Sixième-dame 節烈六 娘姑氏, 1682, 1798, T 1006.

Cliché Claude Delhaye.
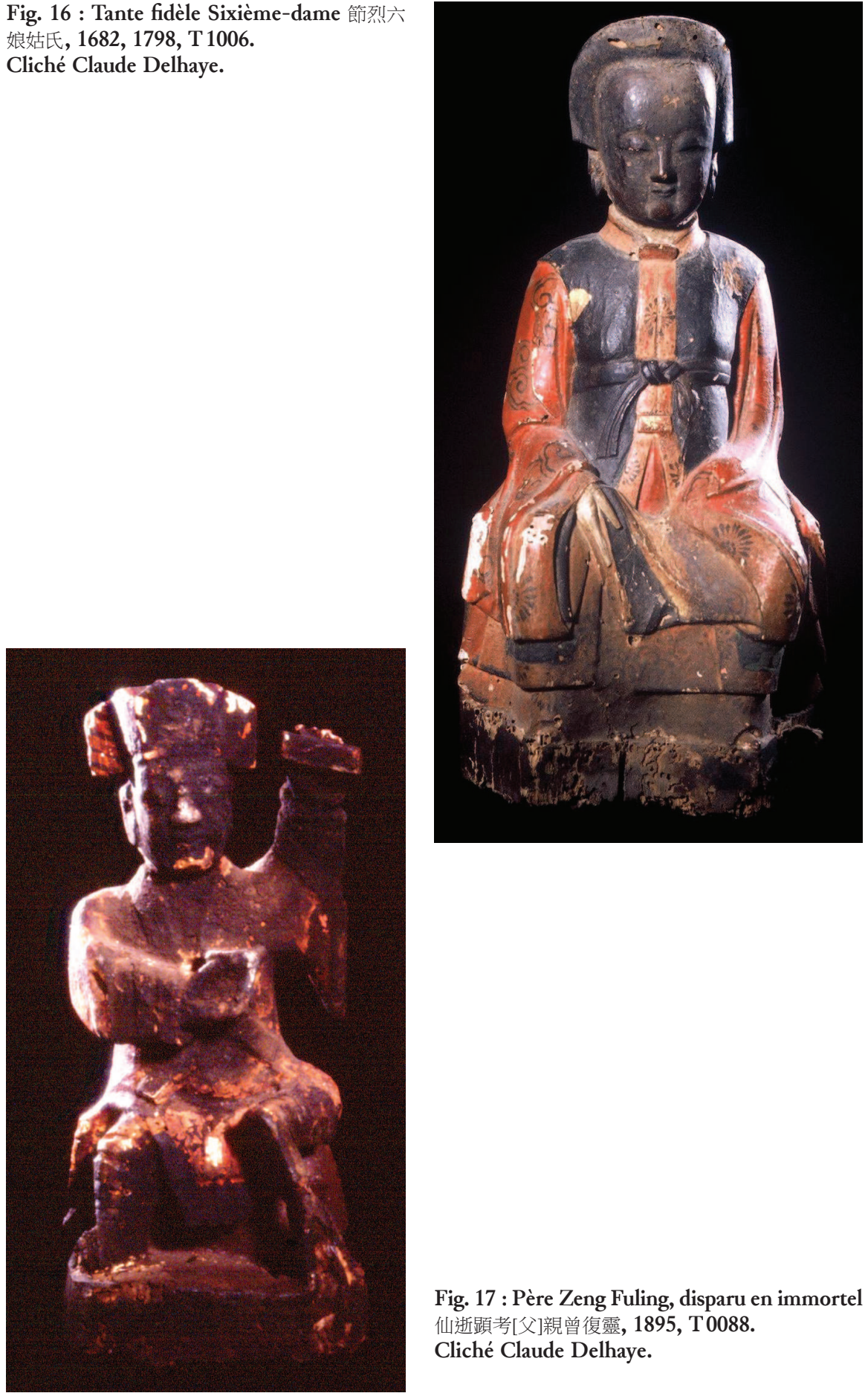

Fig. 17 : Père Zeng Fuling, disparu en immortel 仙逝顕考[父]親曾復靈, 1895, T 0088.

Cliché Claude Delhaye.

(C) École française d'Extrême-Orient, Paris, 2012

Do not circulate without permission of the editor / Ne pas diffuser sans autorisation de l'éditeur 


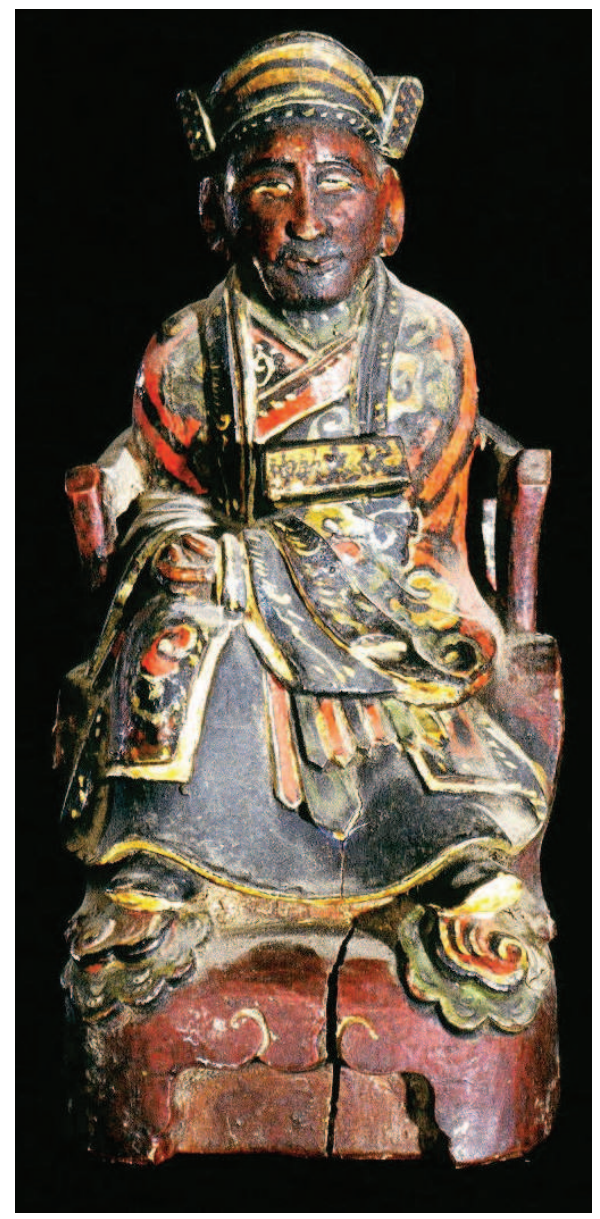

Fig. 18 : Père de la vingtième génération sieur Jiang Hanqiu, nom d'ordination Faqiong [ $\uplus]$ 派先父蔣公漢秋老大人奏名法瓊 (1885-1945), 1946, T0471. Cliché Zhang Chaoyin.

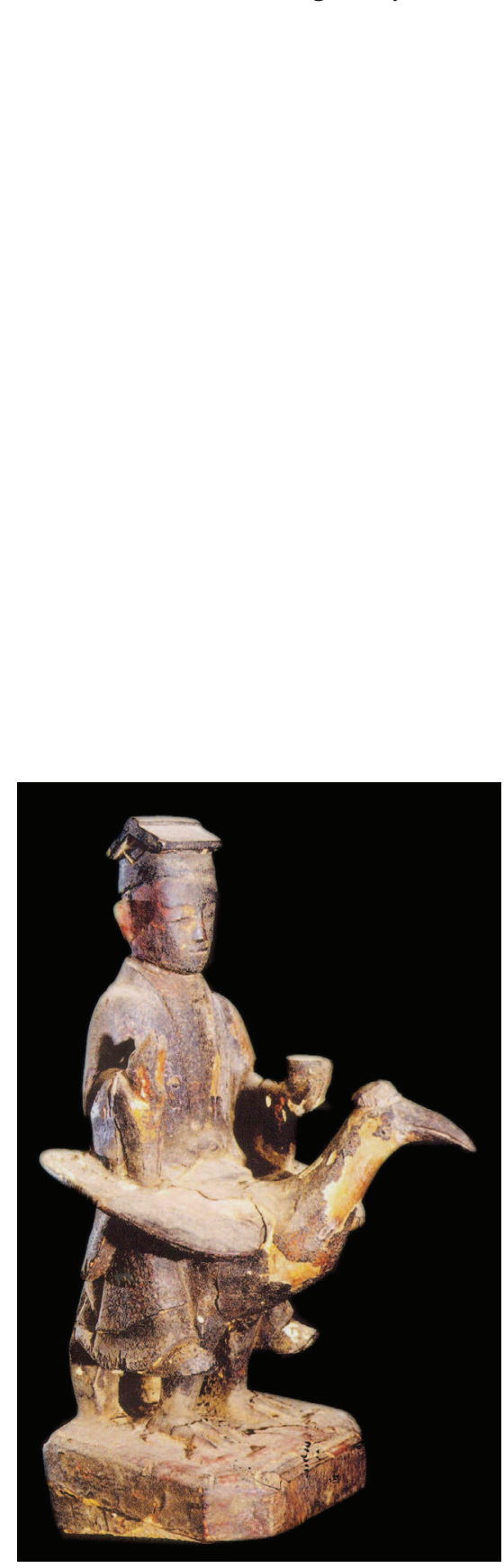

Fig. 19 : Père sieur He Yiyun, nom d'ordination Fayun 顯考何公義雲奏名法運 (1860-1934), 1937， T0690. Cliché Zhang Chaoyin.

(C) École française d'Extrême-Orient, Paris, 2012 Do not circulate without permission of the editor / Ne pas diffuser sans autorisation de l'éditeur 
Père. [Nian] pai xianfu Jiang gong Hanqiu lao daren zouming Faqiong [廿]派先父 蔣公漢秋老大人奏名法瓊, (père de la vingtième génération ${ }^{27}$ sieur Jiang Hanqiu, nom d'ordination Faqiong) (I885-1945), To47I, consacré en 1946 (voir fig. I8). La vie de Jiang 蔣 est très précisément résumée : né en 1885 , il perd sa mère à un sui et demi. En I9OI, il prend pour maitre son père Jiang [You]tang 蔣[敒] 堂 auprès duquel il étudie la doctrine du Souverain de l'origine (Yuanhuang zhengjiao 元皇正教). En 1902, il reçoit la transmission; deux ans plus tard il est ordonné (paopai jieyin 抛牌結印), « reçoit une fonction et un brevet de commandement ; le soir de son ordination des troupes célestes lui sont distribuées et des chevaux lui sont choisis » 授職領馮, 夜晚分兵擇馬. En 1905, son autel, grâce à l'examen des blocs divinatoires (jiangua 鋻卦) destiné à vérifier l'acquiescement des divinités, est achevé. Son père meurt à l'âge de soixante sui en I9I4. Jiang Hanqiu eut quatre fils, dont deux, le deuxième et le quatrième, moururent en bas âge. L'aîné et le troisième, ce dernier étant le commanditaire de cette statue, furent également initiés à la doctrine du Souverain de l'origine par leur père ; tous deux eurent quatre filles dont la deuxième mourut avant l'âge de maturité. La statue porte sur son bras gauche une boîte rectangulaire à laquelle sont attachées des lanières en tissu. Appelée aujourd'hui bingpai 兵牌, la boîte aux soldats, elle contient les certificats d'ordination qui sont faits en deux exemplaires : l'un est brûlé et donc transmis aux autorités célestes, l'autre placé dans cette boîte, disposée à son tour lors du décès du récipiendaire dans sa tombe. Ces deux exemplaires servent de reconnaissance auprès de l'administration céleste qui, grâce à un sceau appliqué sur deux talismans pliés en deux et inscrits sur l'un des documents en deux exemplaires, authentifie le défunt ${ }^{28}$

Père. Xiankao He gong Yiyun zouming Fayun 顯考何公義雲奏名法運 (père sieur He Yiyun, nom d'ordination Fayun) (I860-I934), To69o, consacré en 1937 (voir fig. 19). Une biographie succincte nous apprend que ce père fut également initié à la doctrine du Souverain de l'origine. Ses deux fils ont commandité une statue où leur père est représenté un bol d'eau lustrale dans la main gauche et à califourchon sur une grue, la célèbre monture des immortels.

Oncle, père. Shufu fuqin Xue gong Changxiang zi Xichi zouming Faxiang daren 叔父父親薛公昌祥字西池奏名法祥大人 (oncle père sieur Xue Changxiang, nom public Xichi, nom d'ordination Faxiang) (1796-1870), To40I, consacré en 1872 (voir fig. 20). La double appellation, oncle et père, aussi étrange qu'elle puisse paraitre, s'explique par le fait que ce sont effectivement deux neveux et un fils qui rendent ce culte,

27. Nianpai, vingtième génération : si nous admettons qu'il s'agit de la lignée familiale, le grand ancêtre des Jiang se situerait six cents ans auparavant, aux alentours de I280, soit à la fin de la dynastie des Song ou au début de la dynastie des Yuan.

28. Dans la région d'Anhua, ce talisman est celui du maréchal Yin 殷元帥, voir Zhang Shihong 張式弘, 《Anhua daojiao de diaocha baogao » 安化道教的調查報告, dans Chen et Hua (Arrault), éd., op. cit., sous presse ; et dans ce volume l'article de David Mozina. Cette boîte est aussi utilisée par le maitre lors de certains rituels de type martial pour appeler les légions dont il dispose afin de lutter contre les puissances maléfiques.

(C) École française d'Extrême-Orient, Paris, 2012

Do not circulate without permission of the editor / Ne pas diffuser sans autorisation de l'éditeur 
accompagnés d'un petit-fils et de nombreux petits-neveux. Du défunt, on nous dit que «son yang dépéri, il monta au département céleste, (son âme) avec son corps atteignirent le Dao. Après avoir accompli de bonnes actions [c'est-à-dire les rituels funéraires] pendant trois jours et trois nuits, les mérites acquis étant complets, on porta son cercueil dans la montagne. Enterré en dessous de la demeure dans la montagne en Forme de phénix, il fut inhumé avec ses frères... 》卸陽登䡐, 隨身超道, 善果三旦夕, 功果圓滿, 送[相]歸山, 安莰屋下[于]鳳形山, 与兄弟合塚... L'ancêtre est cette fois-ci à cheval, et sa main droite devait tenir quelque chose comme une épée.

Oncle, beau-père. Xianshi Yuan gong hui Zhangyou zi Shiquan fujun 先師袁公諱 章佑字石泉府君 (premier maitre sieur Yuan, nom personnel Zhangyou, nom public Shiquan, seigneur de la résidence), et Yuan gong Zhangyou zi Shiquan lao yueweng daren 袁公章佑字石泉老岳翁大人 (vénérable beau-père sieur Yuan Zhangyou, nom public Shiquan) (I782-I839), oI80/C:I632, consacré en I839 et en I879 (voir fig. 2I). Contrairement à un exemple précédent (voir ci-dessus le paragraphe « Tante, grandtante »), les deux consécrations sont rédigées sur deux papiers différents, la situation la plus fréquente en cas de consécrations multiples. Bien qu'il n'existe pas d'appellation de parenté pour Yuan dans le premier certificat de consécration, nous savons qu'il s'agit bien de l'oncle des commanditaires, qui se désignent comme « neveux héritiers du métier» (shouye zhi 受業侄) de leur oncle. La seconde appellation est confirmée par le donateur principal qui porte un patronyme différent, Yang 楊, mais qui est marié avec une Yuan. La statue tient dans la main gauche un vase. Hormis la déesse de la Miséricorde Guanyin qui se présente avec un vase - qui constitue en fait un cas à part -, d'autres statuettes portent cet attribut, parmi lesquelles certaines sont clairement identifiées comme représentant un médecin ${ }^{29}$ : ce vase serait donc plutôt une fiole emplie de produits pharmaceutiques. La main droite tenait visiblement un autre attribut, probablement un éventail ${ }^{30}$.

Beau-père. Dushi Zhao Xiukai zi Sanyuan zouming Fayuan 度師趙修開字三元 奏名法源 (maitre d'initiation Zhao Xiukai, nom public Sanyuan, nom d'ordination Fayuan), et Yuefu Zhao Sanyuan zouming [ ]yuan 岳父趙三元奏名[]元 (beau-père Zhao Sanyuan, nom d'ordination [ ]yuan) (I850-1913), To775, consacré en I909 et I913 (voir fig. 22). Ses deux consécrations sont faites par le même commanditaire, Ding Yisheng 丁義陸, qui se présente d'abord comme disciple avec son nom d'ordination Fasheng 法陸, puis comme gendre. Une incohérence toutefois : si, comme le dit le second certificat, Zhao est mort en I9I3, alors la première consécration aurait été faite avant son décès...

29. Voir To579 (a obtenu son Dao du roi de la Médecine, Yaowang 藥王) et T0542 (présenté comme un chirurgien 外科醫士). Une autre statuette, 0445/C:805, représente la divinité locale Feng jun Sanlang 奉君三郎 avec cette fiole, et commanditée par un médium (jiaoma 脚馬), ce qui signifierait que Feng jun Sanlang a un rapport avec la médecine. Au sujet de Feng jun Sanlang, voir Alain Arrault, “Analytic essay", p. 28-32.

30. C'est le cas de To542. 


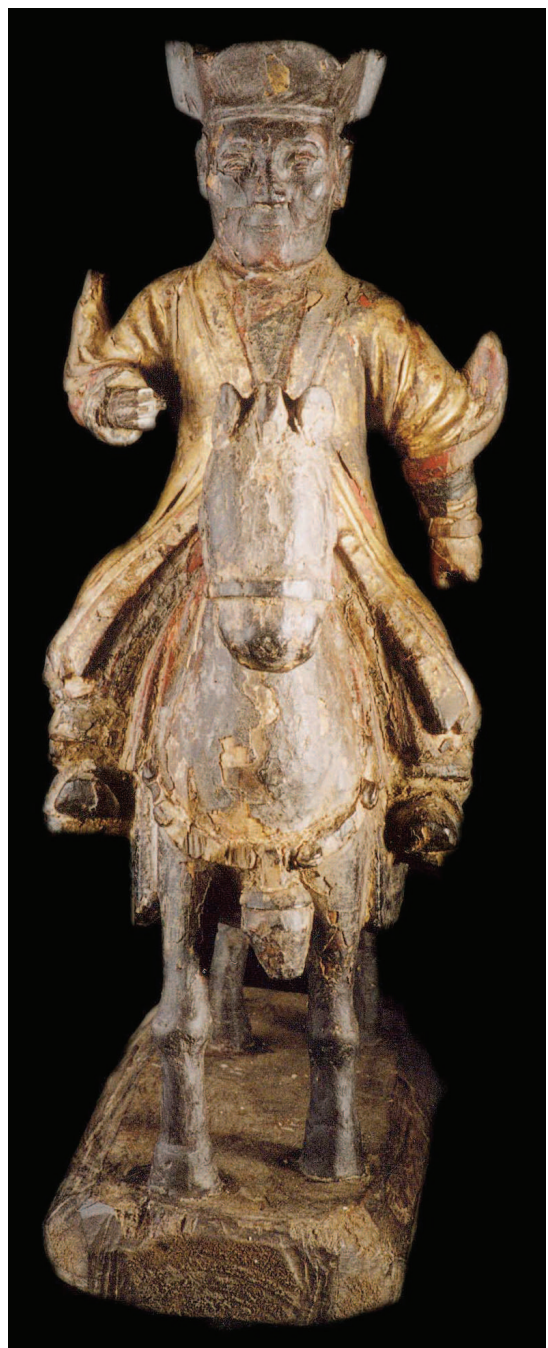

Fig. 20 : Oncle père sieur Xue Changxiang, nom public Xichi, nom d'ordination Faxiang 叔父父親 薛公昌祥字西池奏名法祥大人 (1796-1870), 1872, T0401. Cliché Zhang Chaoyin.

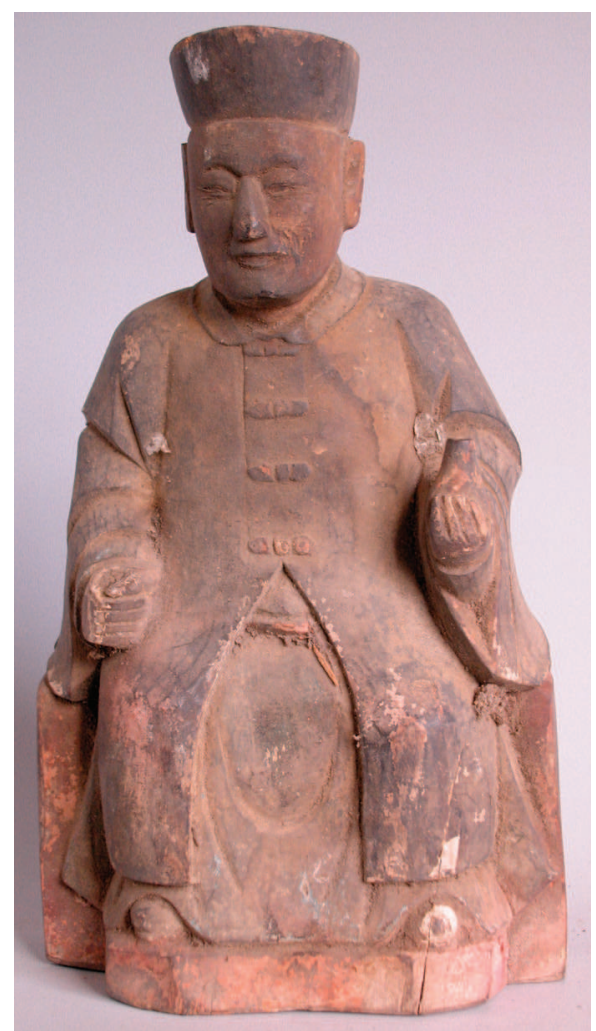

Fig. 21 : Premier maître sieur Yuan, nom personnel Zhangyou, nom public Shiquan, seigneur de la résidence 先師袁公諱章佑 字石泉府君, et Vénérable beau-père sieur Yuan Zhangyou, nom public Shiquan 袁公 章佑字石泉老岳翁大人 (1782-1839), 1839, 1879, 0180/C:1632. Cliché Musée du Hunan.

(C) École française d'Extrême-Orient, Paris, 2012

Do not circulate without permission of the editor / Ne pas diffuser sans autorisation de l'éditeur 


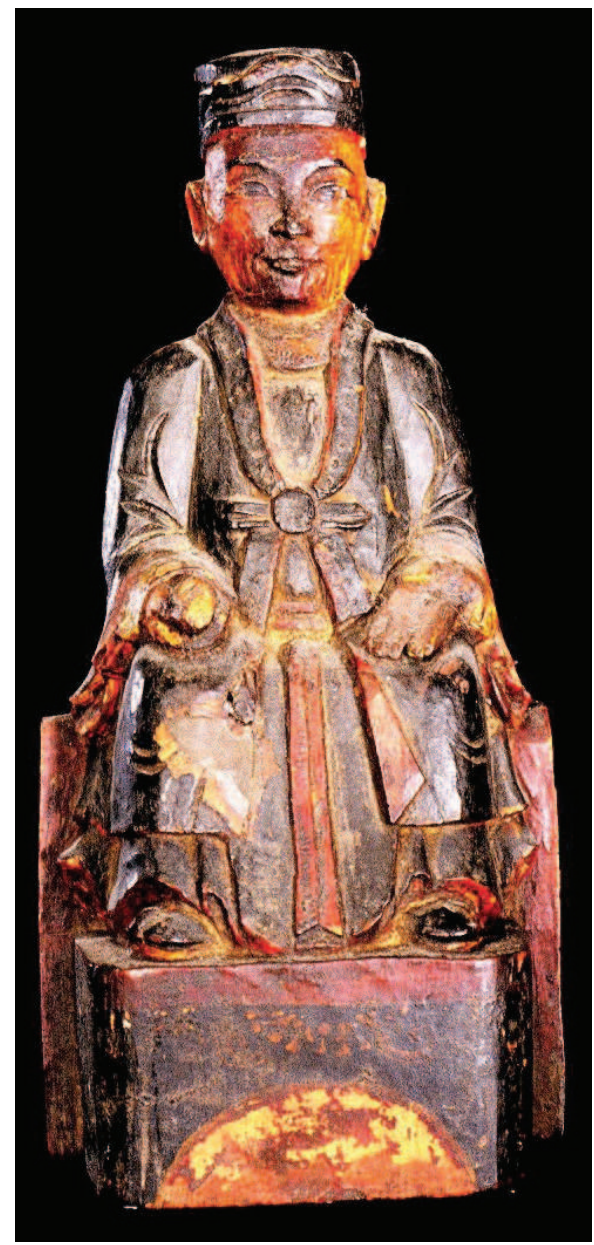

Fig. 22 : Maitre d'initiation Zhao Xiukai, nom public Sanyuan, nom d'ordination Fayuan 度 師趙修開字三元奏名法源, et Beau-père Zhao Sanyuan, nom d'ordination []yuan 岳父趙三 元奏名[]元 (1850-1913), 1909, 1913, T 0775. Cliché Zhang Chaoyin.

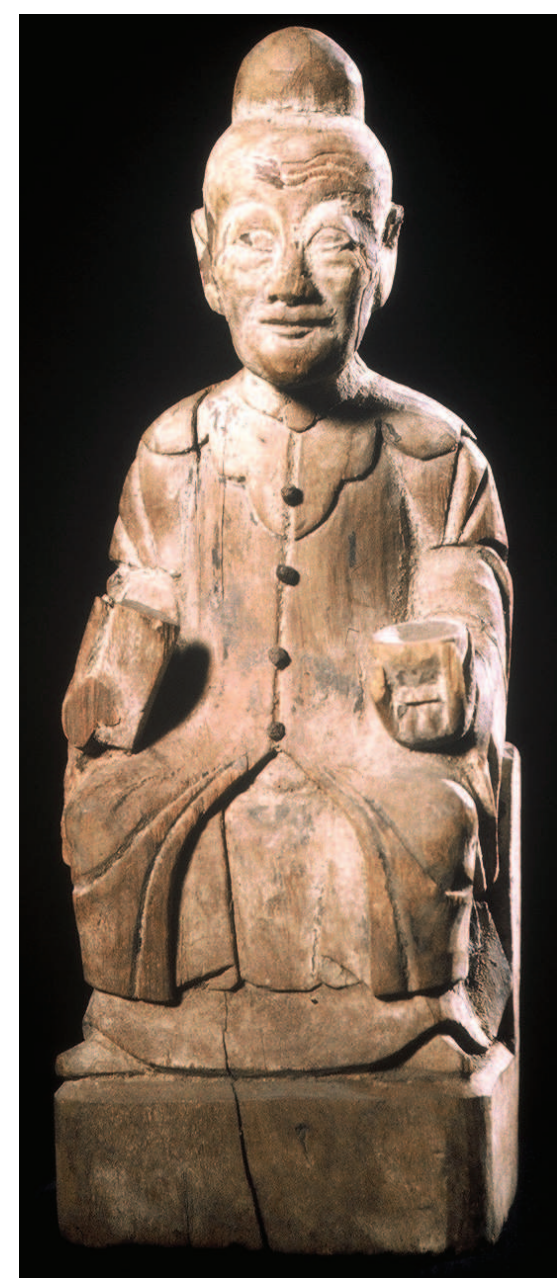

Fig. 23 : Statue de la belle-mère épouse He née Wu, maîtresse de l'eau 岳母生像何門吳氏水師, 1862, T 0037. Cliché Claude Delhaye.

(C) École française d'Extrême-Orient, Paris, 2012 Do not circulate without permission of the editor / Ne pas diffuser sans autorisation de l'éditeur 
Fig. 24 : Belle-sœur Peng née Li 嬏母彭李氏, 1913, Y 1121019. Cliché Yan Xinyuan.

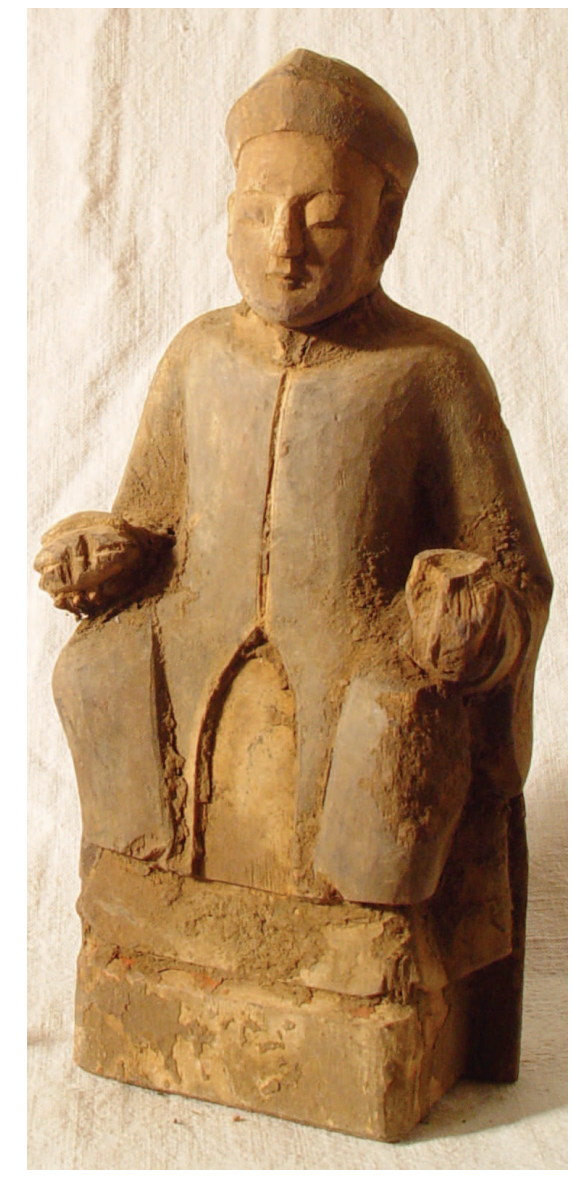

Belle-mère. Yuemu shengxiang He men Wu shi shuishi 岳母生像何門吳氏水師 (statue de la belle-mère épouse He née Wu, maitresse de l'eau), To037, consacrée en 1862 (voir fig. 23). Marié à une He, le commanditaire principal s'appelle Wu 吳 et se dit « fidèle » de sa belle-mère, qu'il interpelle en termes généraux pour obtenir d'elle la protection de sa famille. Une maîtresse de l'eau, ou un maittre de l'eau, traduit le terme chinois shuishi 水師, qu'il ne faut pas confondre avec un chef de la marine ! Un shuishi dans ce cas est une sorte de guérisseur qui recourt à l'eau charmée, en particulier à l'aide de talismans et d'incantations (fuzbou 符咒) distincts en fonction des maladies (maux de tête et de ventre, hémorragies, plaies, fractures, empoisonnements, os ou arêtes coincés dans la gorge, etc.), afin d'expulser le mauvais esprit responsable de ces maladies. Il s'agit donc de cérémonies exorcistiques. Dans certaines circonstances, on associe à cette médecine symbolique l'usage de recettes 
à base de materia medica pour parachever la guérison. Inutile de préciser que ce métier suppose une initiation et l'apprentissage de rites immémoriaux ${ }^{31} \ldots$

Belle-sour. Fanmu Peng Li shi 嬏母彭李氏 (Belle-sœur Peng née Li), Y II2ıoı9, consacré en 1913 (voir fig. 24). La donatrice est également une épouse Peng, née Zhou 周. Zhou vit le jour en I860 et c'est à partir de I888 qu'elle reçut de sa bellesœur «les formules magiques orales pour faciliter la naissance et protéger l'enfant » 推生保産口訣, autrement dit une formation de sage-femme.

Face à ce phénomène d'ordination massive des ancêtres, on a parfois avancé l'idée que ces ancêtres auraient été ordonnés postmortem, une procédure permettant à l'initié d'atteindre le salut sans coup férir ; sachant qu'un initié a par définition les portes du Ciel grandes ouvertes, qu'il n'a pas à subir les affres de la cour des Enfers, même s'il aborde, dans les pires situations, sa carrière de fonctionnaire céleste aux degrés les plus bas. Cette hypothèse a l'avantage de répondre à la question du nombre et aux raisons de ces cultes. Outre le fait que dans les exemples que nous avons présentés, certains personnages ont une biographie spirituelle prouvant qu'ils ont été initiés de leur vivant, d'autres cas montrent la double identité d'ancêtre et de maître, un fait réfutant l'improvisation d'une ordination aux derniers moments de la vie.

Dans les trois collections, le nombre de cas cumulant la double identité ou la double fonction est peu élevé, de l'ordre d'une bonne dizaine. Nous avons déjà rencontré le grand-père ou grand-oncle Jiang Zeyuan et Jiang Zexuan, les deux beaux-pères Yuan Zhangyou et Zhao Xiukai, la belle-søur Peng née Li, qui jouent également le rôle d'initiateurs. Dans le même ordre d'idée, le grand-père de l'épouse Yu 唋 se voit dédier une statuette de la part de Wen Lingui 文林桂, nom d'ordination Fayu 法裕, mari de Yu, qui se dit lui-même «disciple de la pratique religieuse » (xingjiao dizi 行教弟子) de son grand-père par alliance (YII2303I) ; Yuan Qingpo 袁清波 est appelé oncle maître (shishu 師叔) par un fidèle dont le nom patronymique $\mathrm{Yu}$ 喻 prouverait a priori que cet oncle relève de la branche maternelle (o546/C:844).

Parvenu à ce stade de notre enquête, nous serions tentés d'y voir la règle d'une transmission distanciée, soit intra-familiale par le saut de deux générations, soit extra-familiale par une alliance, sans que nous puissions par ailleurs savoir si c'est l'alliance qui permet la transmission ou l'inverse, autrement dit que la formation et l'initiation religieuses doivent être conduites à l'extérieur du nucleus familial, quand bien même la parenté proche serait tout à fait apte à opérer ce travail d'initiation. Mais nous avons en réalité des contre-exemples à ce modèle. Dans la branche paternelle, Luo Faqing 羅法清 (I817 ? -I89I) est ainsi l'oncle maitre d'initiation de Luo Fajiu 羅法㰠(T 0247). Plus proche encore, Peng Weiqing 彭魏卿 est le père maitre d'initiation (fuqin dushi 父親度師) de son fils Peng Zufu 彭祖富, nom de maitre exorciste Faqing 法清, né en I894, et qui fut initié par son père dans «la véritable doctrine de Ge Weng 》 暮翁正教 (To584, voir fig. 25). Yu Guomin 唋國 民 et ses frères se disent « disciples qui ont reçu la doctrine » (jiejiao dizi 接教弟子)

3I. Sur les « maîtres de l'eau », voir Li Kui 李魁, « Meishan shuishi de ge’an diaocha yu yitong bijiao » 梅山水師的個案調査與異同比教, dans Chen et Hua (Arrault), éd., op. cit., sous presse. 


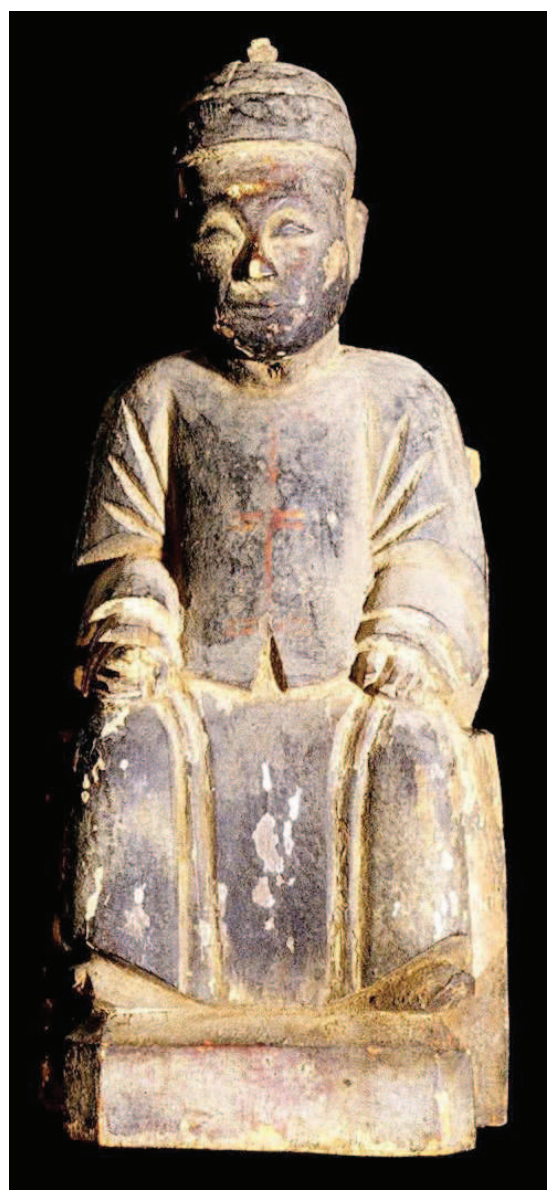

Fig. 25 : Père maître Peng Weiqing 父親度師 彭魏卿, 1929, T 0584. Cliché Zhang Chaoyin.

Fig. 26 : Père sieur [Yu] Meitao 先考[唋]公 美桃 (1917-1977), 1980, Y 1123008. Cliché Yan Xinyuan.

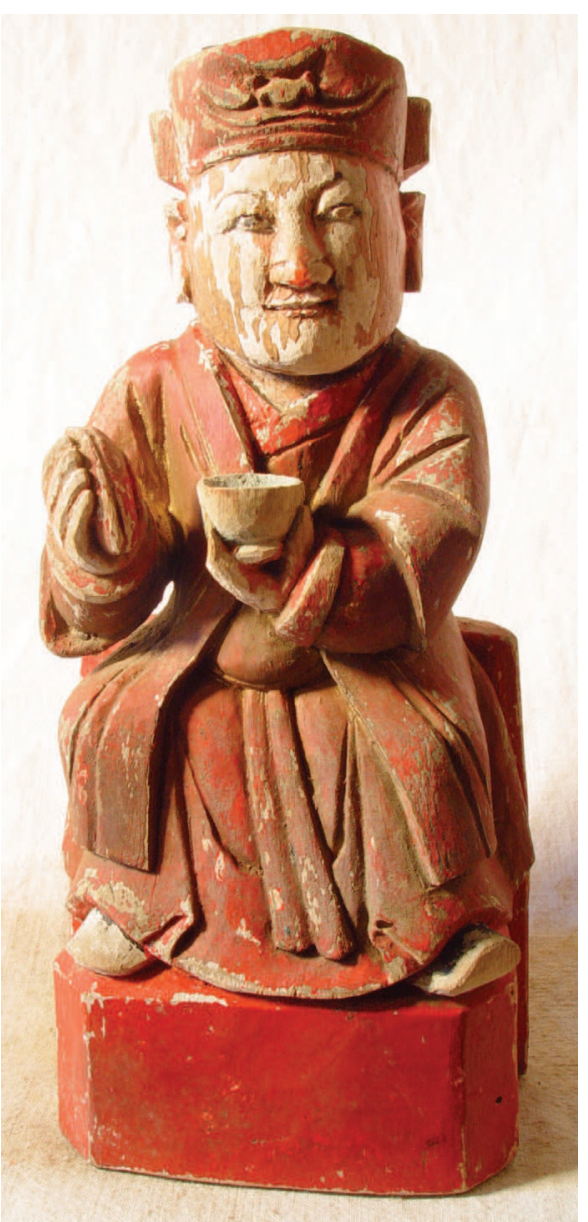

(C) École française d'Extrême-Orient, Paris, 2012

Do not circulate without permission of the editor / Ne pas diffuser sans autorisation de l'éditeur 
de leur père [Yu] Meitao [唋]公美桃 (I9I7-I977) (YII23008, voir fig. 26) ${ }^{32}$. Le cas est rare, mais il existe : «au moment de monter au département céleste, mon frère aîné initiateur Zeng Fayi (I793 ? -I849) m’a initié, moi son disciple Zeng Fahe... » (度兄曾法詒) 登曹之時, 界 [解] 度弟子曾法和... Cette procédure d'initiation, faite sur le lit de mort, est aussi un rite de transmission pendant lequel le maître, en révélant la partie plus ésotérique de son savoir (talismans, incantations, etc.), fait du disciple son héritier exclusif (Tor62) ${ }^{33}$.

S'il n'est donc pas, en matière de transmission des savoirs religieux, de règle absolue quant à la nécessité d'une initiation extra-familiale, la règle inverse n'en est pas pour autant vraie : les statues dédiées aux maîtres directs hors de toute relation familiale forment un nombre suffisamment consistant pour rendre caduque toute généralisation ${ }^{34}$.

\section{B) Statues de maîtres}

\section{Maîtres ancestraux (zusbi 祖師)}

En premier lieu, ce sont bien sûr les maîtres spirituels — des divinités nationales ou locales, tels que Yaowang 藥王, Lu Ban 魯班, Zhang Wulang 張五郎 et Lutou 爐頭 ${ }^{35}$, zushi d'un ordre religieux, d'une guilde - qu'il faut vénérer. Mais ils ne sont pas les seuls : d'autres personnages, beaucoup moins célèbres, ont également reçu ce titre.

En i896, Chen Faming 陳法明 dédie une statuette au zushi seigneur Zhang Fayu 張君法玉 (voir fig. 27), pour que les Furies ${ }^{36}$, palanquins et chevaux soient ensemble mis en branle :

Pour que les dix chefs des Furies, les chevaux et les soldats des cinq Furies reçoivent sacrifices et récompenses sur l'autel du tonnerre, [...] qu'en haut (que le jour) les soldats ne s'arrêtent pas, que le soir les chevaux ne se reposent pas ; que le Dao de la famille soit à son apogée, qu'il y ait de grandes célébrations, que l'encens et le feu de l'autel du tonnerre soient protégés, que le fondateur et ancêtre de l'ordre révèle [son pouvoir] rituel et son corps de dragon, que de génération en génération encens et feu manifestent leur efficace puissance, que les grandes méthodes rituelles de Jiang Fazheng 姜法正 soient dotées de la puissance divine, que l'on ordonne aux chevaux, aux soldats et aux Furies de se rendre dans les grottes et les temples, que le général Liu vienne, que sa bouche ayant le pouvoir rituel soit dotée de la puissance divine...

啟猖轎馬一齊, 十[大都猖, 五猖兵馬, 祭賞雷坛……不亭(停)兵, [睡]不放馬, 家道興隆,

大有慶世, 坐鎮香火雷坛, 啟教一派, 祖出法龍身, 世世香火顕威灵, 姜法正大法神通, [ 封]

猖兵馬到[銅]庙, 柳將軍來有法力口神通… (To624-4-I)

32. Par ailleurs, nous avons rencontré précédemment le cas de Jiang Hanqiu dont la notice biographique dit qu'il a initié ses deux fils, voir p. 72.

33. Le certificat de consécration a été placé dans une autre statue, celle du roi efficient du Bien et du Mal (Shan’e lingwang 善惡靈王).

34. Sur ces transmissions, voir également plus bas, p. 8I-85.

35. Voir Alain Arrault, "Analytic essay", p. I0-25; Alain Arrault et Michela Bussotti, «Statuettes religieuses", p. 39-43.

36. «Furie » traduit le terme chang 猖, démon converti et mis au service des dieux, notamment de Zhang Wulang, pour exterminer les puissances maléfiques. 
Fig. 27 : Maître spirituel sieur Zhang Fayu 張 君法玉祖師, consacré en 1896, T 0624. Cliché Zhang Chaoyin.
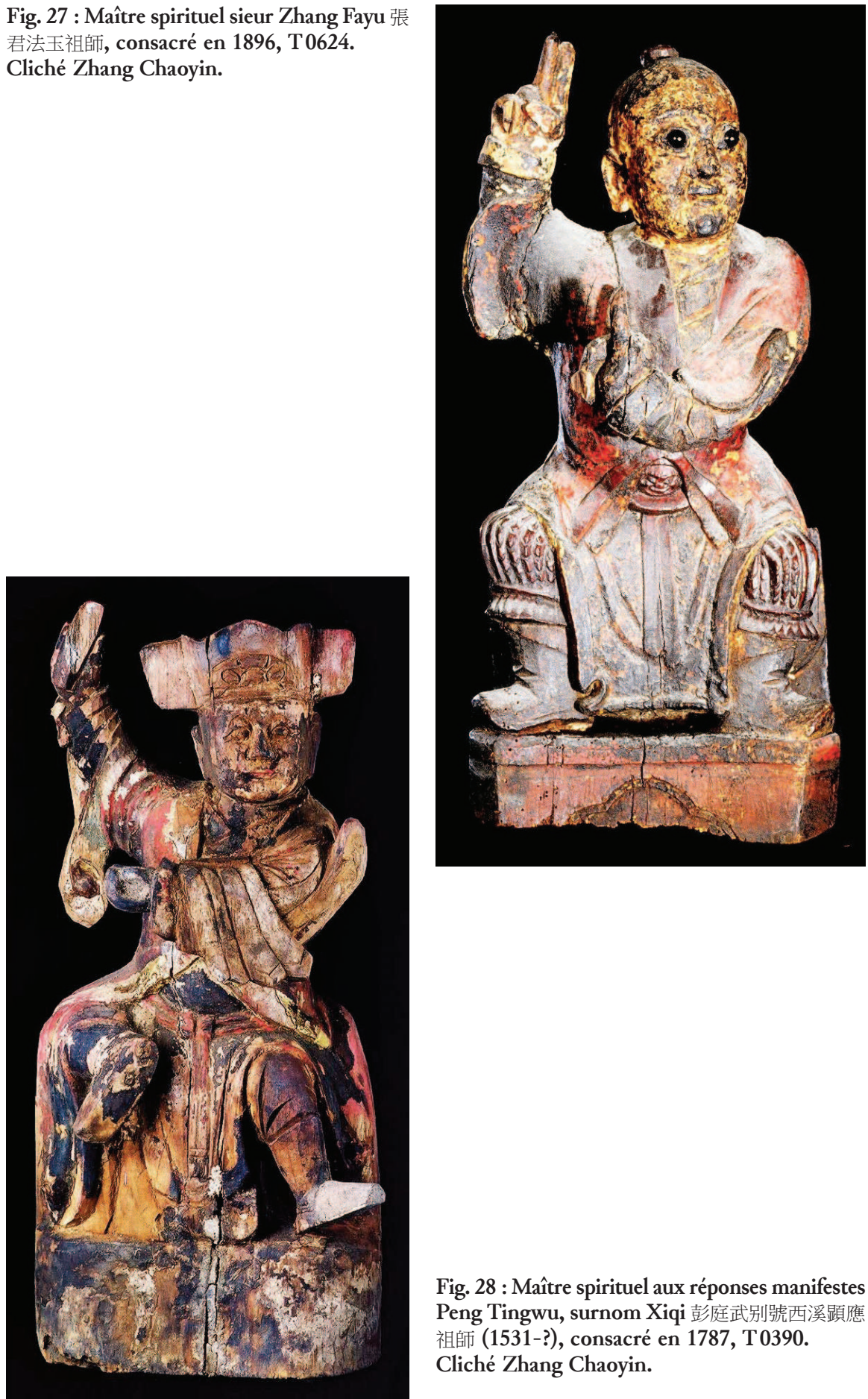

Fig. 28 : Maître spirituel aux réponses manifestes Peng Tingwu, surnom Xiqi 彭庭武别號西溪顕應 祖師 (1531-?), consacré en 1787, T 0390. Cliché Zhang Chaoyin.

(C) École française d'Extrême-Orient, Paris, 2012

Do not circulate without permission of the editor / Ne pas diffuser sans autorisation de l'éditeur 
Peng Tingwu 彭庭武, de son surnom Xiqi 西溪, et de nom d'initié Fawu 法武, est né en I53I (voir fig. 28). Au service de la maison impériale, il fut initié, mais afin de connaître les rites authentiques, il se rendit à Wuzhou 武州, l'actuel district de Changde 常德 dans le Hunan, pour y apprendre l'art des rituels ${ }^{37}$. C'est avec grand respect qu'il accomplissait les services religieux, c'est en suivant les règles rituelles qu'il commandait aux divinités. Sous l’ère Wanli 萬暦 (1573-1620), un écrit céleste (tianshu 天書) lui ordonna de monter au département céleste. Monté sur un cheval blanc, il parvint au Palais céleste et l'empereur de Jade en personne lui offrit de l'eau pure, et que ce soit pour obtenir le beau temps ou la pluie, pour supprimer les calamités, expulser les démons, protéger les hommes et les femmes, exorciser les passes néfastes des enfants, décider de la vie et de la mort, il suffit de l'implorer pour qu'il réponde... Partout lui ont été installés des autels, partout il se manifeste ; ni immortel ni saint, il descend en personne et révèle son efficacité, lui le maître spirituel (zushi) et authentique seigneur (zhenjun 真君) (To39o)!

Bien que l'expression employée dans ces deux derniers cas, et dans bien d'autres, soit celle qui caractérise les maitres spirituels, ce doit être par abus de langage, par confusion ou par volonté de magnifier ces maitres que l'on a remplacé shizu 師祖 par $z u s h i$ 祖師, les maîtres ancestraux par les maîtres spirituels. Il est vrai cependant que le partage est parfois délicat à opérer, mais les livres de rituels sont en général assez clairs pour distinguer la liste des maitres spirituels, du plus grand au plus petit de la liste, commençant par le fondateur de lignée, suivi de ses héritiers en droite ligne, et se terminant finalement sur l'indication des maîtres directs.

Dans un autre domaine, mais dans un contexte similaire, Lu Yinyou 蘆蔭佑, initié sous le nom de Fayou 法有, avait, semble-t-il, dans sa date de naissance des étoiles néfastes pour ses parents. Pour cette raison, il entra en religion, prit en I880 comme maitre d'initiation de l'autel du tonnerre Tang Faying 唐法應, auprès duquel il étudia la religion orthodoxe Guinan ([Gui]nan zhengiiao 桂南正教, la religion orthodoxe de Huainan 淮南 ?). Cependant, ce n'est pas à ce dernier que Lu consacre une statuette mais au maître ancestral (shizu) sieur Zhao Faquan 趙君法全, un geste filial qu'un bon disciple se doit d'accomplir (T0555) ${ }^{38}$.

\section{Maîtres directs}

Les maitres directs forment légion. En dehors des maîtres issus de la famille que nous avons évoqués précédemment, ces maitres répondent à plusieurs types

37. Plus loin, c'est l'empereur de l'Origine (Yuanhuang 元皇) qui lui ordonna d'étudier l'art des rituels de Wuzhou 武州.

38. Un autre sieur Zhao Faquan, de prénom personnel Guicheng 貴成, de prénom public Hanzun 漢尊, né en I695 dans le district de Shaoyang 邵陽 et mort en 176I dans le district de Ningxiang 寧鄉, est vénéré par un certain Deng 鄧, maître exorciste de son état, habitant le même district que Lu, Yiyang 益陽, mais dans un canton voisin (To208). Au vu de la date d'entrée en religion de Lu Yinyou (I880), la date de consécration de I908 pour ce second sieur Zhao pourrait coïncider avec celle de la statuette commanditée par Lu Yinyou. Deng appelle Zhao Faquan maitre spirituel, zushi. 
d'appellations. Il peut s'agir du terme très moderne de shifu, écrit pour le deuxième caractère tantôt fu 父 (père), tantôt fu 付 (sic !) ou fu 傅, ce dernier étant la bonne graphie. Dans les trois exemples que nous avons, ce sont bien des disciples (dizi 弟子 ou tudi 徒弟), avec des noms de famille différents de celui de leur maitre, qui procèdent à « l'ouverture des yeux » d'une statuette dans la deuxième moitié du XIX siècle (To76r : 1844, To216 : 1855) et au début du XXe siècle (T0793 : 1919).

Les shigong 師公, qu'il faut distinguer des gongshi 公師, font partie du lot. Sur les seize occurrences ${ }^{39}$, onze concernent des disciples dont le nom de famille diverge de celui de leur shigong. Xue Faqi 薛法棋 et Xue Fazhen 薛法珍, qui rendent hommage à Xue Fazhao 薛法照, sont des exceptions à la règle, bien que rien n'empêche que ces Xue soient des parents en ligne directe. Les deux Xue, disciples qui véhiculent l'art de la «sorcellerie » ( $w u$ 巫), ont étudié la méthode des talismans du Meishan de l'ordre Yuanhuang 元皇梅山符法. Dans le certificat de consécration, ils donnent en seize phrases quadrisyllabes une description saisissante de la statuette et de leur maitre :

La statue de l'effigie de notre maître est une imitation de sa bonté.

Elle lui conserve (sa puissance) rituelle, elle en a l'autorité.

Sortant à cheval, elle vole, rapide comme l'éclair.

À cheval elle retourne à l'autel, [l'âme de notre maitre] l'habite ${ }^{40}$.

Elle élimine les esprits possédant les gens, elle les délivre des malheurs.

On la rétribue avec de l'alcool, on lui brûle de l'encens ;

Quand on songe à la merveilleuse efficience de notre maitre, il descend aussitôt à nos côtés ;

Quant à ses mérites que nous invoquons, nous les garderons pour toujours dans nos cœurs

et ne les oublierons jamais (To40o).

塑公之像, [慕]公之[徽], 守公之法, 仗公之威, 乘馬出外, 如電如飛, 乘馬歸壇, 式憑式依,

為人除崇, 為人解殊, 酬之(以)酒, 焚之以香, 想公之靈, 陟降在旁, 感公之德, 永懷不忘。

Les maitres d'initiation (dushi 度師) ou encore les « maîtres d'initiation qui ont enseigné en personne » (qinkou dushi 親口度師), constituent à eux seuls une catégorie de statuettes, pour un total de plus de soixante-dix pièces, l'emportant nettement sur les autres types d'effigies de maitres directs. Parmi elles, cinquantecinq concernent des relations extra familiales, ne laissant subsister aucun doute sur l'importance d'une telle initiation. Qui plus est, même les familles de spécialistes religieux peuvent avoir avantage à pousser leur progéniture vers d'autres familles : cette stratégie permet de combiner un double héritage, celui de la famille et celui d'une autre, qui se traduit non seulement en termes de cumuls de savoirs, mais aussi d'agrégation de nouveaux territoires d'exercice du culte, un maitre ayant par définition sous sa tutelle un certain nombre de « clients » englobés dans son aire rituelle ( $\tan$ 壇).

Cette volonté d'élargir le spectre de ses compétences « rituelles » transparaît parfois dans le fait que le disciple se reconnait plusieurs maitres. Wang Chengfu

39. Ces occurrences proviennent toutes des collections PF et YXY.

40. Shiping shiyi 式憑式依. Une expression similaire, lingshuang shiping 靈爽式憑, est employée en relation avec la statuette pour signifier que l'âme du défunt y demeure (To834, To578). Pour une statuette de Lu Ban, « en s'y appuyant, [Lu Ban] descend ici bas » 式憑式降, voir To780.

(C) École française d'Extrême-Orient, Paris, 2012

Do not circulate without permission of the editor / Ne pas diffuser sans autorisation de l'éditeur 
Fig. 29 : De gauche à droite : maître d'initiation Liu Fayun $(1823$ - ?) 度師劉法雲, sieur maître Li Ying[tong] (1786 - ?) 公師李盈[通], père maître Li Chaoyan (1807 - ?) 父師李朝言, consacré en 1876, T0678-A/-B/-C. Cliché Zhang Chaoyin.

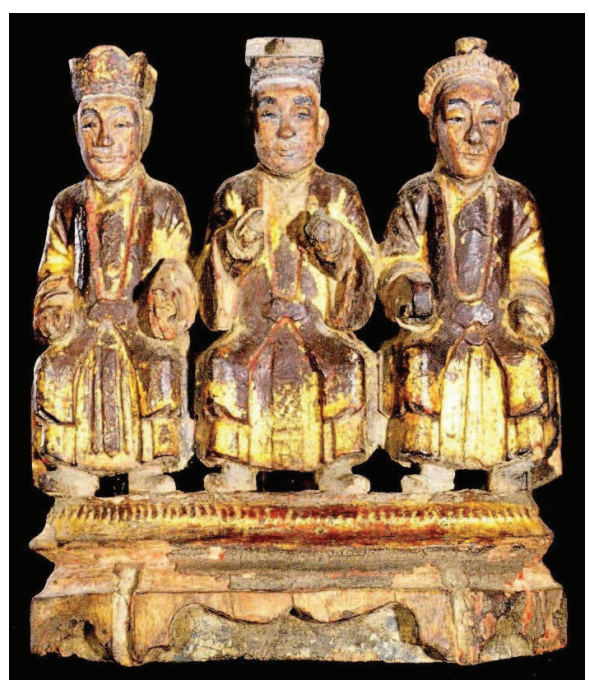

王成馥, de nom public Guiquan 桂泉 et de nom d'ordination Fagui 法桂, a selon ses dires pris comme maitre d'initiation Yu Fayun 喻法雲 en I89I (?) ; la même année il lui faisait faire une statue. Mais Wang mentionne par ailleurs ses trois shigong : Liao Faguang 廖法廣, Wu Fayu 吳法餘 et Wu Faxiang 吳法祥. Avec ses quatre maîtres, Wang a étudié, «à leurs genoux », toutes les sortes de formules secrètes et talismans pour rassembler les Furies de la montagne des Abricotiers du souverain de l'Origine (Yuanhuang Meishan shouchang zhuban fufa mijue 元皇梅山收猖諸般 符法秘訣) (To590) ${ }^{4+}$. De même, Lu Guoli 盧國禮 a commandé une statue mais trois personnages sont mentionnés : son maitre d'initiation, Lu Fazhen 盧法珍, son sbigong Zhou Farong 周法榮, et son shitai 師太, Zhou Fasheng 周法勝 (ToIr4). Cette triade de maîtres, qui ici désigne plus vraisemblablement une généalogie ${ }^{42}$, peut aussi être une imitation des trois maîtres du taoïsme (jing 經, $j i$ 籍, $d u$ 度). Un certain $\mathrm{Li}$ 李 rend ainsi un culte à son père-maître (fushi), né en I807, à son gongshi 公師 (même nom de famille) et à son maître d'initiation (dushi), Liu Fayun 劉法雲, né en I823. Ces personnages sont iconographiquement représentés par trois statuettes fixées sur un même piédestal, un assemblage unique dans les collections (To678, voir fig. 29).

\section{Les ordres religieux}

Qui dit ordre religieux dit aussi initiation, et naturellement temps d'apprentissage. Ce temps est signifié par des expressions telle que xiannian 先年 (dans les années précédentes), qui ne permettent pas de déterminer une durée réelle, mais d'autres

4I. Au sujet de cet ordre, voir plus bas, p. 92 et ss.

42. Sur le certificat de consécration, le disciple Jiang Youqing 姜佑卿 a pris soin de faire écrire la liste de ses maitres dans son lignage. Après onze noms, la liste se termine par son sbitai $i$ 師太, son shigong 師公 et son dushi 度師, qu'il faudrait donc comprendre comme étant respectivement «le grand-père » et « le père » de son maître d'initiation, et le maître d'initiation lui-même (To70o). 
sont plus concrètes. À l'exception de deux cas de maitres pris dès la plus tendre enfance et une initiation de cinq années, la majorité indique deux ans (qian nian 前年) ou un an (shang nian 上年). Ouyang Fasheng 歐陽法笙 est né en I880 et c'est le huitième jour du deuxième mois de l'an 1932 que Zhang Xiangui 張先桂, à l'âge de $29 s u i$ 歲, le prit comme maitre d'initiation. L'apprentissage fut apparemment rondement mené puisque les seizième, dix-septième et dix-huitième jours du dixième mois de la même année le rituel d'ordination (paopai zhouzbi 抛牌奏職) eut lieu. Et c'est à cette occasion que fut faite et consacrée la statue du maître que l'on doit donc supposer être mort à l'âge de cinquante-deux ans ( $\mathrm{T}_{0303}$ ).

Afin d'avoir un aperçu le plus complet possible des relations de maitrise, nous avons procédé à un recensement des savoirs transmis et des ordres religieux évoqués dans les certificats de consécration. Pour ce faire, nous avons élargi notre enquête au-delà des statuettes formellement dédiées à des maittres, sachant en particulier qu'un disciple commanditant une statuette de divinité peut évoquer l'ordre dont il se réclame, et en incluant par ailleurs celles des parents-maittres, cette manière de procéder permettant d'avoir un tableau plus réaliste de la situation religieuse de la région (voir le tableau des ordres religieux en appendice).

Le nom de l'ordre religieux lors d'une consécration de statuette est mentionné avec précision dans soixante-dix certificats, qui proviennent par ordre d'importance des districts de Ningxiang (22), Xiangxiang (II), Xinhua (8), Anhua (7), Yiyang 益 陽 (5), Longhui 隆回 (2), Lianyuan 漣源 (I) et Xiangtan 湘潭 (I), et couvrent une période de temps allant de 1794 à 1987 . Nous avons réparti d'une part ces ordres en fonction de la nature de la transmission, intra familiale ou extra familiale, lorsqu'il s'agit d'une dédication à un maitre direct, et d'autre part recensé l'ordre invoqué dans le cas d'un culte rendu à une divinité.

Dans ce dernier cas de figure, la divinité objet du culte fait en réalité office de maitre spirituel, ou de patron de guilde : il existe un lien étroit entre le commanditaire et la divinité, lien créé par le métier qu'exerce le premier. C'est ainsi que l'on rend grâce à $\mathrm{Lu}$ Ban, le protecteur des travailleurs du bois, sous la tutelle duquel on se place en faisant valoir son statut de disciple de « la doctrine orthodoxe de Lu Ban » (Lu Ban zhengjiao 魯班正教), ou encore « des arts orthodoxes de Lu Ban du souverain de l'Origine » (Yuanhuang Lu Ban zhengyi 元皇魯班正藝). En I983, un disciple marque tout simplement son allégeance à « la doctrine orthodoxe des travailleurs du bois » (Mujiang zhengjiao 木匠正教). Zhang Wulang 張五郎, dont la position avec la tête en bas est immédiatement identifiable, est quant à lui associé à 《la doctrine orthodoxe du souverain de l'Origine 》 (Yuanhuang zhengjiao 元皇正教) (T 0823), que le donateur dit avoir étudiée à la fin du XVIII ${ }^{\mathrm{e}}$ siècle, ou à « la doctrine du souverain de l'Origine du Ciel antérieur» (Xiantian Yuanhuang zhengjiao 先天 元皇正教) dont un certain Luo [Jiao] song 羅[教]松 se dit être un disciple (To6oI). Cette mention du courant religieux du souverain de l'Origine est omniprésente dans la région centrale du Hunan, comme nous le verrons plus bas, et elle vient nous rappeler que Zhang Wulang, dieu des chasseurs, est aussi présenté localement comme le fondateur du lignage spirituel du souverain de l'Origine, et qu'il est, pour cette raison, présent sous l'autel principal lors de l'accomplissement de services religieux. Il va de soi que les statuettes dédiées au roi de la Médecine (Yaowang 藥王), relati-

(C) École française d'Extrême-Orient, Paris, 2012

Do not circulate without permission of the editor / Ne pas diffuser sans autorisation de l'éditeur 
vement nombreuses dans les trois collections, ou au médecin Hua Tuo 華它, ou au dieu de la Forge (Lutou 爐頭), bien que les certificats ne fassent pas expressément référence à un ordre religieux particulier, sont vraisemblablement consacrées par des gens de métier, les médecins ou pharmaciens pour les deux premiers, et les travailleurs du fer pour le dernier.

Les divinités tutélaires avec mention de l'ordre religieux ne se comptent qu'au nombre de dix, il en va évidemment tout autrement pour les statuettes dédiées aux maitres directs, qui totalisent cinquante-sept pièces. Parmi ces dernières, quinze témoignent d'une initiation familiale, et quarante-trois d'une transmission hors du contexte de la famille, accréditant l'idée que nous avons évoquée ci-dessus d'une stratégie de cumul des savoirs et des territoires " paroissiaux». Signalons toutefois qu'un certificat fait état des deux types de transmissions (T 0746) et huit, bien que ne faisant pas mention de liens de parenté, indiquent un nom patronymique identique pour le maître et le disciple (marqués d'un astérisque dans le tableau en appendice). Nous émettons donc pour ces exemples des réserves quant à la nature de la transmission, qui pourrait être ni familiale, ni strictement extra familiale, mais clanique.

Ceci dit, nous devons confesser que le recensement auquel nous nous sommes livrés nous place face à de riches, nombreuses et diverses dénominations d'ordre religieux, un foisonnement au milieu duquel nous allons tenter d'apporter quelques repères.

\section{a) Religions « institutionnelles»}

Le bouddhisme, fojiao 佛教, est invoqué à deux reprises. Peng Zhongwei 彭鍾維 déclare que depuis sa tendre jeunesse il a étudié le bouddhisme auprès de son maitre Zhou Mugui 周木桂 (I892-1942), à qui il dédie une statuette en I946 (voir fig. 30). Pour rendre grâce à son maître, il a fait faire sa statuette à laquelle il rend un culte matins et soirs : l'âme de son maître, toujours présente dans cette effigie en bois, permet au disciple et au maître de n'être jamais séparés, d'être par «le cœur et la bouche à l'unisson ». La statuette en question porte une tunique bouddhique, mais elle a aussi pour attributs un bol d'eau lustrale et un bâton de commandement, instruments typiques des maîtres exorcistes, une iconographie cohérente avec le fait que Zhou présente également un faming (To834). Nous apprenons par la courte notice biographique qui lui est consacrée que Chen Xianjian 陳顯釗 (I852-I926) a dès sa naissance pris pour maître le moine Daxing 大興 de l'ermitage de Xiangzhu 香箨 afin d'étudier le bouddhisme. À première vue, que ce soit dans l'iconographie de la statuette - une statuette typiquement du genre des maitres exorcistes ou dans les noms d'ordination de Chen, rien ne transparaît de son apprentissage bouddhique (To237).

Zhou [Jun] qi 周[鈞]祺, nom d'ordination Qianqi 乾祺 et nom bouddhique Xinqi 心祺, emploie une autre expression pour dire la conjonction du bouddhisme et de la religion des maîtres exorcistes : « la doctrine orthodoxe du bouddhisme et du chamanisme » 巫釋正教, qu'il dit tenir de son maittre d'initiation Ye Zhenru 葉震儒 (I894 - ?) (voir fig. 3I). Le $w u$-chamanisme désignant ici les maittres exorcistes, 


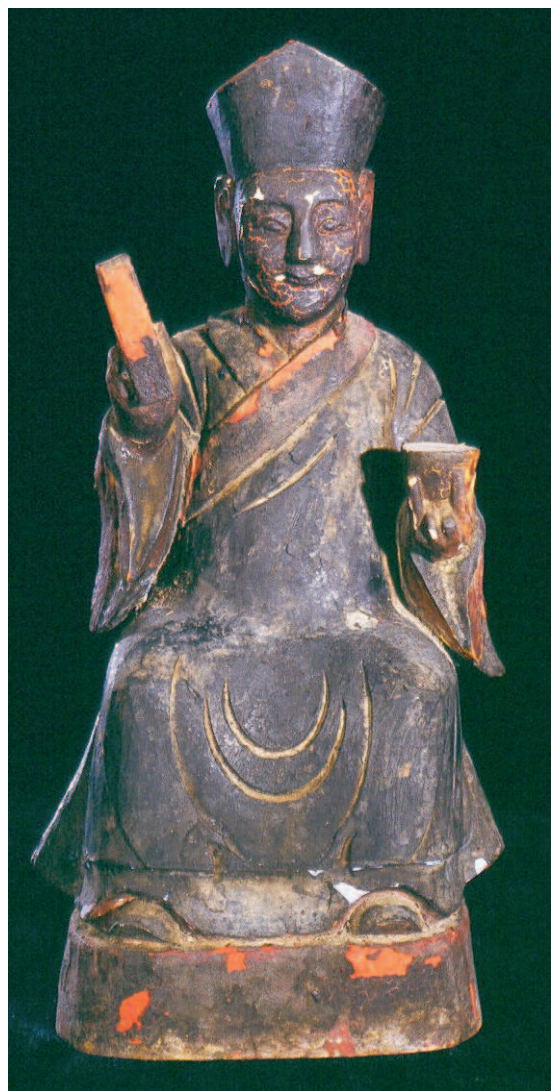

Fig. 30 : Maitre d'initiation seigneur Zhou Mugui 周君木桂 (1892-1942), nom de maître exorciste Chengjiao 成嶠, consacré en 1946, T0834. Cliché Zhang Chaoyin.

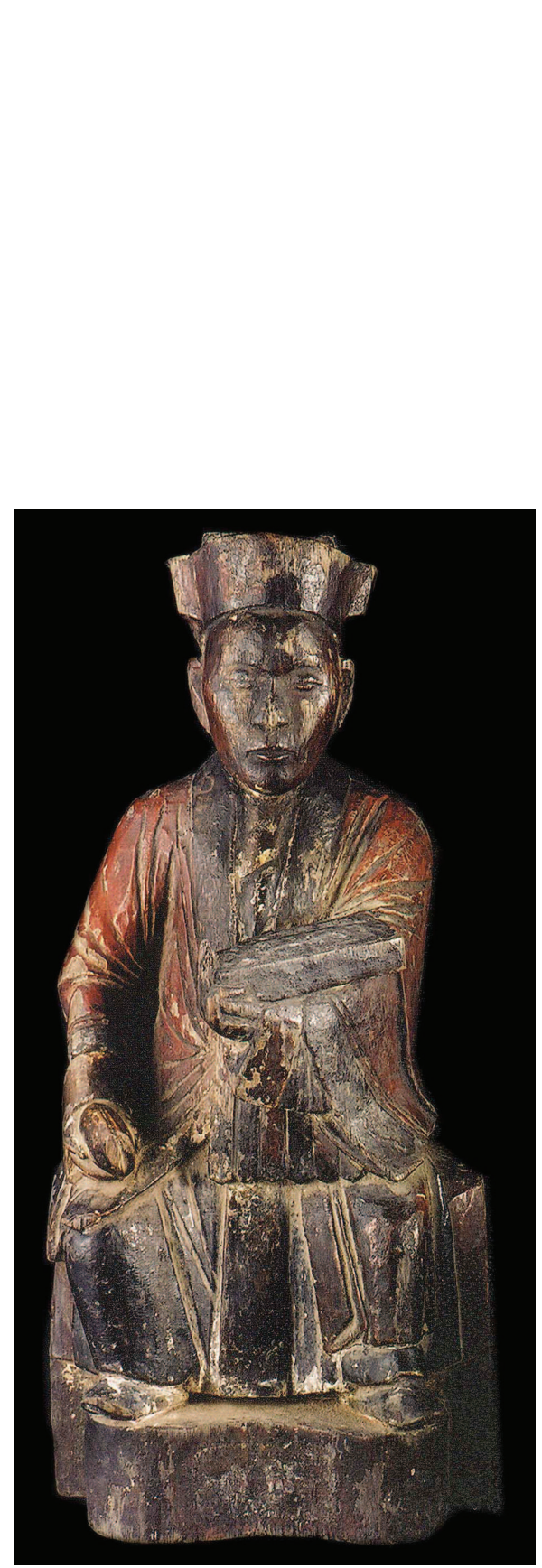

Fig. 31 : Maître d'initiation Ye Zhenru葉震 儒 (1894 - ?), consacré en 1922, T0466-2-1. Cliché Zhang Chaoyin.

(C) École française d'Extrême-Orient, Paris, 2012

Do not circulate without permission of the editor / Ne pas diffuser sans autorisation de l'éditeur 
il confère ainsi à la religion pratiquée localement un statut « officiel». Une fois de plus, la composante bouddhique est totalement absente de la statuette, qui tient la boîte aux soldats (bingpai) ${ }^{43}$ et des blocs divinatoires (gua 卦), et dont les vêtements ne trahissent aucune affiliation au bouddhisme (To466-2-I). Nous observons la même chose dans la statuette de Chen Shenhu 陳身湖, avec qui son fils Yuan[ji] 逗[吉] et son neveu, Yuanshang 薹上, ont étudié « les deux religions taoïste et bouddhiste » (fodao liangjiao 佛道两教), alors que Chen, portraituré en maitre exorciste, n'a comme nom d'ordination qu'un nom bouddhique, Shengxiu 聖修 (To452)!

À l'instar du bouddhisme, le taoïsme en tant que tel est très peu évoqué. Un certain Ning 甯 se voit dédier une sorte d'éloge funèbre dans lequel il est clairement fait allusion au fait que son dao relève de celui du Vieux seigneur (Laojun 老君), le Laozi divinisé :

Gardant sa nature droite et intègre, se consacrant de tout cœur à l'équité, son dao fait partie de la doctrine du Vieux seigneur, dont la réputation précède celle de la Reine mère. C'est sous le pont Yangzi 楊子橋 qu'il a reçu de son divin maitre les méthodes rituelles, qui comprennent des formules merveilleuses et les techniques magiques que l'on pratique d'un cœur sincère. Il prêta serment devant le temple des Trois Purs et sa vie durant il eut la pénétration complète des techniques rituelles. Lorsqu'elle monta au département céleste, son âme pleine de vitalité ne fut pas tourmentée (To544).

秉性正直, 存心公道, 道分老君之教, 名例王母之前, 拜法仙師楊子桥下, 有妙訣誠心巫術, 三清殿前作証盟, 生前之法術精通, 登曹之精爽不磨.

En y regardant de plus près, et bien que l'aspect taoïste soit renforcé par le serment prêté devant le temple des Trois purs (sanqing 三清) — les trois plus hautes instances du taoïsme - , ce passage évoque toutefois une caractéristique typiquement locale de la cérémonie d'ordination, que l'on accomplit «sous le pont Yangzi». Le pont Yangzi pourrait faire référence à un lieu réel situé à proximité de Yangzhou 楊州, dans la province du Jiangsu 江蘇, ou encore à un toponyme de la région du Fujian 福建, où Chen Jinggu 陳靖姑, ne pouvant traverser un fleuve, aurait vu apparaitre un pont en forme d'arc et le grand maître du Lüshan 閭山 venu l'accueillir. Mais, rituellement, c'est sur ce pont que le maitre d'initiation se place et qu'il transmet au disciple, agenouillé sur « la tortue de bronze » (jingui 金龜), les légions célestes, les livres et instruments rituels qui lui reviennent, ainsi que les prescriptions qu'il doit observer. En souvenir de ce moment crucial où le disciple devient un maitre, certains services se terminent, notamment ceux d'action de grâce (buanyuan 還愿), par la construction symbolique de ce pont, devant lequel le maitre de cérémonie invite toutes les divinités et soldats célestes à festoyer et où il se remémore la scène de son intronisation, son maître, ses instructions, etc., avant de jeter les blocs divinatoires afin de vérifier qu'il a bien reçu l'agrément des divinités ${ }^{44}$. À cette couleur locale, il

43. Au sujet de cette «boîte aux soldats », voir plus haut, p. 72.

44. Le pont Yangzi est mentionné dans l'avis annonçant une ordination (bangwen 榜文), voir Huang Zhen 黃鎮, «Meishan shigong de fafu, faqi yu mianju » 梅山師公的法服, 法器與面具, dans Chen et Hua (Arrault), éd., op. cit., sous presse. Pour plus de détails sur cette cérémonie et sa remémoration dans un service d'action de grâce, voir Huang Zhen et Liu Qigui 劉期貴, «Longhui xian shigong de fashi, fafu, faqi ji you guan zhuanshuo » 隆回縣師公的法事, 法服, 法器及有關傳說, dans ibid. 
faut ajouter que la statue de Ning et son nom d'ordination (Falong 法龍) ne reflètent que la doctrine des maitres exorcistes, dans laquelle le Vieux seigneur, bien plus que les Trois purs, l'empereur de Jade ou tout autre sommité taö̈ste, joue effectivement un rôle de premier plan. Est-ce un hasard si la référence locale au taoïsme se fonde sur la divinité centrale (Laojun, Taishang laojun 太上老君) du premier taoïsme, du $\mathrm{II}^{\mathrm{e}}-\mathrm{III}^{\mathrm{e}}$ siècle, autour de laquelle vont s'établir les premières institutions religieuses taoïstes qui, au fil du temps, transformeront radicalement son statut et son titre ?

Nous avons rencontré précédemment Peng Zufu 彭祖富 (I894 - ?), qui déclare avoir étudié avec son maître d'initiation et père «la doctrine orthodoxe de Ge Weng » (Ge Weng zhengjiao 葛翁正教) (To584). Cette doctrine fait probablement allusion à l'un des grands auteurs taoïstes, Ge Hong 葛洪 (284- ?), auteur du Baopu zi 抱朴子. C'est là une indication précieuse mais qui hélas n'est pas répétée, et dont nous ne savons pas ce qu'elle renferme exactement. Par ailleurs, bis repetita, Peng n'est gratifié que d'un nom d'ordination de maitre exorciste.

\section{b) La doctrine du souverain de l'Origine (Yuanbuang jiao 元皇教)}

L'expression désignant cette doctrine apparaît pas moins de trente fois au début du nom des doctrines revendiquées comme transmises. Il s'agit tout d'abord de l'expression simple : « doctrine orthodoxe du souverain de l'Origine » (Yuanhuang zhengjiao 元皇正教), et de ses variantes comme « la transmission du souverain de l'Origine » (Yuanhuang zhi jiao 元皇之教), 《la doctrine divine du souverain de l'Origine » (Yuanhuang shenjiao 元皇神教), etc ${ }^{45}$. La signification et les antécédents du terme «souverain de l'Origine » sont source de perplexités.

Avant le monde, il n'y avait qu'un grand rien, un immense vide, seul le Vieux seigneur résidait au milieu de cette vacuité. Puis s'ensuivirent plusieurs phases, le Grand début (Taichu 太初), le Grand commencement (Taishi 太始), la Grande simplicité (Taisu 太素), le Chaos (Hundun 混沌), les Neuf palais (Jiu gong 九宮). À la fin de ce processus, l'univers est formé : le ciel, la terre, les montagnes et les vallées, le yin et le yang, les hommes et leurs cinq organes existent enfin. Dans chacun de ces moments, le Vieux seigneur intervient comme maitre, et c'est ce qu'il fait auprès du souverain de l'Origine, à qui « il prêche » le Livre du souverain de l'Origine (Yuanbuang jing 元皇經) et enseigne comment gouverner le monde, marquant ainsi le début de la gouvernance grâce à « la transformation du souverain » (buang bua 皇化), qui se répandra sur les générations futures. L'épopée se poursuit avec le souverain du Ciel (Tianhuang 天皇), de la Terre (Dihuang 地皇) et de l'Homme (Renhuang 人皇); les grands civilisateurs (Fuxi 伏羲, Shennong 神農, Zhurong 祝融, Huangdi 黃帝, etc.) font ensuite leur apparition, avant de laisser la place aux fondateurs de dynasties : Yao 堯, Shun 舜 et Yu 禹 ${ }^{46}$. Pourtant à la jonction entre la formation de l'univers et

45. On pourrait ajouter à cette liste la « doctrine familiale du souverain de l'Origine des ancêtres » (Xianzu yuanhuang jiajiao 先祖元皇家教).

46. Voir Taishang Laojun kaitian jing 太上老君開天經, $D Z$ I437, fasc. ${ }^{\circ}$ I059; Zhonghua Daozang 中華道藏, 49 vol., Pékin, Huaxia chubanshe 華夏出版社, 2004, vol. 8, p. 160-162. Ce texte est daté des Six dynasties (220-589), voir K. Schipper, F. Verellen, éd., The Taoist Canon: A

(C) École française d'Extrême-Orient, Paris, 2012

Do not circulate without permission of the editor / Ne pas diffuser sans autorisation de l'éditeur 
la gouvernance du monde, le souverain de l'Origine n'est l'objet de références que par intermittence. Dans le volumineux dossier de la diatribe opposant le taoïsme et le bouddhisme sous la dynastie des Tang, il est évoqué pour indiquer que « depuis le souverain de l'Origine ", il n'y a aucune technique occulte (contrôler les esprits, avaler le souffle, entrer dans le feu sans se brûler, marcher sur l'eau sans se noyer, monter au ciel en plein jour, etc.) que « les taoïstes des montagnes sacrées » ne maittrisent $\mathrm{pas}^{47}$; deux ouvrages alchimiques datés aux alentours des $\mathrm{X}^{\mathrm{e}}-\mathrm{XI}^{\mathrm{e}}$ siècles citent les « Formules secrètes du seigneur souverain de l'Origine » (Yuanbuang jun jue 元皇君訣) et le 《Premier livre du souverain de l'Origine 》 (Yuanbuang shangjing 元皇上經) pour ce qui concerne la transmutation du plomb et du mercure ${ }^{48}$; datant probablement du début du XviII e siècle, les titres de deux livres placés sous l'égide du dieu de la Glorification des lettres (Wenchang 文昌), appartenant au genre des livres de morale révélés par médiumnie, «d'incitation au bien et du rejet du mal » afin de "se délivrer des malheurs » et de "prolonger sa descendance », se voient affublés, sans justification particulière, de l'expression «le souverain de l'Origine »" .

Il va de soi que toutes ces références, hormis la première, demeurent pratiquement sans contexte, si ce n'est de nous fournir des repères au fil du temps, finalement très éloignés et sans lien entre eux. Dans tous les cas, le terme et son environnement textuel ne nous offrent rien - si ce n'est un nom - de suffisamment explicite qui puisse faire penser de près ou de loin à un ordre ou à un courant religieux structuré.

Il en va tout autrement pour les maitres exorcistes du Hunan qui se désignent le plus souvent comme appartenant à la doctrine des maitres (Shi jiao 師教, Shigong jiao 師公教), ou encore à la doctrine du souverain de l'Origine ${ }^{\varsigma^{\circ}}$. La partie finale du

Historical Companion to the Daozang, Chicago, University of Chicago Press, 2004, p. I08-ı09. Il

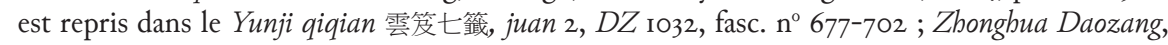
op. cit., vol. 29, p. 39-4I.

47. Voir Guang Hongming ji 廣弘明集, juan I, « Guizheng pian » 歸正篇, T. vol. 52, n 2103, p. 98c-99b. Ce texte, qui est censé rapporter un plaidoyer en faveur du taoïsme en l'an 7I, précise que les taö̈stes des Cinq pics sacrés s'appuient dans leurs pratiques sur le Lingbao zhenwen taishang yujue sanyuan fulu 靈寶真文太上玉訣三元符録 en 509 juan 卷. Il est repris, avec des variantes importantes, dans un autre texte bouddhique, le Sifen lü xingshi chao jianzheng ji 四 分律行事鈔簡正記, juan 9, daté de la fin des Tang (895), qui parle de Lingbao zhenwen taishang wangjue 王訣 yuanbuang 元皇 fulu, ZZ., vol. 43, n ${ }^{\circ} 737$, p. 236b-236c. Cette dernière version du titre du Lingbao semble erronée, de même qu'est anachronique dans les deux cas la référence à l'année 7I de notre ère!

48. Il s'agit du Xiudan miaoyong zhili lun 修丹妙用至理論, $D Z_{234}$, fasc. $n^{\circ}$ II3, voir Zhonghua Daozang, vol. I8, p. 744-745; et du Xishan qunxian buizhen ji 西山群仙會真記, $D Z$ 246, fasc. nº II6, voir Zhonghua Daozang, vol. 19, p. 136-137.

49. Voir Yuanbuang dadao zhenjun jiujie baojing 元皇大道真君救劫寶經, Daozang jiyao 道藏 輯要, Taipei 臺北, Xinwenfeng chuban gongsi 新文豐出版公司, 1977, xingji 星集 9, p. I8a-25b, et le Wenchang yinghua yuanbuang dadao zhenjun shuo zhusheng yansi miaoying zhenjing 文昌應化元 皇大道真君說注生延嗣妙應真經, Daozang jiyao, xingji 9, p. 26a-35a. La préface de ce dernier texte donne la date de 1734 .

50. Dans le district de Yuanling 沅陵 (sud-ouest du Hunan), la soi-disant « culture Nuo 儺 》 serait divisée en deux branches principales : la première se réclamant de la doctrine de l'empereur de Jade (ou du Sud du fleuve, Henan 河南), la seconde de l'empereur de l'Origine (ou de l'Amont 
service d'ordination appelée «Pantan jing » 盤壇經, Examen de l'autel, qui consiste en une série de questions du maitre d'initiation à laquelle le disciple doit répondre, se présente sous la forme d'un livret dont le titre fait clairement référence au souverain de l'Origine, «Livre complet de la conversion et de la transmission de l'autel du souverain de l'Origine " (Yuanbuang chuan tan guodu quanben 元皇傳壇過度全本). Lors de sa première réponse, le disciple se présente comme "le disciple qui d'un cœur pur reçoit les rituels et se rallie à l'autel », puis dans la seconde, mû par un mouvement de dénégation et d'humilité, il dit : «Suis-je le disciple qui reçoit les rituels et se rallie à l'autel, qui oserait se rendre devant le palais du Vieux seigneur en frappant le gong et battant le tambour ? » Le palais du Vieux seigneur (Laojun dian 老君殿) apparaissant ainsi comme au cœur de l'ordination, le souverain de l'Origine est identifié comme étant le Vieux seigneur ${ }^{s i}$. Ce personnage est également central dans le Hunzu liupai quanzong 混祖流派全宗, les « Principes complets des lignées de l'ancêtre Chaos "s. Le Laozi jing 老子經 — qui n'a rien de commun avec le Daode jing ou autres écrits attribués à Laozi — est cité dès la première phrase comme la source décrivant en détails la généalogie de ces lignées. On y apprend notamment qu'il y a huit Laozi mais que seul le Vieux seigneur de l'origine chaotique :

[...] s'est réincarné en trois endroits et a conçu les quatre-vingt-une méthodes talismaniques. Comme il y eut une période de paix de huit années, soixante-douze disciples reçurent ces méthodes. Mais ils se retournèrent contre leur maitre et s'enfuirent. Laozi, ivre de colère, détruisit en les enterrant les fondements de la doctrine, seule grande sour Xiuzhen put transmettre dans le monde trente-six méthodes talismaniques. Zhang Zhao le deuxième seigneur en obtint les authentiques méthodes pour guérir les maladies et expulser les nuisances ${ }^{53}$.

只有混元老君, 三處投胎, 造成八十一階符法 - 後因平安八年, 七十二人拜法, 返師逃走, 老 子大怒, 埋滅教門, 只有秀珍小姊傳流天下三十六階符法・張趙二郎得受真法, 治病祛邪 ·

Des maitres locaux expliquent que le souverain de l'Origine est un abrégé du titre que reçut Laozi de l'empereur Gaozong 高宗 des Tang ( $r$. 649-683), Taishang xuanyuan huangdi 太上玄元皇帝, dont on aurait retenu que le yuan et le buang ${ }^{54}$. Ce choix n'est évidemment pas anodin : il permet de se distinguer du taoïsme orthodoxe pour qui Laozi fait partie, parmi ses multiples identités, des Trois purs sous le nom de Taiqing dadi 太清大帝, grand empereur de la Pureté suprêmess.

Quoi qu'il en soit, il est remarquable de voir la manière dont les certificats de consécration caractérisent la doctrine du souverain de l'Origine. On parle en effet

du fleuve, Shanghe 上河). Voir Zhong Yuru 鍾玉如, «Yuanling de wunuo wenhua » 沅陵的巫儺 文化, Huaibua xueyuan xuebao 懷化學院學報, 23-3 (2004), p. 57.

5I. Voir Li Xinwu 李新吾, «Lenhshui jiang Yangyuanzhang tan shigong yu daoshi de yitong bijiao » 冷水江楊源倀壇師公與道士的異同比較, dans Chen et Hua (Arrault), éd., op. cit., sous presse.

52. Ce livret est une sorte de vade mecum, présentant l'essentiel de ce qu'il faut savoir de la doctrine, de la généalogie aux instruments liturgiques, en passant par des notions de cosmologie. Il fait partie des livres d'initiation, qui sert de base au rituel de l'Examen de l'autel.

53. Hunzu liupai quanzong 混祖流派全宗, p. 8b-9a, copié par Qin Chuhu 秦楚湖, Xinhua 新 化, Yangxi zhen 洋溪鎮, 1904 .

54. Jiu Tang sbu 舊唐書, juan 5, Beijing, Zhonghua shuju 中華書局, p. 90.

55. Voir Li Xinwu, «Lengshui jiang... », dans Chen et Hua (Arrault), éd., op. cit., sous presse. 
de cette doctrine comme celle de toutes les méthodes talismaniques (zbuban fufa 諸般符法), ou des formules secrètes, des méthodes talismaniques de rassemblement des Furies du Meishan (Yuanhuang Meishan [shou]chang zhuban fufa mijue 元皇 梅山[收]猖諸盤符法秘訣), etc. Mieux encore : il est précisé ailleurs que toutes ces méthodes, qui consistent à calligraphier des talismans, fabriquer de l'eau lustrale, servent à guérir les maladies et expulser les nuisances, apaiser et chasser les dieux des pestilences, balayer les esprits hétérodoxes et revenir aux puissances orthodoxes (shufu zhoushui, zhibing quxie, bewen qiansong, saoxie guizheng 書符咒水, 治病驅邪, 和瘟遣送, 掃邪歸正). Tout ceci est en parfait accord avec la geste de Laozi, de la grande sœur Xiuzhen 秀珍小姊 et de Zhang Zhao le deuxième seigneur 張趙二郎 répandant dans le monde les «méthodes talismaniques » : il ne s'agit pas d'imposantes messes, de grands services accomplis en grande pompe, mais des petits rites et rituels ( $x i a o f a$ 小法), impliquant un combat, des interventions martiales contre les mauvais esprits, causes de tous les maux. Il n'est donc pas étonnant que Yuanhuang soit aussi associé à des pratiques thérapeutiques particulières, relevant de la médecine magique : «les formules rituelles de lever et reculer du souverain de l'Origine » (Yuanhuang pengtui fajue 元皇捧退法訣) sont à mettre en relation avec la guérison des plaies ouvertes et des os cassés (kaidao pogu 開刀破骨), techniques qui sont par ailleurs attribuées sans surprise au médecin de l'antiquité Hua Tuo (Hua Tuo pengtui 華佗捧退) $)^{5}$.

Nous avons rencontré précédemment les statuettes dédiées au patron de la guilde des charpentiers, Lu Ban, c'est donc sans surprise que nous apprenons que certaines des statuettes dédiées à des maitres d'initiation ont été commanditées par des disciples ayant reçu en partage la « doctrine de Lu Ban du souverain de l'Origine » (Yuanhuang Lu Ban jiao 元皇魯班教), mettant en relief une transmission d'ordre artisanal, présente sur tout le territoire chinois, mais volontairement rehaussée de couleur locale ${ }^{57}$.

Les données à notre disposition dans les statuettes, ainsi que les enquêtes de terrain, prouvent l'existence d'une doctrine indépendante, au sens où elle revendique une généalogie particulière, des rituels et des textes spécifiques. La doctrine du souverain de l'Origine se marie toutefois avec d'autres ordres religieux. Ces mariages s'expriment fréquemment par l'expression «Xiantian yuanhuang zhengjiao » 先天 元皇正教, dans laquelle xiantia 先天 serait une référence au taoïsme institutionnel. Un mariage dont les enquêtes de terrain nous disent avec clarté qu'il s'agit bien d'une double ordination : deux textes d'annonce d'ordination différents, l'un pour la cérémonie taoïste, l'autre pour la cérémonie de maître exorciste ; la cérémonie

56. Au sujet de toutes ces techniques médicales magico-rituelles, on lira avec profit l'article de Li Kui 李魁 sur les «maîtres de l'eau ", «Meishan shuishi de ge'an diaocha yu yitong bijiao » 梅山水師的個案調查與異同比教, et celui de Ma Tieying 馬鐵鷹, 《Bei Longhui de minjian yisu 》 北隆回的民間醫俗, dans Chen et Hua (Arrault), éd., op. cit., sous presse. Le Longqi jiao 龍啟教, accolé au nom de Yang Falong 楊法龍, est le dernier maillon d’un lignage associé à la médecine de Sun Simiao 孫思激, qui comprend Shennong 神農, Wang Shuhe 王叔和, Zhang Zhongjing 張 仲景 et bien d'autres, puis Zhang Wulang 張五郎 et enfin Yang Falong (Tor85).

57. Voir les numéros Y iI2I058, YII22026, T036I, T0458. 
d'ordination elle-même comprend des rituels dits taoïstes et des rituels dits de «maitre exorciste », au cours de laquelle l'impétrant reçoit un zouming 奏名 ou un daoming 道名, et un faming 法名. Il ne s'agit donc pas de deux grades différents - le faming ne représentant pas ici un grade inférieur -, ni de deux fonctions à l'intérieur d'un même corps, mais de deux noms d'ordination distincts. Nous avons ainsi, dans la majorité des cas où yuanbuang 元皇 se combine, comme nous l'avons vu, avec xiantian, mais aussi avec qingwei 清微, et incidemment avec le bouddhisme (Tooog), la présence d'un prénom commençant par fa 法 et un autre prénom d'ordination censé contenir le caractère générationnel d'un ordre taoïste ${ }^{\varsigma 8}$. Par exemple, le commanditaire Luo Yaohe 羅耀和 a pour nom d'ordination Taixiang 泰祥 et pour nom de maitre exorciste Fayao 法耀, et se réclame du « Qingwei yuanhuang zhengjiao » 清微元皇正教 auquel il a été initié par Chen Jiyun 陳際雲 (TIO42). Nous noterons cependant que malgré la double épaisseur religieuse, l'iconographie des statuettes ne subit aucune modification, nous restons dans le style " maitre exorciste », sans l'ajout d'un signe distinctif qui puisse rendre compte d'une double identité.

\section{c) La doctrine de la montagne des Abricotiers (Meishan jiao 梅山教)}

Alors que Yuanhuang définit un ordre religieux, avec la doctrine de Meishan nous entrons dans un lieu. L'apparente clarté que peut offrir un toponyme est pourtant dans ce cas trompeuse : ce lieu peut en effet être entendu dans un sens concret ou symbolique. Il y a de fait autant d'arguments qui plaident pour une délimitation géographique, initiée par l'Histoire des Song (Songshi 宋史) qui en fait une aire correspondant plus ou moins à la région centrale du Hunan, confirmée par la répartition géographique des statuettes, que pour un lieu symbolique attesté par des écrits rituels - en chinois - détenus par les Yao, qui en font le lieu de passage des défunts pour accéder au paradis céleste. Cette double acception est attestée dans les certificats. Il y a tout d'abord des sculpteurs du district d'Anhua qui se présentent comme les «disciples du centre de la montagne des Abricotiers » (zhongmei dizi 中梅弟子) ${ }^{59}$, et une statuette qui est dite de la montagne des Abricotiers (Meishan shenxiang 梅山神像, To794). Puis nous entrons progressivement dans le domaine doctrinal : tel personnage a obtenu le Dao de la montagne des Abricotiers (Meishan de dao 梅山得道), et mieux encore pour Li Xiangsheng 李祥生 qui a obtenu le Dao de «la doctrine orthodoxe de la montagne des Abricotiers » (Meishan zhengjiao 梅山正教, T 0454). Quelques exemples offrent des variations sur un même thème : on évoque alors « la doctrine orthodoxe du roi de la montagne des Abricotiers »

58. Il existe une seule exception à cette pratique : Kang Zhongliu 康忠柳, qui a étudié le 《Lingbao xiantian Yuanhuang jiao » 靈寶先天元皇教 avec son père, n'a qu'un nom d'ordination, Yuanda 元達 ( $\mathrm{T}_{\text {IO42 }}$ ).

59. La région du Meishan est couramment divisée en trois secteurs : la partie supérieure (shang 上 Meishan) correspond au district de Xinhua, la partie centrale au district d'Anhua (zhong 中 Meishan) d'où viennent les sculpteurs évoqués ici, et la partie inférieure (xia 下 Meishan) au district de Yiyang 益陽. Cette division correspond de fait aux cours supérieur, moyen et inférieur du fleuve Zijiang 資江. 
(Mei wang zhengjiao 梅王正教, Y II2IO62), l'étude « des rituels de conciliation de la montagne de Meishan » (Meishan he shan fadu 梅山和山法度, To77I ${ }^{60}$, ou encore la technique médicale pour guérir les plaies ouvertes et les os rompus et les formules secrètes de lever et reculer de la montagne des Abricotiers des cinq Tonnerres (Wulei Meishan pengtui kaidao pogu 五雷梅山捧退開刀破骨, To746 ${ }^{61}$ ). D'autres noms de lieu font preuve de la même ambiguïté, il serait par conséquent prudent de ne pas voir dans ces toponymes une quelconque origine des pratiques religieuses du Hunan ${ }^{62}$. Maoshan 茅山, la montagne de la Hutte, qui fait immédiatement penser au grand taoïsme du Maoshan, n'est pourtant qu'une « petite doctrine » (Maoshan xiaojiao 茅山小教, T0313), fréquemment associée aux guérisseurs (shuishi 水師) qui se répartissent entre ceux de la montagne des Abricotiers et ceux de la montagne de la Hutte : les premiers semblent soumis à une discipline relativement rigoureuse, ils doivent être initiés et ordonnés, alors que les seconds, « des huttes et des cabanons ", pratiquent leur art de manière plus spontanée $e^{6_{3}}$. Dans le domaine des artisans, si les menuisiers se situent volontiers dans la «doctrine de Lu Ban », les fabricants de briques et de tuiles (sbaowa jiang 燒瓦匠) s'estiment relever de la « doctrine de la montagne de la Hutte ${ }^{64}$. Il s'agit donc à la fois d'une appellation péjorative, usitée par des personnes extérieures pour désigner un courant non structuré et considéré comme «sauvage ${ }^{65}$ et, en se servant du nom d'un ordre dont les taoïstes font grand cas, d'une valorisation de soi-même et de son corps de métier.

En d'autres circonstances, Meishan et Maoshan sont équivalents, ou carrément confondus. Il arrive ainsi qu'on emploie dans les certificats l'expression la « doctrine orthodoxe du jardin des Abricotiers » (Meimao zhengjiao 梅茅正教66) et qu'ailleurs on forme l'expression «Meimao tanshe» 梅茅壇社, l'autel de la Hutte d'abricotier :

6o. «Les rituels de la conciliation » font allusion aux rituels de conciliation de la montagne des Abricotiers (he Meishan 和梅山). Ces rituels concernent plus particulièrement les divinités locales et sont accomplis pour exorciser les maladies, à des fins propitiatoires ou régulièrement par les médiums qui sont les messagers de ces divinités. Voir Zeng Di 曾迪, «Meishan nuoxi 'He Meishan’ » 梅山儺戲和梅山, dans Chen et Hua (Arrault), éd., op. cit., sous presse.

6I. Dans la courte biographie qui lui est consacrée, le personnage à qui est dédiée cette statuette, Ouyang Huanhua 歐陽煥華 (1803-I857), de nom d'ordination Faying 法應, a été initié par un certain Liu Fatong 劉法通, et il a lui-même transmis cette doctrine au fils de son cousin et ensuite à un certain Yang Faseng 楊法僧, en conséquence nous sommes en présence d'une transmission intra-familiale et d'une transmission extra-familiale.

62. Par exemple, dans le nom de la doctrine «HuainanYuanhuang Xueshan fumi [jue] yi zong 》 淮南元皇雪山符秘决 [訣]一宗 (To303), il n’est pas nécessaire de voir dans Huainan une référence à l'origine géographique de cette doctrine.

63. Cf. Li Kui 李魁, "Meishan shuishi de ge'an diaocha yu yitong bijiao ", dans Chen et Hua (Arrault), éd., op. cit., sous presse.

64. Communication personnelle de Li Xinwu 李新吾, que nous remercions ici.

65. Il semblerait que les pratiques religieuses locales aient été péjorativement perçues par les migrants, notamment ceux venus du Jiangxi, comme faisant partie de la «manshan jiao 蠻山教» (doctrine des montagnes sauvages), qu'un glissement phonétique aurait transformé en « maoshan jiao ». Communication personnelle de Li Xinwu.

66. Voir par exemple Yis032 et To562 ci-dessous. 
Au temps de l'empereur Yao, le monde n'était pas encore en paix, les céréales ne poussaient pas, les bêtes proliféraient, les animaux hurlaient et les oiseaux piaillaient. Shun [confia à] Yi la charge du feu, dans les monts et les marais ils furent brûlés. Il enseigna aux chasseurs à pourchasser les animaux et à leur décocher des flèches ; jusqu'aux confins des quatre mers, on chantait ses louanges. Au même moment, le roi Yu contrôla les rivières, poursuivit les démons des eaux et les expulsa, c'est pour cela que furent offertes les règles des printemps et automnes. Comme le monde était en ordre et que les céréales poussaient, on lui éleva, dans la grotte des monts Zhongnan de la préfecture de Xi'an dans le Shaanxi, l'autel de la Hutte d'abricotier, son nom fut inscrit sur le mont Tai, ses mérites se répandirent pendant des siècles, sa réputation se perpétue comme le métal et la pierre ${ }^{67}$.

當堯帝之時, 天下未平, 五穀不登, 禽獸繁殖, 獸啼鳥叫・舜[使]益掌火, 山澤焚之・教獵 者驅而射之, 以致四海謳歌 - 同禹王治水, 逐水妖而懕(厭)之, 故供春秋之典 - 天下治而五 穀登, 故封陝西西安府終南山之硐梅茅枟(壇)社, 名注泰山之上, 功垂千古, 名同金石也 .

Extraite du vade mecum des maîtres exorcistes du Hunan, cette histoire s'inspire librement d'un récit conté par Mencius ${ }^{68}$. La partie la plus originale est la construction de l'autel de la Hutte d'abricotier sur les monts Zhongnan 終南山, le lieu où l'on dit que Laozi, avant de partir pour les contrées occidentales, remit au gardien de la passe Yinxi 關令尹喜 le Livre de la Voie et de la vertu (Daode jing 道德經). La hutte en question fait donc allusion à un monde rustique, encore à peine civilisé, à l'image des autels de Meishan, élevés dans des contrées sauvages.

\section{d) Doctrines diverses}

Chen Jingtai 陳敬台 déclare qu'il a étudié auprès de son maître d'initiation, Chen Fake 陳法科, le buacang [shao] shou 花蒼 [燒]手. Comment faut-il entendre cette expression? Si nous corrigions le deuxième et le troisième caractère, nous pourrions obtenir quelque chose comme huaqiang chongshou 花槍銃手, « la lance fleurie et l'expert du mousquet ». La statue, qui se présente debout, les deux mains jointes sur le côté, rappelle effectivement celles de chasseurs, au détail près que ceux-ci ne tiennent pas leur mousquet de cette manière (Y I5032, fig. 32)69. Par ailleurs, "la lance fleurie », si elle fait allusion à une belle passe d'armes avec une lance, est surtout employée au théâtre pour parler de passes d'armes éblouissantes ${ }^{70}$. Une autre statue, les pieds nus, les deux mains également jointes sur le côté du corps, a été commandée par

67. Hunzu liupai quanzong, p. 27b-28a, copié par Qin Chuhu 秦楚湖, Xinhua, Yangxi zhen, 1904.

68. Mengzi, juan 3, «Tengwen gong 》滕文公, I ; voir D. C. Lau (trad.), Mencius, Hong Kong, The Chinese University Press, I984, p. I04-I05.

69. Dans la collection de YXY, parmi les statuettes debout, on peut repérer deux types : le premier, qui visiblement tient un fusil, soit dans une main, le fusil posé à terre, soit dans les deux mains séparées, et le second, avec les deux mains jointes sur le côté, parfois avec le corps légèrement tourné pour mimer le mouvement. Ces deux types portent toutefois le même genre d'accoutrement particulier, un chapeau rond, une veste boutonnée sur une robe descendant à mi-genoux.

70. Li Xinwu considère que le terme buacang devrait être écrit 花倉, l'entrepôt des papiers fleuris, une métaphore pour désigner les bualou 花樓, ces maisons de papier que les artisans des paraphernalia funéraires brûlent ([shao]shou [燒]手) à la fin des funérailles. Il s'agirait donc ici d'un disciple de ce métier. Communication personnelle de Li Xinwu, que nous remercions ici.

(C) École française d'Extrême-Orient, Paris, 2012

Do not circulate without permission of the editor / Ne pas diffuser sans autorisation de l'éditeur 
Fig. 32 : Maitre d'initiation Chen Fake 陳法科, consacré en 1914, Y 15032.

Cliché Yan Xinyuan.
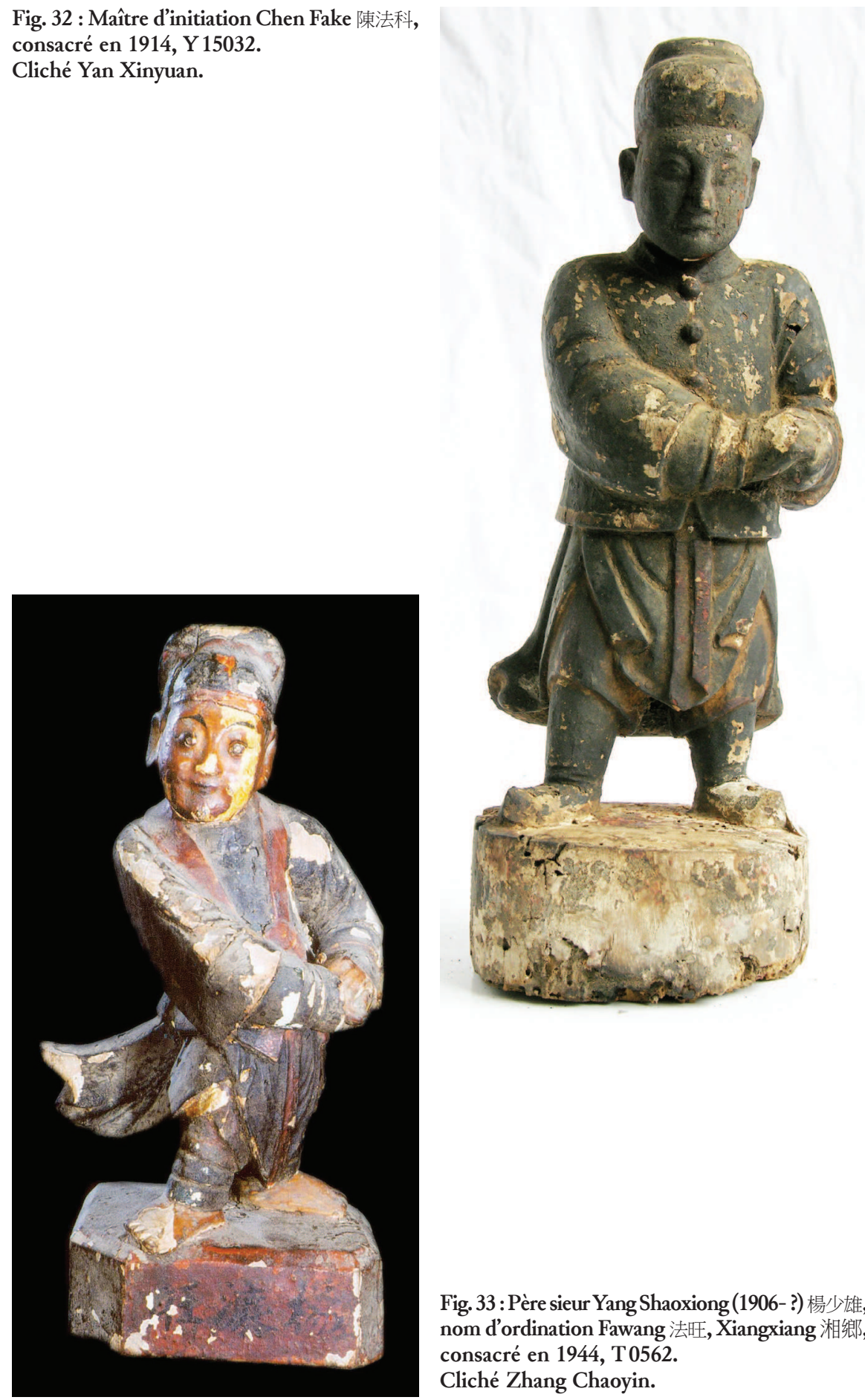

Fig. 33 : Père sieur Yang Shaoxiong (1906- ?) 楊少雄, nom d'ordination Fawang 法旺, Xiangxiang 湘鄉, consacré en 1944, T 0562.

Cliché Zhang Chaoyin.

(C) École française d'Extrême-Orient, Paris, 2012 Do not circulate without permission of the editor / Ne pas diffuser sans autorisation de l'éditeur 
un disciple qui prétend avoir appris auprès de son maître le Meimao zhengjiao 梅苑 正教 (T 0562, fig. 33). Le caractère mao 荈 doit être remplacé par mao 茅, la hutte, le cabanon, nous renvoyant à « la vraie doctrine de la Hutte d'abricotier » que nous avons déjà rencontrée. Nous avons la même expression, avec quasiment les mêmes confusions de caractères, pour qualifier le maître de Chen Jingtai : Chen Fake est dit de Meimao (梅荈).

Si nous ne pouvons pas décider de la nature de l'enseignement transmis dans les exemples précédents, il ne fait par contre aucun doute que Pan Zhixian 潘知先 a bien été initié par son maitre Huang Dingcong 黄定聰 dans « la vraie doctrine du jardin des Poiriers » (Liyuan zhengjiao 黎䓟正教), en d'autres termes formé comme acteur de théâtre $(\mathrm{T} 0685)^{71}$. Les types de théâtres les plus courants dans la région comprennent le théâtre de Qi (Qi xiju 祁戲劇) et les théâtres de marionnettes qui, suivant les endroits, utilisent des marionnettes à fil, à gaine ou à tige, etc. La présence du théâtre de Qi est attestée dans l'ensemble de la partie méridionale du Hunan. Il s'inspirerait du théâtre de Yiyang 七陽 du Jiangxi, avec comme épicentre le district de Qiyang 祁陽 dans le Hunan, et dériverait du théâtre de Mulian 目連戲. Dès la fin des Ming, des sources le mentionnent à Qiyang, puis il se répand dans les régions avoisinantes, dans le Guangxi 廣西, le Fujian 福建 et le nord du Guangdong 廣東 : à la fin du XVIII ${ }^{\mathrm{e}}$ siècle et au début du XIX ${ }^{\mathrm{e}}$ siècle, parmi plus de cinquante troupes recensées au Hunan, la plupart appartenait au genre du théâtre de $\mathrm{Qi}^{7^{2}}$. Mais la forme de la statue de maître Huang, là où nous aurions pu nous attendre à quelque chose de particulier - par exemple du genre des statues debout que nous venons de voir -, révèle un personnage assis, tenant dans une main un bol, qui ne renvoie à rien d'autre qu'à la statue traditionnelle du maitre exorciste. Rappelons toutefois que le théâtre est considéré comme faisant partie intégrante du corps des spécialistes du religieux.

\section{Une statue pour soi ?}

Le phénomène est suffisamment énigmatique pour que nous y consacrions quelques lignes, même s'il ne représente pas en termes quantitatif un fait majeur. À première vue, nous n'aurions en effet dans les trois collections que dix statuettes de ce type. Wang Benqing 王本清, né en I862, est dit avoir gravé ou fait graver ${ }^{73}$ une statuette

7I. Liyuan 黎䄇, qu'il est opportun de corriger en Liyuan 黎園, est un synonyme de Liyuan 梨園, le Jardin des poiriers, qui désignait à l'époque des Tang une troupe très réputée à Chang'an, et dont le nom en est progressivement venu à signifier théâtre.

72. Cf. Zhongguo xiju yinyue jicheng 中國戲劇音樂集成, Hunan juan 湖南卷, 2 vol., Beijing, Wenhua yishu chubanshe 文化㙯術出版社, 1992, p. 467-469.

73. Bien que nous puissions penser que le fidèle n'a pas sculpté lui-même la statue, il est intéressant de noter que dans tous les exemples, à l'exception de To66r, on ne mentionne ni ne fait allusion à un sculpteur. Par commodité, nous ne retiendrons dans notre exposé que la forme active (il a fait), sauf mention contraire, ce qui ne signifie pas l'exclusion de la forme factitive (il a fait faire).

(C) École française d'Extrême-Orient, Paris, 2012

Do not circulate without permission of the editor / Ne pas diffuser sans autorisation de l'éditeur 


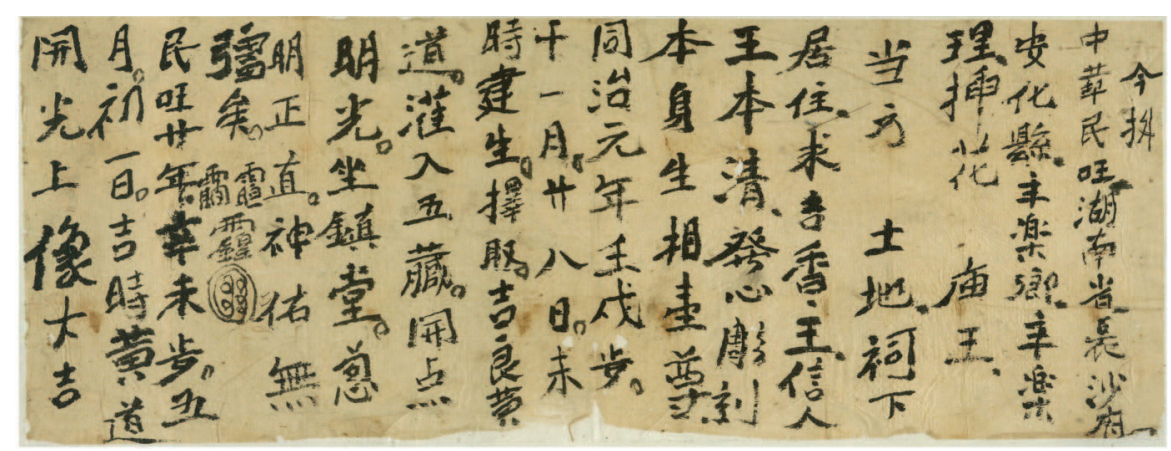

Fig. 34 : Certificat de consécration $\mathrm{n}^{\circ} \mathrm{T}$ 0030, le fidèle Wang Benqing 王本清, né en 1862, "a fait graver une statue de lui-même ", consacrée en 1931. CEFEO

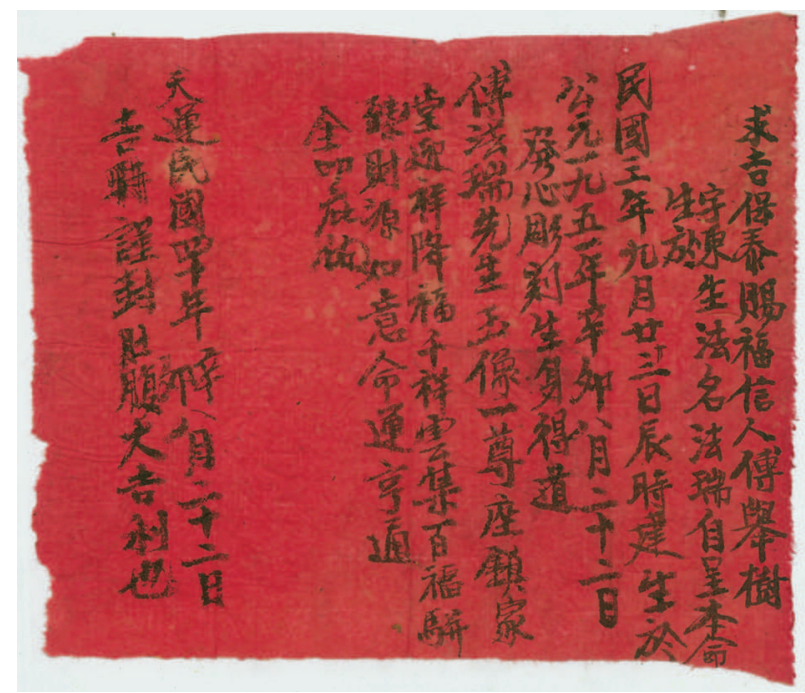

Fig. 35 : Certificat de consécration $n^{\circ}$ Y 1122031, le fidèle Fu Jushu 傅舉樹, nom public Dongsheng 東生, nom de maître exorciste Farui 法瑞, né en 1914, " a fait graver de son vivant une statue de jade du sieur Fu Farui qui a obtenu le Dao ", consacrée en 1951. CEFEO

de benshen (benshen shengxiang yi zun 本身生相一尊), en 1931, soit à l'âge de 69 sui (To030, fig. 34). La difficulté réside dans l'interprétation du terme benshen 本身. On peut en effet estimer qu'à cause du premier caractère, il désigne un frère ou un cousin germain de Wang Benqing, ben 本 étant alors le caractère générationnel de cette génération des Wang, quoi que le nom Wang Benshen 王本身, Wang Moimême, soit pour le moins étrange! Une autre interprétation consiste à dire que Wang Benqing a tout simplement fait une statue pour lui-même. Si, dans ce cas précis, une ambiguïté subsiste, il n'en va pas de même pour les autres exemples. Wang Benmao 王本惁, né en 1873 et disciple de Wang Fachang 王法常, auprès duquel il a étudié 
la « doctrine orthodoxe de Lu Ban », a sculpté une statuette de benming shengshen 本命生身, c'est-à-dire une statuette «de son destin fondamental, de son vivant ", en 1916, à lâge de 43 sui (T0577). Le certificat de consécration de cette statuette est rédigé de manière originale : alors que la majorité des certificats commence systématiquement par l'adresse, celui-ci introduit d'emblée le nom du commanditaire, qui est en même temps le personnage incarné dans la statuette. L'adresse n'est pas mentionnée ${ }^{74}$ et la feuille est de couleur rouge. Quatre autres certificats présentent une mise en pages et un contenu identiques. Les commanditaires-récipiendaires ont respectivement 26 sui (Y II3092), 27 sui (To595), 32 sui (Y II3098) et 37 sui (Y II2203I, fig. 35). Tous sans exception datent de la première moitié du $\mathrm{Xx}^{\mathrm{e}}$ siècle et évoquent une statue faite de "leur vivant » (shengshen) $)^{75}$. Le second d'entre eux précise même qu' «il a lui-même gravé de son vivant la statue de jade » (ziji diaoke shengshen yuxiang 自己彫刻生身玉像), tandis que le troisième fait en réalité état de deux consécrations : la première en 1928, alors que Hu Fazhou 胡法洲, né en I896, avait 32 sui, et la seconde en 1965 , à l'occasion d'une restauration de la statuette. Cette dernière a-t-elle été opérée par Hu lui-même - il a alors 69 sui -, ou futelle le fait du ou des commanditaires, qui se seraient contentés de mettre à jour le certificat sans prendre la peine de mentionner leurs noms ?

Il est pour le moins étonnant que des statuettes généralement dédiées à des défunts soient exécutées pour des vivants, par eux-mêmes. On pourrait supposer qu'il s'agisse de l'une des pratiques relevant de la préparation de son cercueil et de sa tombe ante mortem (shouzang 壽藏), attestée en Chine dès la dynastie des Han. Quelques témoignages confirment en effet que certaines personnes dans le Hunan préparaient leurs statuettes avant la mort, qui n'étaient cependant consacrées qu'après la mort, ce qui n'est pas le cas ici. Il semble donc plus logique de voir dans ces statuettes pour soi autre chose que la préparation de ses propres funérailles ${ }^{76}$. Né en I879, He Zhugeng 賀朱庚, à cause de problèmes aux yeux, a reçu la permission de sculpter une statuette «de son vivant » afin d'honorer «son destin fondamental » (benming 本命) (To66I). Fu Lianquan 傅蓮泉, né en 1915 et dont la naissance est placée sous l'égide de la quatrième étoile du Boisseau du Nord (Wenqu xing 文曲 星), porte dans son destin (ming 命) les influences néfastes des esprits Kui 魁 et

74. Dans notre petit corpus, cinq certificats sur dix indiquent une adresse. Quatre concernent le district de Xiangxiang et une le district d'Anhua.

75. Le certificat Y II2104I emploie également l'expression shengshen (de son vivant). Un seul fidèle est mentionné : Liao Canrong 廖喍榮, nom public Anfu 安富, nom de fonction Farong 法榮, né en 1865 , qui fait sculpter en 1898 « de son vivant une statue de jade au visage d'or de Liao Farong qui a obtenu le Dao » (diaoke shengshen dedao Liao Farong jinrong yuxiang yi zun 雕刻生 身得道廖法榮金容玉像一尊). Cependant, la forme est différente et plus conventionnelle : l'adresse est placée en premier et le certificat est inscrit sur une feuille de couleur beige, comme celui de To030 (voir ci-dessous).

76. Mais apparemment rien n'empêche les membres de la famille de se servir de cette "statue pour soi » après le décès, ce qui semble être le cas de Fu Xinglian 傅星連, qui a sculpté en I880 à l'âge de trente ans une statue de lui-même (To66o-2-I), reconsacrée plus tard par sa propre fille, à un moment qui se situe probablement après la mort de Fu (To66o-2-2).

(C) École française d'Extrême-Orient, Paris, 2012

Do not circulate without permission of the editor / Ne pas diffuser sans autorisation de l'éditeur 
Gang 罡77. Lui aussi a fait une statuette (Y II3092). Ces quelques indices, aussi ténus soient-ils, nous montrent que ces statuettes très particulières ont probablement pour fonction de changer le destin marqué négativement, la mauvaise santé chronique, ou peut-être plus généralement d'accomplir par elles et avec elles un rituel propitiatoire de protection et de prolongation de la vie. La rareté des exemples démontre sans aucun doute que cette procédure n'était exécutée que de manière très exceptionnelle, peut-être dans des situations d'une extrême gravité, lorsque les autres tentatives de résolution des problèmes avaient échoué.

\section{Les statuettes en situation}

\section{A) Consécration}

La transmission de vie et de souffle aux icônes par des moyens rituels est attestée aussi bien en Égypte hellénistique qu’à Byzance. Si en Chine des témoignages concernant des statues vivantes apparaissent quelques centaines d'années après notre ère, les premiers textes rituels indiquant la manière de construire des statues et de les consacrer proviennent d'Inde, où semble-t-il existait une tradition structurée et systématisée. Deux textes inclus dans le Canon bouddhique chinois sont datés du $\mathrm{VIII}^{\mathrm{e}}$ siècle et aux alentours de l'an mille, mais avant cela, au VII ${ }^{\mathrm{e}}$ siècle, des témoignages provenant du Japon évoquent avec précision l'inauguration d'images de Bouddha ${ }^{78}$. Bien que l'habitude de consacrer les images cultuelles, notamment les statues, semble devenir une pratique courante en Chine à la fin de l'époque médiévale, allant audelà des cercles bouddhiques, les sources littéraires et archéologiques qui l'attestent sont très éparses et souvent allusives. Il est ainsi remarquable que le Canon taoïste (Daozang 道藏) ne comprenne aucun texte décrivant cette cérémonie, alors que De Groot (I854-I92I), à la fin du XIX $x^{e}$ siècle, fait des «prêtres de la religion du Tao » dans le Fujian les spécialistes de la consécration, non seulement des statues taoïstes et populaires dans les temples, mais aussi des effigies bouddhiques. Et c'est encore lui qui révèle, avec force détails, l'« ouverture des yeux » des tablettes d'ancêtres, opérée par des mandarins, des lettrés ou des géomanciens ${ }^{79}$.

Il ne fait pourtant pas de doute que cette pratique était amplement partagée : le Yuxia ji 玉匣記, attribué à l'immortel Xu 許真人, et le grand traité d'hémérologie Xieji bianfang shu 協紀辨方書, inclus dans l'anthologie impériale Siku quanshu 四庫全書, mentionnent la méthode divinatoire permettant de déterminer le jour faste pour

77. La mauvaise influence de ces deux esprits est également souvent indiquée comme étant la cause qui a conduit des personnes à recevoir une initiation religieuse.

78. Voir Michel Strickmann, «L'icône animée », dans son ouvrage Mantras et mandarins, Paris, NRF, Gallimard, 1996, p. 165-2II.

79. Pour ce qui concerne la consécration des statues de divinités, voir J.J.M. De Groot, Les fêtes annuellement célébrées à Emoui (Amoy), Paris, Ernest Leroux, 1886, p. 270-271; au sujet du " pointage » des tablettes d'ancêtres, voir ibid., p. 18-23, et De Groot, Religious system of China, 6 vol., Taipei, Cheng-wen Publishing 成文出版社, 1967, vol. I, book I, p. 213-219. 
consacrer les icônes peintes ou sculptées, le prérequis indispensable à l'accomplissement du ritue ${ }^{80}$. Dans ces deux documents, à la méthode concernant la consécration s'ajoute celle ayant trait à la fabrication des icônes ${ }^{81}$. La technique employée, bien que n'étant pas rigoureusement identique dans les deux écrits, recourt invariablement à des paramètres communs : les vingt-huit étapes célestes (ershiba xiu二十八宿), les esprits journaliers et les marqueurs jianchu 建除. Néanmoins, la confrontation de ces techniques avec quatre-vingt-quatre dates de consécration dans les « certificats de consécration » (yizhi) montre à l'évidence que les spécialistes du Hunan n'utilisaient pas les méthodes recensées dans le Yuxia ji et le Xieji bianfang shu $u^{82}$. Les enquêtes de terrain ont permis de dégager d'autres méthodes ${ }^{8_{3}}$ :

i) Une méthode privilégiant les jours dotés d'un des dix marqueurs sexagésimaux suivants : 乙亥, 癸未, 庚寅, 丁酉, 王寅, 甲辰, 庚戌, 辛亥, 丙辰, 戊午. Vingt et une dates de consécration sur quatre-vingt-quatre correspondent à ce critère.

ii) Les jours fastes de la "voie jaune » (buangdao 黃道, «l'écliptique »), déterminés en fonction des douze marqueurs Jianchu : jian 建 (instauration), chu 除 (éviction), man 滿 (plénitude), ping 平 (équilibre), ding 定 (fixité), zbi 執 (maintien), po 破 (destruction), wei 危 (danger), cheng 成 (maturité), shou 收 (réception), $k a i$ 開 (ouverture), $b i$ 閉 (fermeture). $\mathrm{Au}$ premier mois solaire (après le souffle initial lichun 立春, début de printemps), le premier terme (jian, instauration) coïncide avec les jours dont le binôme contient la branche yin 寅, les autres termes venant se loger dans l'ordre sur les jours suivants. Au second mois solaire (après le souffle initial jingzhe 驚督, éveil des insectes), ce même premier terme coïncidera avec les jours de branche mao 印, etc ${ }^{84}$. Les calendriers traditionnels comportent cette information dans les données calendaires des jours. Les jours fastes de l'écliptique sont ceux marqués des termes $c h u, w e i$, ding, zhi, cheng et kai. Tous les autres termes sont associés à l'orbite de la lune (la « voie noire », beidao 黑道), néfastes par définition (voir tableau récapitulatif ci-dessous). Quarante-huit dates de consécration répondent aux critères de cette méthode.

8o. La version en un juan 卷 du Yuxia ji dans le Canon taö̈ste - Xu zhenren Yuxia ji 許真

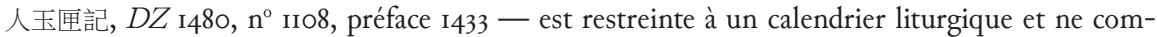
prend pas cette méthode. Ce sont des versions complétées et amplifiées plus tardives qui en font état, recensant un nombre important de diverses méthodes divinatoires, faisant ainsi de ce livre un véritable traité d'hémérologie. Une édition intitulée Zengbu Yuxia ji tongshu 增補玉匣記通書, datée de I9II, affiche fièrement une préface de I684. Au vu des nombreuses éditions recensées dans les bibliothèques, ou vendues actuellement sur les marchés d'antiquités, il ne fait guère de doute que la version amplifiée était très répandue sous les Qing (I644-I9II). Grande compilation impériale, le Xieji bianfang shu 協紀辨方書 a été achevé en 1739 .

8I. Cf. Zengbu Yuxia ji tongshu, shang juan 上卷, s. 1., Sanyi tang 三義堂, 19II, p. 9b ; Xieji bianfang shu, juan 35, dans Siku quanshu 四庫全書, vol. 8II, Taibei, Taiwan Shangwu yinshuguan, 1983-1986, p. 33a-34b.

82. Nous avons retenu quatre-vingt-quatre dates de consécration en fonction des calendriers à notre disposition, de 1878 à 1949 .

83. La recension des diverses méthodes du choix du jour de consécration a été rendue possible grâce à l'aide de Zou Shengyun 㮲升雲, que nous remercions ici vivement.

84. Pour plus de détails concernant cette méthode jianchu, voir Alain Arrault, «Les calendriers de Dunhuang », dans Marc Kalinowski, éd., Divination et société dans la Chine médiévale, Paris, BNF, 2003, p. IOI-IO2.

(C) École française d'Extrême-Orient, Paris, 2012

Do not circulate without permission of the editor / Ne pas diffuser sans autorisation de l'éditeur 
Tableau 3 : Jours fastes et néfastes en fonction des douze marqueurs jianchu

\begin{tabular}{|c|c|}
\hline «Voie jaune » 黃道, jours fastes & "Voie noire » 黑道, jours néfastes \\
\hline$c b u, w e i$, ding, zhi, cheng, kai & jian, po, man, ping, shou, bi \\
\hline
\end{tabular}

iii) Le choix des jours fastes de «l'écliptique » peut être déterminé par une autre méthode. Douze termes, résumés par l'expression daoyuan 道遠, sont également à l'œuvre, il s'agit de : 道遠幾時通達, 路遙何日還鄉 (daoyuan jishi tongda, luyao heri buanxiang la route est longue, combien d'heures pour arriver? Le chemin est long, quel jour retourneronsnous dans notre pays ?). Leur positionnement, en fonction des mois, se fait de toute autre manière que pour les marqueurs jianchu (voir tableau ci-dessous). Les termes fastes sont ceux qui ont la clé de la marche dans leur caractère (soulignés dans le tableau 4). Cinquante-six dates de consécration correspondent à cette méthode ${ }^{85}$.

Tableau 4 : Localisation des jours fastes de l' « écliptique » selon la méthode des termes daoyuan

\begin{tabular}{|c|c|c|c|c|c|c|c|c|c|c|c|c|}
\hline $\begin{array}{c}\text { Termes } \\
\text { Mois }\end{array}$ & $\begin{array}{c}1 \\
\text { 道 }\end{array}$ & $\begin{array}{c}2 \\
\text { 遠 } \\
\end{array}$ & $\begin{array}{c}3 \\
\text { 幾 }\end{array}$ & $\begin{array}{c}4 \\
\text { 時 }\end{array}$ & $\begin{array}{r}5 \\
\text { 通 }\end{array}$ & $\begin{array}{c}6 \\
\text { 達 } \\
\end{array}$ & $\begin{array}{c}7 \\
\text { 路 }\end{array}$ & $\begin{array}{c}8 \\
\text { 遥 } \\
\end{array}$ & $\begin{array}{l}9 \\
\text { 何 }\end{array}$ & $\begin{array}{c}10 \\
\text { 日 }\end{array}$ & $\begin{array}{l}11 \\
\text { 還 } \\
\end{array}$ & $\begin{array}{l}12 \\
\text { 鄉 }\end{array}$ \\
\hline 正月 & 寅 & 卯 & 辰 & 巳 & 午 & 未 & 申 & 酉 & 戌 & 亥 & 子 & 丑 \\
\hline 二月 & 子 & 丑 & 寅 & 卯 & 辰 & 巳 & 午 & 未 & 申 & 酉 & 戌 & 亥 \\
\hline 三月 & 戌 & 亥 & 子 & 丑 & 寅 & 卯 & 辰 & 巳 & 午 & 未 & 申 & 酉 \\
\hline 四月 & 申 & 酉 & 戌 & 亥 & 子 & 丑 & 寅 & 卯 & 辰 & 巳 & 午 & 未 \\
\hline 五月 & 午 & 未 & 申 & 酉 & 戌 & 亥 & 子 & 丑 & 寅 & 卯 & 辰 & 巳 \\
\hline 六月 & 辰 & 巳 & 午 & 未 & 申 & 酉 & 戌 & 亥 & 子 & 丑 & 寅 & 卯 \\
\hline 七月 & 寅 & 卯 & 辰 & 巳 & 午 & 未 & 申 & 酉 & 戌 & 亥 & 子 & 井 \\
\hline 八月 & 子 & 丑 & 寅 & 卯 & 辰 & 巳 & 午 & 未 & 申 & 酉 & 戌 & 亥 \\
\hline 九月 & 戌 & 亥 & 子 & 丑 & 寅 & 卯 & 辰 & 巳 & 午 & 未 & 申 & 酉 \\
\hline 十月 & 申 & 酉 & 戌 & 亥 & 子 & 丑 & 寅 & 卯 & 辰 & 巳 & 午 & 未 \\
\hline 十一月 & 午 & 未 & 申 & 酉 & 戌 & 亥 & 子 & 丑 & 寅 & 卯 & 辰 & 巳 \\
\hline 十二月 & 辰 & 巳 & 午 & 未 & 申 & 酉 & 戌 & 亥 & 子 & 丑 & 寅 & 卯 \\
\hline
\end{tabular}

iv) La méthode précédente, véhiculée de nos jours parmi les sculpteurs, ressemble à s’y méprendre à la méthode de la «voie jaune » et de la « voie noire » exposée dans le Xieji bianfang shu : une liste de douze esprits — Qinglong 青龍, Mingtang 明堂, etc. — est associée aux jours des douze mois de l'année. Les premiers, deuxième, cinquième, sixième, huitième et onzième esprits désignent « la voie jaune », et les autres « la voie noire ». La liste est positionnée de la même manière sur deux mois différents, par exemple le

85. C'est le nombre obtenu si nous calculons en fonction des mois lunaires. Si nous le faisons en fonction des mois solaires, quarante-six dates seulement suivent cette méthode. Normalement, ce sont les mois solaires qui devraient être pris en compte, mais il est fort possible que, par souci de simplification, on se soit fondé sur les mois lunaires. 
premier et le septième mois, etc. Néanmoins la localisation en fonction des mois n'est pas identique : par exemple le premier terme, Qinglong, est placé sur un jour $z i$ 子 le premier mois (voir tableau 6 ci-dessous) ${ }^{86}$, alors que le premier terme de la méthode précédente, dao 道, est positionné sur un jour yin 寅.

Tableau 5 : Localisation des jours de la « voie jaune » et de la « voie noire »

\begin{tabular}{|c|c|c|c|c|c|c|c|c|c|c|c|c|}
\hline $\begin{array}{c}\text { Termes } \\
\text { Mois }\end{array}$ & $\begin{array}{c}1 \\
\text { 青龍 }\end{array}$ & $\begin{array}{c}2 \\
\text { 明堂 }\end{array}$ & $\begin{array}{c}3 \\
\text { 天刑 }\end{array}$ & $\begin{array}{c}4 \\
\text { 朱雀 }\end{array}$ & $\begin{array}{c}5 \\
\text { 金圚 } \\
\end{array}$ & $\begin{array}{c}6 \\
\text { 天德 }\end{array}$ & $\begin{array}{c}7 \\
\text { 白虎 }\end{array}$ & $\begin{array}{c}8 \\
\text { 玉堂 }\end{array}$ & $\begin{array}{c}9 \\
\text { 天牢 }\end{array}$ & $\begin{array}{c}10 \\
\text { 玄武 }\end{array}$ & $\begin{array}{c}11 \\
\text { 司命 }\end{array}$ & $\begin{array}{c}12 \\
\text { 勾陳 }\end{array}$ \\
\hline 寅 & 子 & 丑 & 寅 & 卯 & 辰 & 巳 & 午 & 未 & 申 & 酉 & 戌 & 亥 \\
\hline 卯 & 寅 & 卯 & 辰 & 巳 & 午 & 未 & 申 & 酉 & 戌 & 亥 & 子 & 丑 \\
\hline $\begin{array}{l}\text { 辰 } \\
\end{array}$ & $\begin{array}{l}\text { 辰 } \\
\end{array}$ & 巳 & 午 & 未 & 申 & 酉 & 戌 & 亥 & 子 & 丑 & 寅 & 卯 \\
\hline 巳 & 午 & 未 & 申 & 酉 & 戌 & 亥 & 子 & 丑 & 寅 & 卯 & 辰 & 巳 \\
\hline 午 & 申 & 酉 & 戌 & 亥 & 子 & 丑 & 寅 & 卯 & 辰 & 巳 & 午 & 未 \\
\hline 未 & 戌 & 亥 & 子 & 丑 & 寅 & 卯 & 辰 & 巳 & 午 & 未 & 申 & 酉 \\
\hline 申 & 子 & 丑 & 寅 & 卯 & 辰 & 巳 & 午 & 未 & 申 & 酉 & 戌 & 亥 \\
\hline 酉 & 寅 & 卯 & 辰 & 巳 & 午 & 未 & 申 & 酉 & 戌 & 亥 & 子 & 丑 \\
\hline 戌 & $\begin{array}{l}\text { 辰 } \\
\end{array}$ & 巳 & 午 & 未 & 申 & 酉 & 戌 & 亥 & 子 & 丑 & 寅 & 卯 \\
\hline 亥 & 午 & 未 & 申 & 酉 & 戌 & 亥 & 子 & 丑 & 寅 & 卯 & 辰 & 巳 \\
\hline 子 & 申 & 酉 & 戌 & 亥 & 子 & 丑 & 寅 & 卯 & 辰 & 巳 & 午 & 未 \\
\hline 丑 & 戌 & 亥 & 子 & 丑 & 寅 & 卯 & 辰 & 巳 & 午 & 未 & 申 & 酉 \\
\hline
\end{tabular}

Sur les quatre-vingt-quatre dates, six ne correspondent à aucune des quatre méthodes. Cela peut s'expliquer par le fait que des jours déterminés par la méthode des douze séparations (shi'er ge 十二隔 $)^{87}$, ou marqués notamment par des esprits journaliers ${ }^{88}$, ne peuvent pas être dédiés à la consécration d'une statuette, d'où la nécessité de choisir un jour autre que celui déterminé par les méthodes habituelles. Inversement, il est assez fréquent que plusieurs méthodes aient en commun les mêmes jours : par exemple, la méthode 2 a en commun vingt-huit jours avec la méthode 3 , et trente jours avec la méthode 4 . Néanmoins, la méthode 3 , avec près de $67 \%$ de jours coïncidant avec les dates de consécration, semble la plus usitée de la fin du XIX ${ }^{e}$ siècle aux années 1940 du $\mathrm{XX}^{\mathrm{e}}$ siècle. Il n'est cependant pas exclu que la méthode du jour faste soit beaucoup plus simple : il est ainsi remarquable que les calendriers indiquent pour cinquante-neuf dates que le jour est faste pour « les

86. Cf. Xieji bianfang shu, juan 7, dans Siku quanshu, op. cit., p. 2a-5b. La même méthode est appliquée pour les heures fastes des étoiles célestes (tianxing jishi 天星吉時) : voir juan 35, dans ibid., p. 50b-5ıa, sauf que la liste des esprits est réduite à six.

87. Cette méthode positionne douze termes de la même manière que la méthode 3. Aux jours marqués de deux de ces termes, le quatrième (shen 神) et le septième (gui 鬼), la consécration est impossible.

88. Par exemple, les jours où sont présents les esprits journaliers Fuduan 伏斷, Feilian 飛 廉, etc., sont néfastes.

(C) École française d'Extrême-Orient, Paris, 2012

Do not circulate without permission of the editor / Ne pas diffuser sans autorisation de l'éditeur 
sacrifices et les offrandes 》 (jisi 祭祀) ${ }^{89}$, un paramètre suffisant pour accomplir un rituel, que ce soit celui d'une consécration ou autre.

Hormis la mention de la date, les certificats de consécration ne s'attardent pas sur cette cérémonie. Dans l'un des rares à le faire, To459, nous apprenons que la statue du grand ancêtre Shao Faxing 邵法興, né sous la dynastie des Yuan (I277-I367), a été commanditée par un lointain descendant, Shao Qiankun 邵乾坤, en I864. La raison invoquée pour la fabrication de la statue est «le corps instable » (shenti bu an 身體不安) de l'une des brus de Shao. Au huitième mois de cette annéelà, la statue, dont la hauteur, à plus de quarante centimètres, est plus importante que celle de la plupart des statuettes, est commandée à l'artisan local (chushi 處士) Xiong Baisui 熊白遂. Une fois réalisée, on demanda au «spécialiste de la couleur » (danqing 丹青) de la peindre. Deux ans plus tard, au vingt-deuxième jour du huitième mois de l'an I866, on procéda à la fermeture de la cache et à l'ouverture de la lumière (feng duzang kaidian mingguang 封肚臟開點明光) et, le même jour, on commença une cérémonie ( $f a s h i$ 法事) qui dura trois jours et trois nuits. Le certificat fut écrit par le maitre "sorcier » (wu 巫) Lu Faqing 盧法清. Le luxe de détails rapporté dans ce certificat en fait un cas exceptionnel : généralement, le temps entre la sculpture et la consécration est beaucoup plus court, on ne fait pas allusion à une quelconque cérémonie - qui peut être ici un rituel d'offrande (jiao 醮), un rituel d'ordination ou funéraire ${ }^{9 \circ}$-, et enfin aucun autre nom de spécialiste que celui du sculpteur n'est mentionné. Ce dernier joue bien un rôle central, à la fois technique et religieux, dans la production des statuettes.

Michel Strickmann fait observer qu'en Inde il existe une compétition larvée entre les sculpteurs et les prêtres, chacun ayant un domaine dans lequel l'autre ne peut empiéter, chacun se livrant à une sorte de lutte de prestige pour le sacré. Ôfuchi Ninji 大淵忍爾 décrit en 1983 trois rituels de consécration accomplis à Taiwan par les prêtres taoïstes, les maitres exorcistes (fasbi) et les sculpteurs, les deux premiers opérant dans le cadre d'un rituel d'offrande et dans un temple, les derniers, semble-t-il, à demeure ${ }^{91}$. Lors de nos enquêtes de terrain dans le Hunan, il ne fait pas de doute que l'initiation du sculpteur comprend l'apprentissage du rituel de consécration : trois d'entre eux en possédaient le texte rituel, l'un des rares écrits qu'ils détenaient, et nous avons assisté à l'accomplissement de ce rituel par un quatrième ${ }^{92}$. Bien que le contenu des textes soit loin d'être identique, leur structure

89. Il n'est pas inutile toutefois de préciser que sur les calendriers de cette époque, la fréquence d'apparition de jisi est très élevée, il n'est donc pas impossible que la concomitance « jour de consécration » et jour « jisi » soit le fruit du hasard.

90. T0303 présente le cas d'une statuette dédiée à un mâtre, consacrée le troisième et dernier jour du rituel d'ordination (paopai zouzbi 抛牌奏職) du disciple. Pour ce qui concerne la consécration de la statuette d'un maittre lors de ses funérailles, voir ci-dessous le paragraphe consacré au service funéraire songcao 送曹.

9I. Ōfuchi Ninji 大淵忍爾, Chūgokujin no shūkyō girei : Bukkyō, Dōkyō, minkan shinkō 中國人の 宗教禮儀——佛教・道教・民間信仰, Tōkyō, Fukutake shoten 福武書店, I983, p. 368-369, IO75-1083.

92. Les manuscrits et leurs copistes sont les suivants : Feng Xiaoyuan 奉孝元, sculpteur à Fengjia shan 奉家山 (entre le district de Xinhua et celui de Xupu 漵浦), Laojun shejiao 老君設教, s. 1., s. d., s. p. ; Long Songlin 龍松林, sculpteur dans le village de Guandu qiao cun 官渡橋村 
reste sensiblement la même, une structure commune au rituel in vivo accompli en un peu plus d'une heure : invitation des divinités, des plus grandes aux plus petites, des divinités locales, des maîtres spirituels et d'initiation, des ancêtres et du dieu du Sol, puis des généraux et des armées célestes ; introduction du ou des commanditaires, et lecture du certificat de consécration rédigé auparavant ; «souffle » des commanditaires sur la cache de la statuette avant que celle-ci ne soit scellée ; sacrifice du coq puis pointage à l'aide d'un pinceau trempé dans le sang de l'animal des différentes parties du corps de la statuette, y compris « toutes les articulations et tous les pores de la peau $»^{93}$; lancer des blocs divinatoires pour vérifier si cette consécration a reçu l'agrément des divinités.

Il va de soi que les prêtres taoïstes locaux savent exécuter ce rituel, mais son exécution, le plus souvent liée à un service rituel plus complexe, est plus rare. Les raisons économiques jouent certainement en l'occurrence un rôle déterminant, mais nous pouvons également y voir un partage des rôles en fonction des lieux : les taoïstes opèrent dans le cadre de rituels communautaires dans un temple ou un lieu faisant fonction de temple, tandis que les sculpteurs officient pour une famille dans un cadre domestique. Ce rituel peut aussi n'être qu'une séquence d'une cérémonie plus large. C'est le cas par exemple du service funéraire rendu pour le décès d'un maître, appelé songcao 送曹, «Accompagnement [du défunt] au département céleste 》. Avant de déposer le corps dans le cercueil, on procède à « l'ouverture de la lumière du cadavre » et à celle de la statue, si elle a été sculptée du vivant du défunt. Le corps est installé dans le hall sur une chaise. À l'aide de ficelle, les doigts des deux mains sont disposés de manière à former la mudrā des Sept ancêtres (Qizu jue 七祖訣, main gauche) et celle de l'Épée (Jian jue 劍訣, main droite). Sous les pieds est installé un sac de riz imitant la forme d'une tortue. L'officiant ouvre la lumière sur tout le corps, d'abord avec une lampe, puis avec un pinceau trempé dans le sang d'un coq. Il termine par quatre salutations qu'il adresse au défunt et brûle des petits paniers d'offrande de papier-monnaie ${ }^{94}$.

(canton de Yangxi 洋溪, district de Xinhua), Anshen ben 安神本, s. 1., s. d., s. p. ; Zou Zuwen 鄒 祖文, sculpteur à Yangxi (district de Xinhua), Kaiguang ben quanji 開光本全集, s. 1., s. d., s. p. Le rituel de consécration dont nous avons été témoin a été accompli par Yang Hui 楊輝, sculpteur à Lengshui jiang 冷水江, octobre 2003. Au sujet de Yang Hui et son atelier, voir dans ce volume l'article de Michela Bussotti.

93. Contrairement à ce que nous pouvons observer à Taiwan (voir Ōfuchi Ninji, art. cit.), les officiants n'utilisent pas de miroir pour faire «le pointage ».

94. Voir Zou Shengyun 㱀升雲, "Songcao. Miaotian guan chuancheng de teshu chaodu fashi » 送曹 - 苗田觀傳承的特殊超度法事, dans Chen et Hua (Arrault), éd., op. cit., sous presse. L'auteur a lui-même été ordonné prêtre taoïste et maître exorciste. De Groot, dans sa description des rituels funéraires, décrit le "pointage » de la tablette funéraire, mais pas ce rituel de consécration du cadavre, réservé au corps des spécialistes. Cf. De Groot, Les fêtes annuellement célébrées à Emoui (Amoy), p. I8-23 et Religious system of China, vol. I, book I, p. 213-219.

(C) École française d'Extrême-Orient, Paris, 2012

Do not circulate without permission of the editor / Ne pas diffuser sans autorisation de l'éditeur 


\section{B) L'autel domestique}

Dans Les fêtes annuellement célébrées à Emoui, De Groot indique que les statues dans les maisons d'Amoy (Xiamen 廈門) sont disposées dans une armoire ouverte, en face de l'entrée principale. Le plus souvent, Guanyin 觀音, le dieu tutélaire du Fujian Guo shenwang 郭聖王, le dieu du Sol et celui du Foyer y prennent place, et naturellement d'autres dieux en fonction du rang ou de l'occupation du maittre de maison ${ }^{95}$. En parcourant les données à notre disposition, nous avons relevé trois cas intéressants quant aux « dieux » installés sur les autels du Hunan.

Le premier concerne un certain Li Shengzhen 李盛真 (To20I-A, To20I-B, To23r). Avec sa femme, ses fils, sa fille et ses petites-filles, Li a commandité une statue de son père, Li Yingchun 李映春 (I807 ? - ?), et une de sa grand-mère, dont il faut noter au passage que le nom de famille (Chen 陳) est également celui de la femme de Li. Â ces deux statues, s'ajoute une troisième en la personne du dieu du Pic du Sud (Nanyue shengdi 南獄聖帝). Ces trois statues ont été exécutées la même année, en I889. En suivant un deuxième cas, une famille Li qui n’a de commun avec la précédente que le nom de famille et le lieu de résidence (le district d'Anhua), nous constatons l'élaboration de statues sur trois générations (T 0345, To49I, To32I). Li Fayun 李法雲 est le commanditaire d'une statue de son père, Li Zhongxing 李重興, nom d'ordination Fawang 法旺 (1864? - ?). Cette statue est consacrée une première fois en 1919 puis une seconde en 1928. Li Fayun est à son tour «statufié » par son fils, Li Zuxi 李祖西, en 1956. Nous apprenons à cette occasion que le nom civil de Li Fayun est Li Zongyun 宗雲 et qu'il est né en I89o. Comme pour l'exemple précédent, l'adresse est évidemment identique ${ }^{96}$. Luo Diehe 羅迭和, associé à sa femme, et le plus souvent avec ses frères et ses neveux, a fait faire quatre statuettes, dont trois sont datées des années I89o et I893 (T0386, T 0407, T 0402, T0352). Aucune ne porte le nom de famille Luo. Elles sont respectivement consacrées à Liu Hanxing 劉漢興, Zhang Qingying 張清應 (I8I5 ? - ?), Cao Xianlu 曹先魯 et Gong Zhihe 壟質和. En l'absence d'appellation particulière, nous ne savons pas quel pouvait être le type de relation entre ces statuettes et le donateur, sauf pour l'une d'entre elles : la statue de Zhang Qingying a en effet été consacrée en I886 par une famille Zhang du district de Xinhua qui l'appelle maitre « clanique » (zongshi 宗師) et « maitregrand-père » (shiye 師爺) (To620), ce qui signifierait que ce personnage était le maittre d'un lignage et qu'il jouissait d'une aura suffisamment grande pour recevoir un culte au-delà d'une famille et d'un clan.

À travers l'exemple de ces statuettes, qui regroupent des parents, un maitre, une divinité nationale, il n'est pas difficile d'imaginer qu'ils devaient siéger sur le même autel. Et c'est bien ce que nous pouvons constater aujourd'hui sur les autels domestiques. Deux enquêtes ont été menées, la première dans le village de Huifei 翚飛村, situé à une vingtaine de kilomètres de Pingdong 坪洞, le chef-lieu du district d’Anhua, par Wang Xiaowu 王小悟; la seconde dans le village de Fengjia shan 奉家山,

95. De Groot, Les fêtes annuellement célébrées à Emoui, p. 13.

96. Une troisième statuette est dédiée à un autre Li Fayun (To49I), résidant également dans le district d'Anhua mais dont la date de naissance est différente du Li Fayun dont il est question ici. 
situé entre la ville de Xinhua et celle de Xupu 漵浦, par Feng Yunxing 奉雲星 ${ }^{97}$. Ces deux enquêtes, auxquelles nous ajouterons nos propres observations, ne prétendent pas être exhaustives, elles ont pourtant l'avantage d'offrir sur des lieux relativement éloignés les uns des autres des données certes incomplètes mais complémentaires.

En contexte rural, la proportion d'autels en fonction du nombre total de foyers est très élevée, de l'ordre de $80 \%$ à Huifei. L'absence d'autel parmi les $20 \%$ de familles restantes s'explique le plus souvent par le fait qu'elles sont hébergées, ou qu'elles ont quitté le domicile pour aller travailler à l'extérieur, ou encore qu'elles viennent de faire construire une nouvelle maison qui, pour le moment, est dépourvue d'autel.

Le plus souvent la forme de ces autels se réduit à une ou deux étagères fixées sur le mur en bois ou en brique situé en face de l'entrée dans la pièce centrale. Ces étagères accueillent un brûle parfum, des bougies, des offrandes, un ou des bols de «scellage de l'autel » (jintan 禁壇) ${ }^{98}$, ainsi que les tablettes ou les images des ancêtres et des divinités. Plus intéressants et sophistiqués sont les autels creusés en rectangle dans le mur, ressemblant à des placards sans porte. Ils exigent certes des moyens économiques plus élevés, mais ils sont surtout l'apanage de familles dont les professions exigent un certain niveau culturel - l'usage de l'écrit -, comme les notables et fonctionnaires locaux, les spécialistes du religieux, les artisans, les chasseurs, etc. Les plus imposants comprennent trois parties, qui, suivant les circonstances, peuvent être réduites à deux ou à une seule. Chacune de ces parties est d'ordinaire dotée d'une affiche de couleur rouge collée sur le fond.

La partie supérieure de cette affiche présente en son centre l'expression : "place des divinités du Ciel et de la Terre, du pays ${ }^{99}$, des parents et des maitres » (tiandi guo qin shi wei 天地國親師位). À droite de cette expression est mentionné le nom des ancêtres, dont la liste peut commencer à partir de l'ancêtre à la quatrième génération ( $g a o z u$ 高祖), le plus souvent par le trisaïeul (zengzu 曾祖), puis viennent invariablement le nom du grand-père et du père, parfois celui des oncles, des frères aînés, etc. Les noms des épouses y figurent également et quelquefois, à gauche de l'expression centrale, la parenté du lignage maternel tient une place non négligeable. Les spécialistes du religieux y ajoutent le nom des divinités qu'ils vénèrent, celui du maitre de famille (jiazhu 家主) et des lieux (dizhu 地主). Ils font aussi allusion à leur ordre et au lignage de leurs maitres. Cette prolifération est en quelque sorte inscrite et légitimée par une formule située autour de la sentence centrale :

97. Voir Wang Xiaowu 王小悟, «Anhua Huifei cun shenkan wenhua de diaocha yu yanjiu » 安化啎飛村神龕文化的調查與研究, et Feng Yunxing 奉雲星, «Fengjia shan jumin shekan wenhua diaocha » 奉家山居民神䧻文化調查, dans Chen et Hua (Arrault), éd., op. cit., sous presse. Feng Yunxing donne une description précise des procédures à accomplir pour élaborer un autel.

98. Il est courant dans le Hunan, lorsqu'une femme est enceinte, de faire un rituel propitiatoire pour garantir une bonne parturition et assurer à l'enfant une vie en bonne santé, etc. À la fin de ce rituel, un bol contenant du thé, du riz et les huit caractères de naissance ( $b a z i$ 八字) de la future mère, est scellé et disposé sur l'autel.

99. Le pays, guo 國, a remplacé le mot «seigneur» (jun 君), une référence à l'empereur utilisée autrefois. 


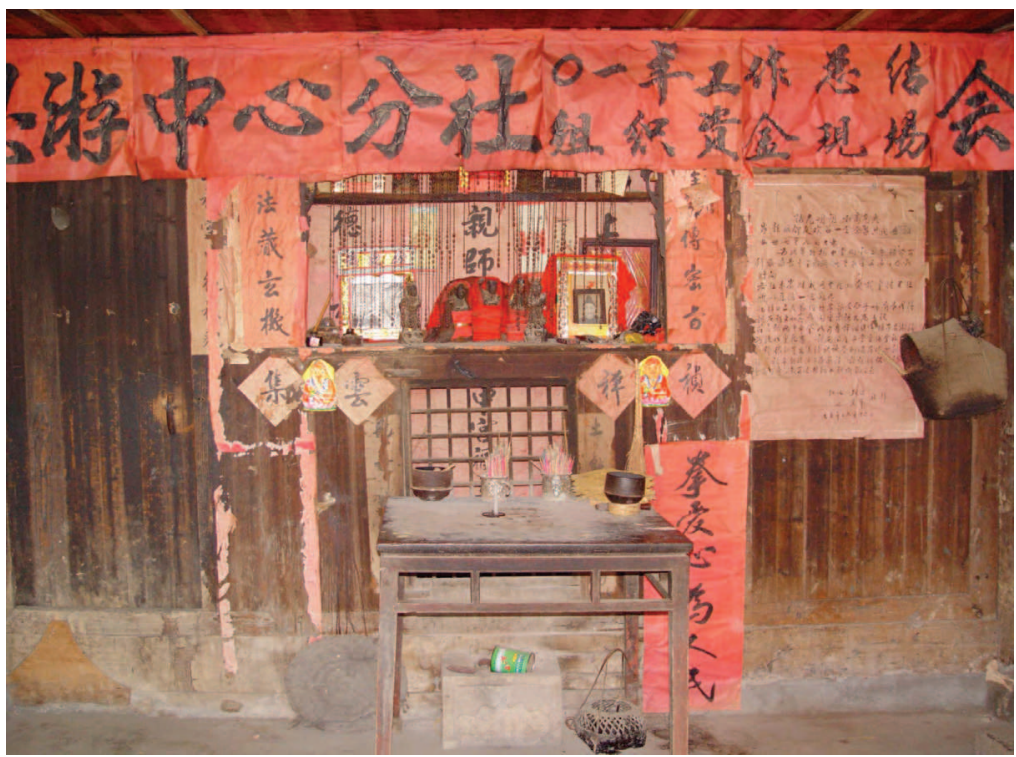

Fig. 36 : Vue d'ensemble de l'autel du Tonnerre de Li Shoubao (1917-2009), district d'Anhua, commune de Le'an 樂安, village de Shuixi 水溪, du territoire administratif de Siyou 思游管區, 2003. La banderole qui cache la partie haute de l'autel est une " enseigne » d'une filiale d'un crédit mutuel gérée par la famille Li. Cliché Alain Arrault.

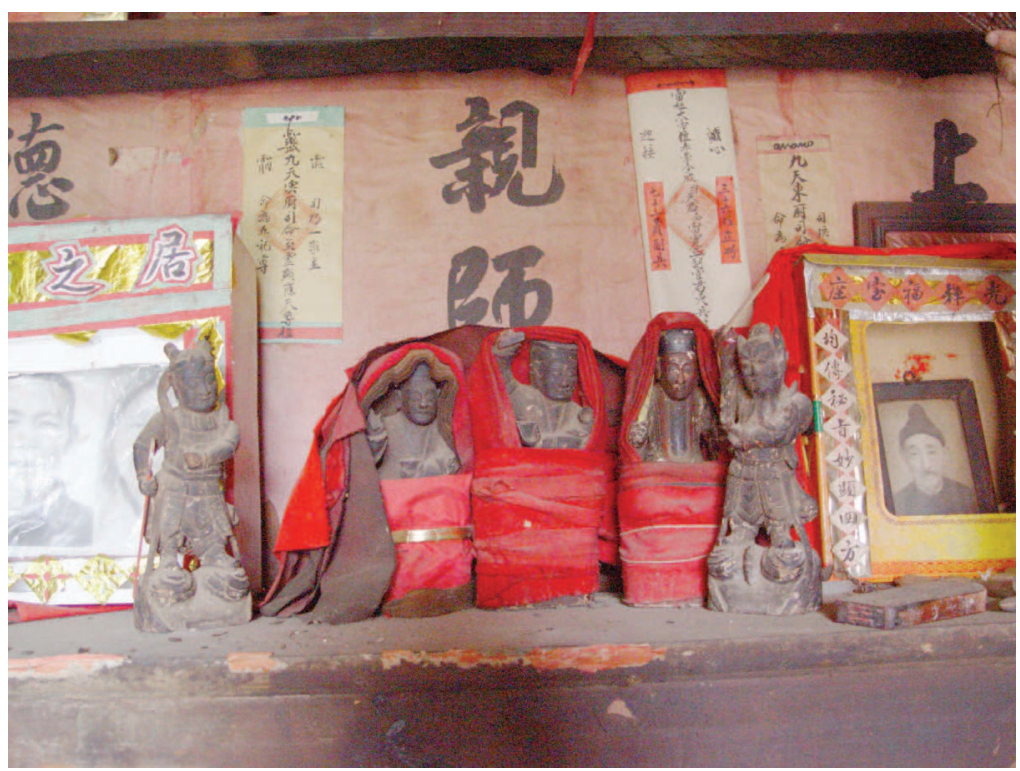

Fig. 37 : Détail de l'autel; de gauche à droite : photo du fils et de la belle-fille, statues du maréchal Yin, du maitre de l'arrière-grand-père, du grand-père, de l'arrière-grandpère, du maréchal Wang ; photo du père. Cliché Alain Arrault. 
« Notre parenté intérieure et extérieure constitue les principes de notre clan; toute la lignée des puissances hérö̈ques et célestes reçoit unanimement des offrandes » 內戚外戚是吾宗旨, 一派英靈普同供養. Il n'y a donc rien d'étrange à ce que des statues d'ancêtres, de maîtres et de divinités, offrant un pendant matériel à l'écrit, soient également honorées. C'est sur le rebord inférieur de cette partie haute qu'elles sont disposées, accompagnées le plus fréquemment d'un brûle-parfum, d'offrandes, etc.

La partie médiane, en quelque sorte une séparation entre les parties supérieure et inférieure, présente des formules propitiatoires et prescriptives : «Que le Ciel, la Terre, le monde obscur et lumineux, l'année, le mois, le jour, l'heure soient sereins ; Grandes sont les divinités, que rien ne soit frappé d’interdit !»天地陰陽年月日時安; 神大百無禁忌. Sur le côté de ces formules sont parfois aménagés des casiers contenant encens, monnaies d'offrande, etc. C'est dans la partie inférieure, qui est au plus près $\mathrm{du}$ sol, que les noms du dieu du Sol et de son épouse apparaissent (changsheng tudi, 長生土地, qingrui furen 瑞慶夫人), flanqués de l'Enfant 《porte-richesse 》 (zhaocai tongzi 招財童子) et du Seigneur 《 amas de trésors 》 (jinbao langjun 進寶郎君). Ces noms peuvent faire place à d'autres divinités en fonction du «métier » de la famille : par exemple, les chasseurs y indiqueront les divinités des trois grottes du Meishan (sandong Meishan 三峒梅山) : les rois Fu 扶, Li 李 et Zhao 趙 ${ }^{100}$.

Il va de soi que ces autels peuvent connaitre sur la base d'une forme commune des variations. C'est le cas par exemple de l'autel de Li Shoubao 李壽寶 (I9I7-2009), ordonné prêtre taoïste, maître exorciste et bouddhiste ${ }^{\mathrm{Iol}}$ et résidant à une bonne dizaine de kilomètres de la ville de Meicheng 梅城, dans le district d'Anhua. Son autel, qu'il désignait du nom générique d'autel du Tonnerre (leitan 雷壇), ne comprend qu'une partie inférieure dédiée au dieu du Sol et une partie supérieure composée de deux étagères (voir fig. 36). Sur l'étagère supérieure reposent quatre statuettes, l'une d'entre elles, placée au centre dans une boîte, représente le dieu du Pic du Sud. L'identité des autres a été perdue. Une «tablette » en papier recense les noms des arrière-grands-parents, des grands-parents et des parents. On note la présence d'un cadre en papier vide qui a été offert à Li Shoubao pour son soixante-dixième anniversaire. On trouve en dessous cinq statuettes incarnant les maréchaux Yin 殷 et Wang 王, l'arrière-grand-père Li Anyi 李安一 (I8I4-I885) et son maittre Luo Xingjing 羅行靜, le grand-père Li Shengyang 李盛煬 (I854-I9I7), ainsi que — signe des temps - les photos du père, Li Daojun 李道均 (I892-I97I), et du fils et sa femme, morts prématurément (voir fig. 37).

La facture de l'autel peut cependant être encore simplifiée. Au milieu des montagnes bordant la commune de Shuiche 水車, dans le sud-ouest du district de Xinhua, dans un lieu difficile d'accès, vit la famille de Luo Chongmei 羅崇美. Paysan et medium, Luo s'est contenté d'un autel sommaire dans sa modeste demeure : une niche d'environ un mètre sur une trentaine de centimètres trône à un mètre cinquante du sol (voir fig. 38). Une simple planche à la base de cet autel soutient en

Ioo. Pour plus de détails sur les différents types d'autels, notamment à Fengjia shan, voir Feng Yunxing, art. cit.

IOI. Au sujet de Li Shoubao, voir Zhang Shihong 張式弘, «Anhua daojiao de diaocha baogao » 安化道教的調查報告, dans Chen et Hua (Arrault), éd., op. cit., sous presse.

(C) École française d'Extrême-Orient, Paris, 2012

Do not circulate without permission of the editor / Ne pas diffuser sans autorisation de l'éditeur 


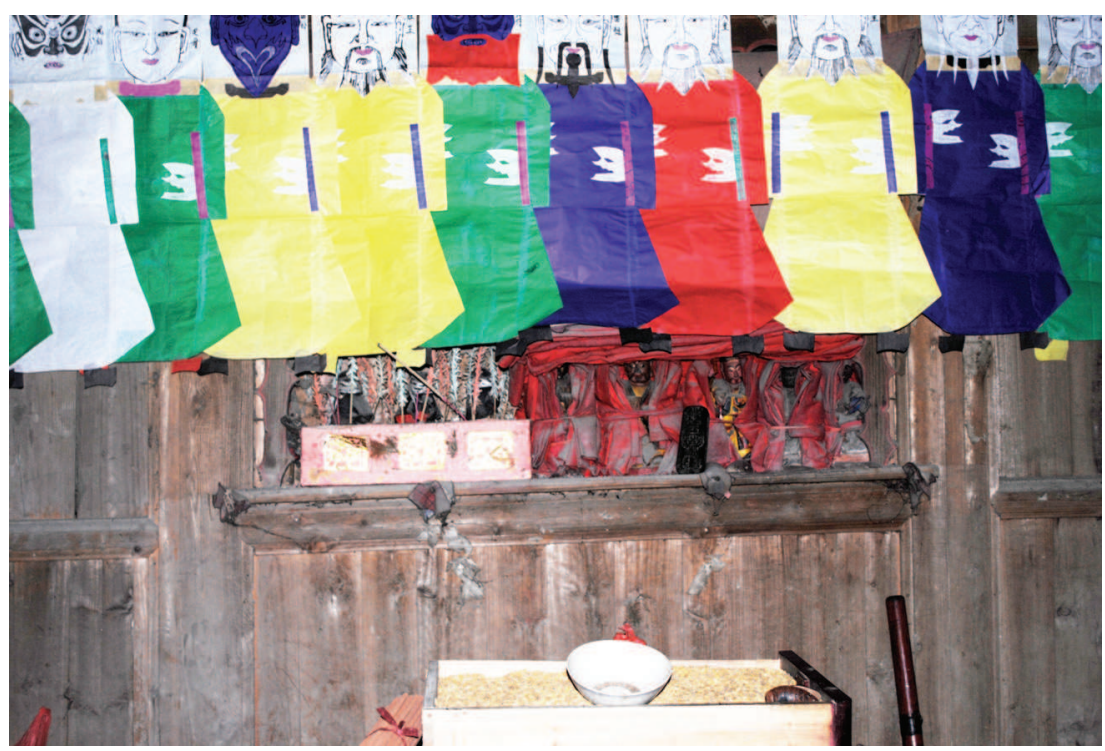

Fig. 38 : Autel de Luo Chongmei, district de Xinhua 新化, canton de Shuiche 水車, village de Baishui 白水, 2009. À droite, cinq statuettes; à gauche, la boîte de la terrasse des Dames (Niangniang tai 娘娘臺). Les images en papier de divinités au-dessus de l'autel ont été installées à l'occasion de l'accomplissement du rituel Leipan jiao 雷盤醮. Cliché Alain Arrault.

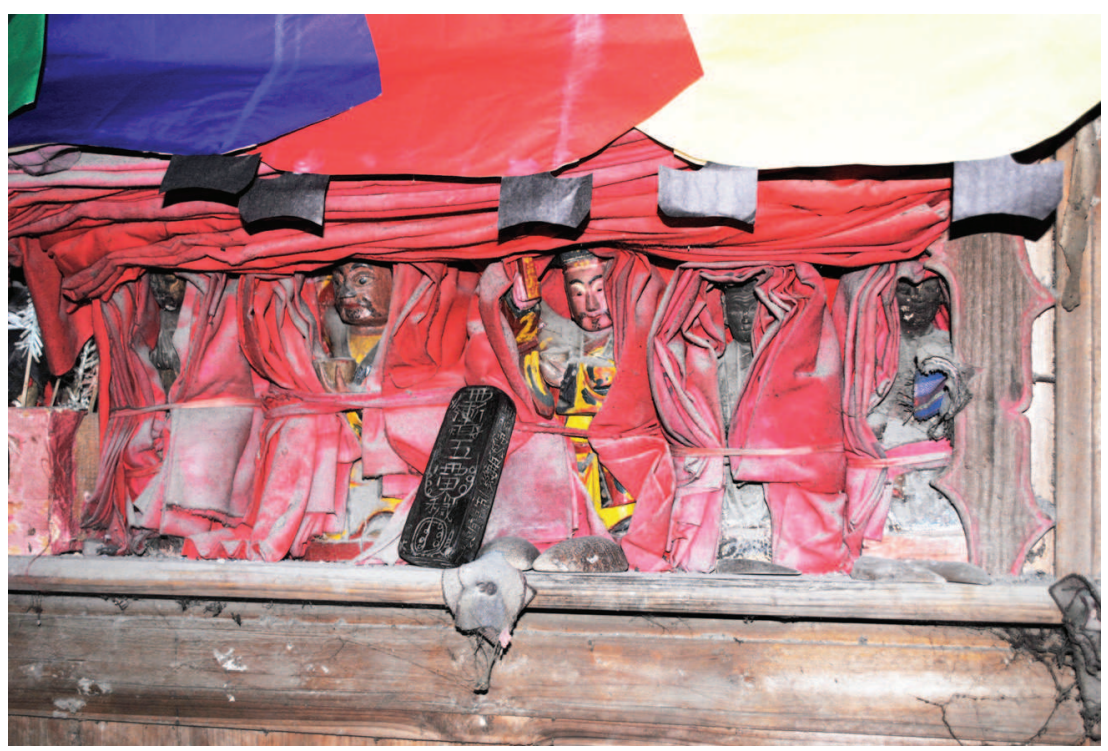

Fig. 39 : Détail de l'autel ; de gauche à droite : statues de Guanyin, Luo Farong 羅法榮, Zou Faling 㱀法靈, Luo Ziyu 羅子瑜 et Luo Zigu 羅子固. Cliché Alain Arrault. 


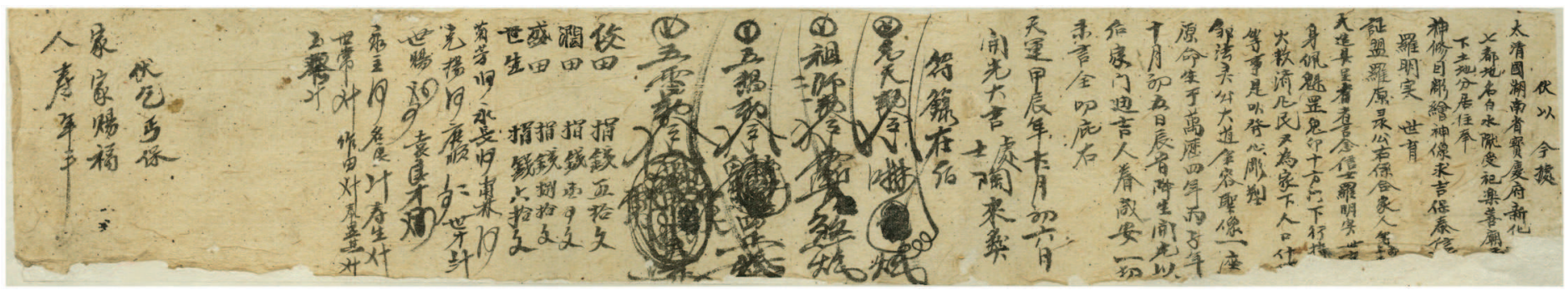

Fig. 40 : Certificat de consécration pour la statuette de Zou Faling 㱀法靈, avec dans la partie finale une liste de donateurs et le montant de leur don, 1844 ou 1904 ?, T 0095-6-1. CEFEO

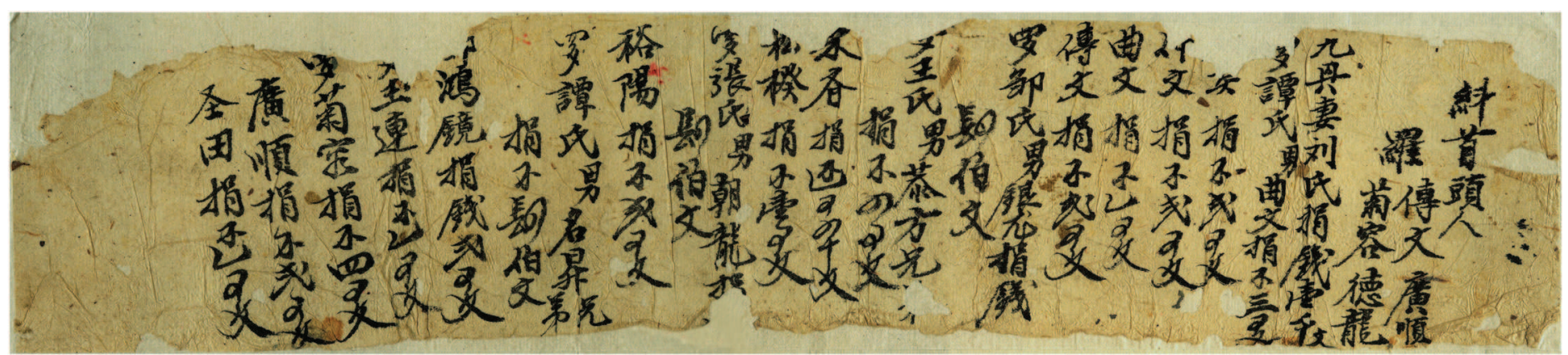

Fig. 41 : Liste de donateurs avec le montant de leur don, 1879 ?, T 0095-6-3. CEFEO 
temps normal un brûle-parfum et des offrandes, etc. Cinq statues sont engoncées dans la niche : Guanyin, la divinité locale Zou Faling 㱀法靈, l'oncle Luo Zigu 羅 子固 et le grand-père Luo Ziyu 羅子瑜, et enfin Luo Farong 羅法榮 (voir fig. 39).

Trois statuettes de Zou Faling ont été cataloguées informatiquement (Too95, To052, T 029I ${ }^{102}$. Les lieux de consécration se situent dans un rayon d'environ trente à quarante kilomètres, entre Shuiche et le nord du district de Shaoyang 邵陽. Les commanditaires principaux ont toujours quelques rapports avec des Luo. Il s'agit dans deux cas de femmes : l'une née Luo, mariée avec un Zou, l'autre née Peng 彭, mariée avec un Luo (To29I, To052). La troisième statuette et son certificat de consécration (To095) sont particulièrement instructifs. Consacrée à au moins deux reprises, en I879 et au début du $\mathrm{Xx}^{\mathrm{e}}$ siècle, elle a bien évidemment été commanditée par des Luo, mais les certificats mentionnent une liste impressionnante de fidèles et, fait rarissime, précisent la contribution financière. Pour ce qui semble être la première consécration, en dehors des deux donateurs principaux, dix-neuf personnes ont contribué pour un total d'environ deux mille sapèques (voir fig. 40). Pour la seconde, vingt-sept personnes ont apporté presque cinq mille sapèques (voir fig. 4I $)^{103}$. Un autre certificat (T 0545) précise que la somme de trois mille sapèques a été dépensée entre 1903 et 1906 pour refaire une statue de la divinité locale Xiao jun Yilang 肖君一郎, qui avait été souillée lors d'un déménagement de la famille Zuo du district de Xinhua vers celui de Xinning 新寧. Sachant qu'un charpentier-menuisier (mugong 木工) et un terrassier (tugong 土工) étaient payés soixante sapèques par jour dans les années I867-I875, puis aux alentours de cent-cinquante sapèques entre I89I et $\mathrm{I} \mathrm{II}^{\mathrm{I04}}$, deux mille sapèques représentaient plus d'un mois ou d'un demi-mois de revenus, selon les deux périodes, et cinq mille sapèques, deux mois et demi ou plus d'un mois. Trois mille sapèques correspondraient, pour la seconde période, à environ vingt jours de travail. Â titre indicatif, la réalisation d'une statuette de trente à quarante centimètres de hauteur - la taille des statuettes de Zou et Xiao

I02. Il existe deux autres statuettes de Zou Faling (To445, To638), qui proviennent du village de Dajiang 大江 (district de Xinhua). Mais la date de naissance de l'une d'entre elles est différente, et Dajiang, situé au nord-est de Xinhua, étant très éloigné de Shuiche et sa région (sud sud-ouest de Xinhua), il est donc fort probable qu'il s'agisse d'un autre Zou Faling.

I03. Six documents sont inclus dans cette statuette (notés Toog5-6-I, -6-2, -6-3, -6-4, -6-5, -6-6) : deux sont des certificats de consécration en bonne et due forme (-6-1, -6-2), le premier comportant une date avec le binôme sexagésimal de l'année mais sans ère [jiachen nian 甲辰年, qui pourrait être I844 ou $1904(-6-\mathrm{I})]$, le second en étant dénué ; un troisième document (-6-3) est une liste de donateurs; les trois derniers $(-6-4,-6-5,-6-6)$, parmi lesquels l'un est daté de I879 (-6-4) et un autre de $1906(-6-6)$, comportent une série de talismans. Nous avons de bonnes raisons de croire que -6-2, -6-3 et -6-4 sont liés, de même que -6-5 et -6-6.

I04. Voir Jun Hyeonggwon 田畑權, «Qingmo zhi Minguo shiqi Hunan Rucheng xian de shangpin liutong he wujia biandong 》 清末至民國時期湖南汝城縣的商品流通和物價變動, Qingshi yanjiu 清史研究, I (2004), p. IO2-IIO. Le district de Rucheng 汝城, dont il est question dans cet article, se trouve à l'extrême sud-ouest du Hunan, à quelque cinquante $\mathrm{km}$ de la province du Jiangxi. Le salaire au Hunan est supérieur à celui qu'annonce S. Gamble pour les artisans de Pékin de I862 à I9II (de vingt-deux à cinquante-sept sapèques). Voir Sidney D. Gamble, Peking Wages, edited by Maxwell S. Stewart, Peiping 北平, The Department of Sociology and Social Work, Yenching University, 1929. 
- dans le Hunan en 2003-2004 coûtait deux cents RMB. Sachant que le salaire moyen dans les années 2000 s'élevait à quarante ou cinquante RMB par jour pour les artisans, le coût de la statuette équivalait à quatre à cinq jours de travail. Il parait donc assez évident que les sommes engagées pour les statuettes de Zou Faling et de Xiao jun Yilang devaient inclure beaucoup plus que la réalisation technique et un simple rituel d'« ouverture des yeux $»^{\text {tos, }}$ d'où le nombre important de contributeurs et la volonté d'inscrire en détail les sommes dépensées.

Les Luo, mentionnés sur les certificats, résident dans la même commune que Luo Chongmei 羅崇美. Qui plus est, l'un des certificats (-6-2) indique clairement que le but était d'obtenir de Zou Faling la protection du médium (jiaoma 腳馬) Luo Shilin 羅世林, un statut qu'il partage aujourd'hui avec le maitre de maison Luo Chongmei. Installé sur l'autel de ce dernier, Luo Farong 羅法榮 représente ainsi l'esprit qui se manifeste au travers de Luo Chongmei. On raconte sur Luo Farong, de nom civil Luo Chengyu 承玉, qu'il a été initié par un Zou au taoïsme et à la doctrine des maitres (sbijiao 師教). Après la libération de 1949, les rituels devinrent de plus en plus rares. Ayant exprimé son mécontentement, Luo fut envoyé en rééducation plusieurs années. Libéré, il mourut sur le chemin du retour, dans le district de Xupu 溆浦. Un mois plus tard, il posséda un médium afin de faire savoir qu'il était mort et, qu'enterré au bord d'une route, il demandait à sa famille de venir récupérer son corps. Ce qui fut fait un mois plus tard. On fit alors pour lui un rituel de salut : installé sur une chaise, son cadavre était non seulement intact, mais ses chairs avaient gardé toute leur élasticitét ${ }^{106}$.

Au-delà de la perpétuation d'une tradition médiumnique, il semble exister entre les deux familles Luo et Zou un lien indéfectible ${ }^{\mathrm{I07}}$. On raconte en effet que Zou Faling, né en 1576 , a marié sa fille avec un Luo et qu'il a transmis son enseignement - à la suite d'une malencontreuse bévue ${ }^{108}$ - au fils de son gendre, donc un Luo, stipulant qu'une seule personne par génération pourrait dorénavant en hériter. Considéré comme un maitre des lieux (dizhu 地主), bien des histoires circulent sur Zou Faling. On dit qu'il a été initié sur les monts Emei 峨嵋 dans le Sichuan. Doté de pouvoirs extraordinaires, sa vie est jalonnée de prodiges les uns plus merveilleux que les autres. Sa mort elle-même est un récit fabuleux : lors d'une campagne de l'armée impériale pour mater une rébellion dans la région, il fut arrêté et décapité sur le champ. La soldatesque partie, il récupéra à tâtons sa tête qu'il replaça sur son cou et souffla dans sa corne de buffle. Alertés par le bruit, les soldats revinrent, et

I05. À ce sujet, voir plus haut, p. 99 et ss.

Io6. Histoire qui a été narrée à l'auteur par Zou Shengyun 㱀升雲, que nous remercions ici vivement.

I07. La photo de l'autel de Luo Chongmei a ainsi été prise à l'occasion d'un rituel appelé Leipan jiao 雷盤醮, dont les deux officiants étaient un Zou, Zou Shengyun 鄒升雲, et un Luo, Luo Zhihui 羅志輝, le grand-oncle de Luo Zhihui ayant été par ailleurs le disciple de l'arrièregrand-père de Zou Shengyun.

I08. Répondant à une provocation grivoise de ses amis, Zou Faling utilisa ses pouvoirs pour faire descendre à distance le pantalon d'une passante, qui se révéla être sa propre fille. Apprenant que c'était son père qui s'était livré à ces exactions, la fille se suicida. Pris de honte et de regret, Zou décida de transmettre son art au fils de sa fille.

(C) École française d'Extrême-Orient, Paris, 2012

Do not circulate without permission of the editor / Ne pas diffuser sans autorisation de l'éditeur 
le décapitèrent à nouveau. Ensuite, il remit une tête, mais cette fois-ci se trompa et fixa sur ses épaules une tête de femme. Qu'importe, il sonna encore une fois de sa corne de buffle, la même cause provoquant le même effet : la tête tranchée, les assassins prirent toutefois le soin d'enduire son cou du sang d'un chien. Souillé par ce sang, Zou ne put remettre sa tête. Aujourd'hui, on raconte qu'il a deux tombes séparées d'un ou deux kilomètres : l'une contient son corps, l'autre sa têter ${ }^{109}$. En souvenir de son sacrifice, on lui éleva, entre autres, un temple sur les flancs du site de culture en terrasses de Zique jie 紫鵲界 (le site de la Pie pourpre), aujourd'hui classé patrimoine mondial de l'Unesco, situé sur le territoire de la commune de Shuiche, dans lequel on lui rend encore actuellement un culte.

Le grand-père, Luo Ziyu 子瑜, et l'oncle, Luo Zigu 子固, ont pour nom civil Luo Chengbang 承榜 et Luo Jiaocan 教燃, le « $\mathrm{zi}$ »子 qu'ils ont dans leur prénom indique que tous deux étaient des acteurs de théâtre. On remarque enfin sur l'autel de Luo Chongmei une boîte décorée de papier doré contenant trois petits bocaux scellés : il s'agit de la terrasse des Dames (Niangniang tai 娘娘臺). Elle indique généralement que quelqu'un de la famille - une femme ou un homme — «porte » les Dames (dai Niangniang 帶娘娘), c'est-à-dire qu'il est possédé par des divinités féminines. En l'occurrence, il s'agit de la maîtresse de maison. Il existe trois situations en cas de possession : I) le possédé a fait faire un rituel pour enfermer (fengïn 封禁) les Dames dans des bocaux, que l'on dispose en général à gauche de l'autel, car il ne désire pas suivre la voie d'un médium ; 2) contrairement au précédent, le possédé accepte les Dames, fait vœu de les servir et de les célébrer régulièrement, mais ce service demeure uniquement familial ; 3) le possédé non seulement accueille les Dames, mais de plus son rôle de médium est " public », il intervient à la demande pour soigner, exorciser, faire de la divination, etc. Quel que soit le contexte, l'autel installé pour les Dames - sur l'autel principal, ou sur les côtés, ou encore à l'étage - fait toujours référence à la source des Pêchers (Taoyuan shengjing 桃源 勝景, Taoyuan xiantong 桃源仙峒, Taoyuan xianjing 桃源仙境, etc.). La terrasse des Dames sur l'autel de Luo répond donc à la situation première. Les divinités sont enfermées dans des bocaux dont le nombre varie de trois à cinq. On procède à la 《présentation de nourriture 》 (shangliang 上糧) en y insérant du riz, du thé, du soja vert, du fil de chanvre, des pièces de monnaie, des plumes, etc ${ }^{\text {110 }}$.

Les formes d'autels que nous venons de présenter ressortissent sans aucun doute à un héritage - redécouvert ou réinventé, la question reste entière - de la tradition, mais il n'est pas inutile de préciser que la forme simplifiée d'un autel, réduit à une planche fixée sur le mur, surplombée d'affiches des leaders de la révolution (Mao

I09. La biographie de Zou Faling, racontée par Luo Lai’an 羅來安, a été recueillie par Zou Shengyun, que nous remercions ici vivement pour nous avoir communiqué ce document.

IIO. Au sujet des Dames, on lira avec profit Su Zhengrong 蘇崢嶸, «Xiangzhong Tuzhu shan qu de Niangniang xinyang » 湘中土主山區的娘娘信仰, Yang Dexiang 楊德湘, “Meishan shigong jiao 'He Niangniang' fashi ji qi yuanyuan yu wenhua neihan» 梅山師公教和娘娘法事及其淵源與 文化內涵, et Chen Zi'ai 陳子艾, “Taiyuan tong huapeng de xinyang wenhua neiwen he tong yu tongshen de yanbian ji yuanyin » 桃源峒花篷的信仰文化內蘊和峒與峒神的演變及原因, dans Chen et Hua (Arrault), éd., op. cit., sous presse. 
Zedong 毛澤東, Zhou Enlai 周恩来, Deng Xiaoping 鄧小平, etc.), de reproductions kitsch de peintures de paysage ou de panneaux plastifiés uniformes et anonymes, occupe proportionnellement une place prépondérante ${ }^{\mathrm{III}}$. Sur la planche, le brûleparfum est remplacé par des ampoules électriques, les statuettes en bois par des statuettes modernes en céramique et des photos. Que l'on voie dans ces pratiques l'empreinte de la modernité est indéniable, mais suffit-il d'invoquer cet argument et des raisons économiques pour justifier la «simplification »? Ne sommes-nous pas en présence d'une distinction socio-religieuse entre spécialistes, "professionnels » et « gens du commun»?

\section{C) Culte et rôle des statues}

De Groot écrit qu'au Fujian « on fait des offrandes aux tablettes le $\mathrm{I}^{\text {er }}$ et le $15^{\mathrm{e}}$ jour de chaque mois, de la même manière qu'on le fait pour les dieux ; et aussi pour les dates de l'anniversaire et du décès des défunts ». Â la question des dates de culte des statuettes, les réponses des Hunanais sont souvent variables et peu précises. Et pour cause, ainsi que nous le rappelle De Groot : le culte aux ancêtres et celui rendu aux divinités vont le plus souvent de pair : les offrandes, les prières et les révérences effectuées le premier et le quinzième jour de chaque mois, le jour des fêtes calendaires, telles que la fête du cinquième jour du cinquième mois (Duanwu jie 端午節), de la mi-automne (Zhongqiu jie 中秋節), du double neuf (Chongyang jie 重陽節), du sacrifice d'hiver (Lajie 臘節), ainsi que les deux jours calendaires de l' « éveil des insectes 》 (Jingzhi jie 驚蟄節) et du sixième jour du sixième mois, s'adressent aux divinités et aux ancêtres. Hormis les dates anniversaires et de décès, il semblerait cependant que trois moments soient plus particulièrement réservés aux ancêtres : il s'agit de la veille du Nouvel An (Da nian sanshi wan 大年三十晚), de la fête des Morts (Qingming jie 清明節), et du milieu du septième mois, mois par ailleurs consacré aux âmes errantes, aux démons affamés et à leur salut. Il va de soi que pour les rituels accomplis occasionnellement, les ancêtres, s'ils ne tiennent pas un rôle de premier plan, sont pour le moins invoqués et sollicités. Pour les mariages, il ne viendrait à l'esprit de personne de ne pas avertir solennellement les ancêtres - et les divinités - de l'arrivée dans la famille d'un nouveau membre ${ }^{\mathrm{II} 2}$.

Il existe cependant des cérémonies qui sont entièrement dédiées aux ancêtres. L'une d'entre elles, la conciliation ou la célébration des Dames (be niangniang 和娘娘, qing niangniang 慶娘娘), les fait intervenir lorsque l'agent du médium fait partie de la famille. Ordinairement, ce service est organisé deux fois sur trois ans et donne lieu à un rituel de type Nuo 儺 accompli par les maitres exorcistes (fashi). Mais ce qui n'est que le fruit du hasard dans ce dernier cas devient une règle lorsqu'il s'agit du maître de famille, jiazhu 家主, appelé également taigong 太公 pour un homme et taipo 太婆 pour une femme. On se souviendra à ce sujet que ce maitre - ou cette «maitresse » - est évidemment un ancêtre, mais pas nécessairement le fondateur de la famille, et qu'il est reconnu pour son rôle charismatique dans le passé et pour sa «puissance rituelle ( (fali 法力). Ces qualités en font le protecteur de la famille,

III. Voir Wang Xiaowu, «Anhua Huifei cun shenkan wenhua de diaocha yu yanjiu », dans ibid.

II2. Voir Feng Yunxing, "Fengjia shan jumin shekan wenhua diaocha », dans ibid. 
une famille extensible à autant de branches existantes. Pour cette raison, le maittre de maison porte le même nom de famille que ceux qui le vénèrent, à l'exception des familles hétéronymes qui, ayant fait alliance avec un clan local puissant, prennent le même maître de maison. C'est évidemment l'inverse pour les maîtres des lieux qui, ayant rang de divinités locales, n'ont pas nécessairement le même nom de famille. Ainsi, dans les deux villages de Yankou 岩 $\square$ et de Maoyi 毛易, situés dans la circonscription de la ville de Lengshui jiang 冷水江, les Su 蘇 se répartissent de la manière suivante : à Yankou, quatre cent vingt foyers ont adopté Su Miaochen 蘇妙宸, trois cents Su Faliang 蘇法亮, sept cents Su Fameng 蘇法盟; à Maoyi, sept cent quarante foyers ont opté pour Su Falin 蘇法霖. En regard, tous les Su de Yankou rendent un culte au dizhu Luo Doulei 羅斗雷, et ceux de Maoyi, de manière différenciée, à Hu Wanlang 胡晚郎, Wen Faguan 溫法官, Liu Qilang 柳七郎 et Liu Balang 柳八郎 ${ }^{113}$.

En dehors des dates de culte communes aux divinités, les maîtres de maison sont honorés à date fixe, tous les ans, le jour de leur anniversaire. Désigné sous le terme générique de « célébrer les maîtres de maison » (qing jiazhu 慶家主), les cérémonies qui leur sont dédiées peuvent être multipliées autant de fois que nécessaire ${ }^{\mathrm{II}}$. Une généalogie du clan des Su signale à ce sujet qu' "à chaque fois que l'on entre dans l'hiver, les bruits des gongs et des tambours se font entendre. Aucune journée n'est laissée vide, les sorciers ( $w u$ 巫) revêtent des vêtements rouges et portent des couvrechefs bleus ; ils tiennent des blocs (pai 牌, de commandement ?) et des bâtons de maître exorciste (shigun 師棍), ils dansent et chantent ${ }^{115}$.

Devant ce maître de maison, bien d'autres cérémonies peuvent être accomplies. C'est notamment le cas lorsqu'un membre de la famille est malade. On procède alors à l'absorption de thé (taoshui 討水), puis si nécessaire à l'offrande d'une bande de tissu rouge (pibong 披紅), dont la statue est enrubannée ${ }^{\mathrm{II}}$, ou à une tenture qui servira de dais à la statuette (guacai 挂彩), et à l'offrande d'alcool et de viande ${ }^{\mathrm{II} 7}$. De nature exorcistique, la cérémonie peut se muer en un service propitiatoire, une demande de protection particulière (xuyuan 許愿) — un enfant à venir, un enfant qui passe ses examens, un commerce, etc. Chaque vœu exaucé doit naturellement être suivi d'une action de grâce (buanyuan 還愿). Ces demandes peuvent s'accompagner d'une consultation divinatoire par écriture médiumnique, ainsi que nous le décrit en 1933 la généalogie des $\mathrm{Su}$ :

Lorsqu'on demande du bonheur au maître de maison, on a en outre à Shirong 時榮 [un village du district de Xinshao] la méthode du jugement par les caractères (panzi 判字). D'une chaise on fait un palanquin, le maître de maison est assis dedans. Sur une planche en bois, on dépose de la cendre. Deux hommes soulèvent le palanquin et utilisent les

II3. Feng Yunxing, art. cit. ; Su Zhuanfeng 蘇傳鳳 et Su Jianwen 蘇建文, « Meishan Su Gan guju di renmen de taigong xinyang » 梅山蘇甘古居地人們的太公信仰, dans ibid.

II4. Pour une description sommaire de cette célébration à Xinshao 新邵, voir Su Qihuan 蘇 其桓, «Xinshao xian Shirong Su jia de jiazhu taipo xinyang minsu diaocha》新召縣時榮蘇家的 家主太婆信仰民俗調查, dans ibid.

II5. Extrait du Su shi wuxiu zupu 蘇氏五修族譜, 1932, cité par Su Yejiang 蘇業江, «Shang Meishan Manwang chongpai »上梅山蠻王崇拜, dans ibid.

iı6. Voir à ce sujet fig. 39 ci-dessus.

II7. Voir Su Zhuanfeng et Su Jianwen, art. cit., in Chen et Hua (Arrault), éd., op. cit. 
pieds du palanquin pour écrire dans la cendre, parfois c'est efficace, parfois non. Comme cette méthode détermine le faste et le néfaste pour le demandeur, et que de plus on dit qu'elle peut résoudre les accouchements difficiles parce que la maitresse de maison, la merveilleuse immortelle Liu, est une femme, les voisins de tout nom de famille viennent nombreux faire des vœux ${ }^{118}$.

向家主祈福時榮更有判字之法, 以椅作橋, 坐家主于內, 用柴灰置木板上, 兩人扶橋, 用橋 腳在灰上寫字語, 或驗或不驗 - 以定問者吉凶, 并謂可度產難, 因家主劉氏妙仙為女人, 鄰 近各姓亦多往許.

La nature familiale du maître de maison n'empêche aucunement sa portée collective et communautaire : l'efficacité d'un jiazhu, sa réputation et son charisme, renforcés par l'influence de la famille qu'il protège, conduisent collègues, voisins et amis à demander au maitre de maison d'intercéder en leur faveur. En quelque sorte, l'autel familial n'est pas réservé aux seuls membres de la famille, mais à tout un chacun que des raisons diverses peuvent amener à venir «consulter » le maître de maison : l'autel du domus devient ainsi en réalité un espace de transition entre la dimension familiale et privée, et celle communautaire et publique. Dans une logique parfaite de réciprocité, de la même manière que l'extérieur vient à lui, le maitre de maison doit aussi aller à l'extérieur, par exemple à l'occasion d'un rituel de demande de pluie, forcément collectif :

Tout d'abord, on fait sortir la statue du maitre de maison, on l'installe sur une autre aire rituelle et les sorciers ( $w u$ 巫) font leurs rituels. Alors le bruit des gongs et des tambours, de la corne de bœuf et des pétards se font entendre ensemble, au point que les tuiles des toits en tremblent, jusqu'aux canards et poulets qui s'agitent de manière désordonnée, et aux bols et coupes qui virevoltent confusément. On appelle ce rituel : activer les Furies (cui chang 催猖). Une fois les Furies réunies, des hommes et des femmes (la plupart du temps le nombre de personnes est fixé) complètement inconscients agitent leurs mains et tapent des pieds, ils bondissent et sautent devant la statue du maitre de maison afin de prévoir le moment où il pleuvra ; ceux-là sont appelés « les pieds des chevaux » [jiaoma 腳馬, les médiums]. Si les prières restent sans effet, les sorciers rassemblent tout le monde pour porter la statue dans la montagne afin d'y accomplir un rituel appelé «ouvrir la grotte »(da dong 打峒). Si pendant de longues années, les Furies ne peuvent pas être activées, il existe encore un rite pour les soutenir : trente, quarante coqs sont tués, leur sang est répandu sur la statue du maître de maison ; à l'extérieur de la grotte une dizaine de personnes [masquées], le visage fardé et portant la barbe, courent de-ci de-là plusieurs jours ; au moment où ils commencent à rentrer, les sorciers emprisonnent alors les Furies (feng chang 封猖), un rituel que l'on pratique une fois toutes les dizaines d'années.

先迎家主神像出外, 另立法壇, 巫作法事, 金鼓聲, 牛角聲, 爆竹聲同時并作, 聲震屋瓦, 甚 或將雞鴨亂橂, 碗盘亂拋, 日催猖・猖盛時, 即有不省人事之男或女 (多有固定之人) 手舞足 蹈, 跳跃于家主太公神像前預報雨期, 稱為腳馬 - 若祈禱無靈, 巫便糾集眾人扛神像人山作法 事, 名曰打峒 - 若年久, 猖不能催, 又用補猖之法, 殺雄雞三四十隻, 用雞血潑于家主像上, 峒外有十餘人, 涂臉掛䰅在外奔走數日・始歸, 巫即封猖, 數十年行一次·

Extrait de la généalogie des Su que nous avons rencontrée précédemment ${ }^{\mathrm{119}}$, cette description montre à quel point on fait jouer à la statue du maittre de maison un

II8. Extrait du Su sbi wuxiu zupu, 1933, cité par Su Yejiang 蘇業江, art. cit., in ibid.

II9. Ibid.

(C) École française d'Extrême-Orient, Paris, 2012

Do not circulate without permission of the editor / Ne pas diffuser sans autorisation de l'éditeur 


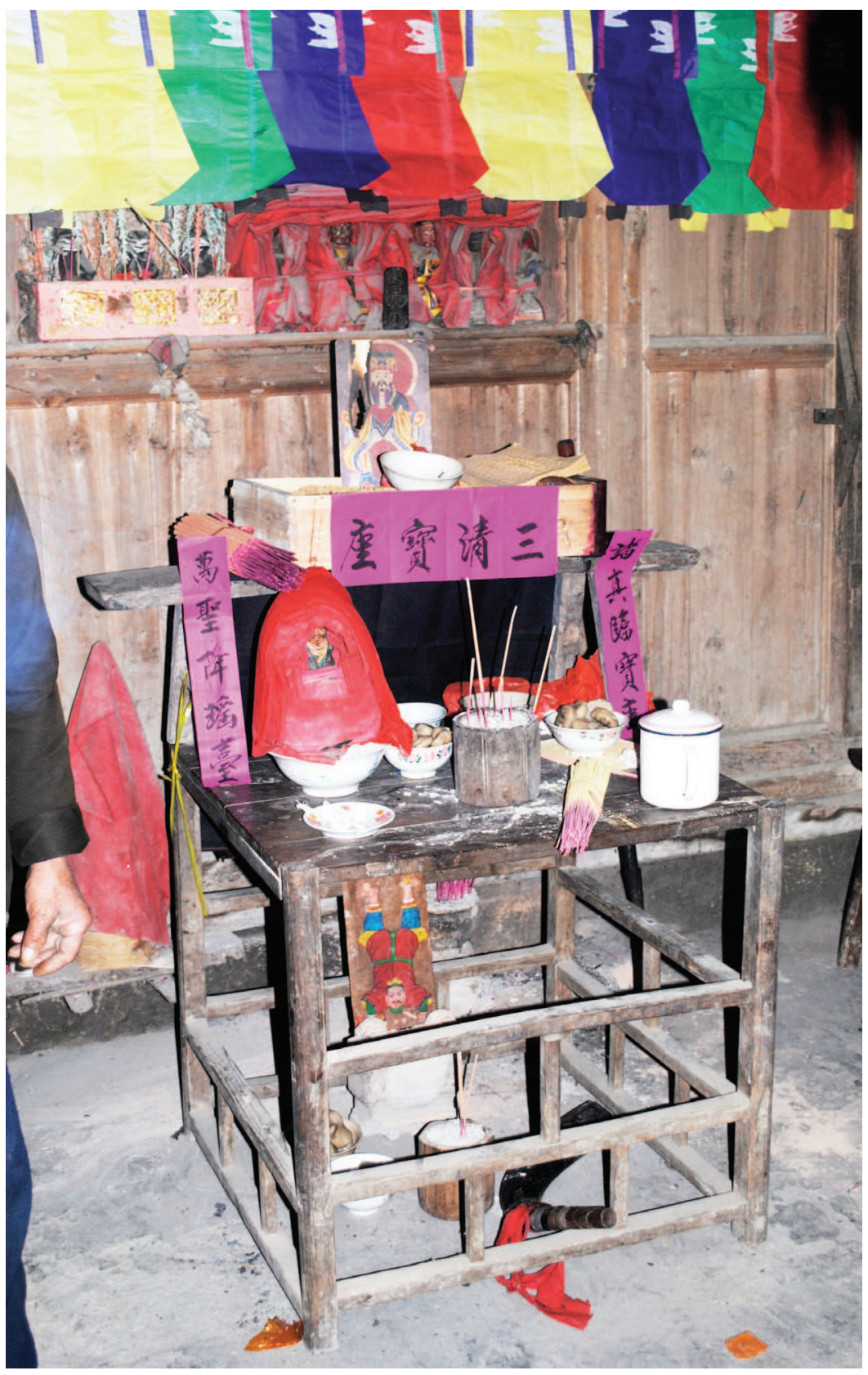

Fig. 42 : Autel installé à l'occasion du rituel Leipan jiao, exécuté dans la demeure de Luo Chongmei, district de Xinhua, canton de Shuiche, village de Baishui 白水, 2009. La statue de Luo Ziyan 羅自炎, nom d'ordination Jiaoming 教銘, père de l'officiant Luo Zhihui 羅志輝, est installée sur la table d'offrande. En dessous, l'image de Zhang Wulang 張五郎. Cliché Alain Arrault. 
rôle de premier plan. Cette cérémonie est en quelque sorte l'apothéose, l'accomplissement d'un culte que l'on rend ad personam à une statue, que ce soit pour son anniversaire, à des moments précis dans l'année, conduisant petit à petit la statue à n'être pas seulement un objet, mais surtout un sujet actif dans l'accomplissement de rites et rituels de plus en plus importants, que ce soit pour guérir, pour consulter, pour protéger et enfin pour mettre fin à une sécheresse menaçant l'ensemble de la population. En d'autres termes, au-delà du culte, de son rôle en tant qu'objet dudit culte, la statue vient à jouer une partition centrale, à l'instar d'une divinité sous l'égide de laquelle des rituels sont accomplis.

Cet usage des statuettes peut être également fait en parallèle avec les divinités dont les images sont accrochées sur les murs tout autour de l'autel : la statuette, celle d'un maitre ou d'un ancêtre proche, est alors mise en évidence, dans la position à la fois d'un témoin privilégié, du «patron » de la cérémonie et de celui qui dispense l'énergie rituelle nécessaire pour le bon déroulement de la liturgie. Lors du rituel Leipan jiao 雷盤醮 conduit par les officiants Luo Zhihui 羅志輝 et Zou Shengyun 㱀升雲 dans la demeure de Luo Chongmei ${ }^{120}$, dont le but était d'obtenir la protection et la guérison d'un membre de la famille par l'entremise d'un corps de remplacement (tishen 替身) expulsé à la toute fin du service, Luo Zhihui avait pris soin d'apporter la statue de son père et de la disposer bien en vue (voir fig. 42). La réussite de Luo fut en partie imputable au «souffle » ( $q$ i 氣), à la puissance rituelle dont son père était animé de son vivant et qu'il sut transmettre à son descendant, lui apportant une aide déterminante dans la bonne réalisation de la cérémonie.

\section{Conclusion}

S'il ne fait aucun doute que le culte que nous venons de décrire relève du foyer, de la famille restreinte, et non du clan et du temple communautaire, il ne cesse cependant de soulever des questions, tant les phénomènes qu'il révèle dérogent de ce que nous connaissons des cultes domestiques. La présence de divinités «traditionnelles » sur les autels domestiques n'est pas en soi une surprise, nous l'observons dans bien d'autres lieux dans le monde sinisé et dans bien d'autres civilisations. De même, le culte rendu aux ancêtres ne constitue pas une étrangeté. Mais le recours à des statues confère une dimension plus immédiate à l'image cultuelle : en trois dimensions, consacrée et vivante, elle apparait comme l'image idéale pour permettre une communication entre le monde des vivants et celui des morts. On peut bien sûr rendre un culte à une pierre, à un arbre, les croire efficients, mais ils demeurent abstraits, finalement très éloignés : de ce point de vue, les religions animistes et iconoclastes demandent plus d'efforts « intellectuels » que les religions de l'image, dont nous savons par ailleurs qu'elles ont souvent oscillé entre période iconomachique et période d'iconodulie.

I20. Voir à ce sujet ci-dessus, p. Io8 et ss. 
Il ne suffit cependant pas de s'arrêter à ces constats généralistes pour rendre compte de pratiques beaucoup plus sophistiquées qu'il n'y parait. L'usage d'une statuaire n'est pas exempt de variations, celle-ci n'est pas nécessairement répétitive et partout la même. C'est ce que prouve à l'évidence l'exemple hunanais. Si çà et là, notamment dans les régions méridionales de la Chine, il arrive de trouver des statues d'ancêtres ou leurs traces, non seulement ces découvertes restent rares et éparses par rapport à la région centrale du Hunan, mais de plus il s'agit le plus souvent de grands ancêtres, de fondateurs, en aucun cas de statues de proches parents et de maitres directs. Ce ne sont pas uniquement les lointains ancêtres ou maîtres qui sont divinisés ${ }^{121}$, mais aussi les défunts dont la mémoire conserve encore des traces vivantes : nul besoin de mythes, de légendes, de contes, pour les transformer ipso facto en divinités ; installés sur les autels, ils sont d'emblée objets de culte et acteurs dans certains rituels, le temps agissant bien sûr en leur faveur pour les rendre encore plus efficaces, merveilleux et prodigieux, élargissant ainsi leur sphère d'influence au-delà de la famille.

Une des caractéristiques de ces ancêtres, qui est par définition celle des maîtres, est d'avoir été initiés. Même les statues d'ancêtres en apparence les plus classiques recèlent par un détail iconographique, par une mention dans le certificat de consécration, une accointance avec quelque savoir-faire en matière de pratiques religieuses. Nous apprenons qu'ils ont été le plus souvent maitres exorcistes (fashi), ou encore médecins, charpentiers, chasseurs, sages-femmes, médiums, autant de métiers qui supposent une initiation ou du moins une inscription de ces personnages parmi les spécialistes du religieux. Au vu du nombre de statues actuellement conservées, il semblerait qu'une partie considérable de la société locale ait été touchée par ce phénomène, qui soulève de nombreuses questions, dont au moins une retiendra notre attention : comment expliquer une proportion aussi importante de spécialistes du religieux, y compris chez les femmes?

Nous savons que chez les Yao et les She 畣, des ethnies non-chinoises du sud de la Chine, tous les hommes sont nécessairement initiés et reçoivent de ce fait un nom d'ordination contenant le terme fa 法. Dans les généalogies des Hakka, nous trouvons le même procédé de langming 郎名, faming 法名 et duming 度名, qui présuppose un rituel d'initiation appelé fengchao 奉朝, accompli pour le futur marié avant ses noces. Selon Chan Winghoi 陳永海, cette pratique, qui est aussi un procédé d'ancestralisation, puisque l'initié entre dès lors dans la généalogie de la famille, aurait disparu aux alentours du XviII ${ }^{\mathrm{e}}$ siècle, à cause notamment de la mode de l'écriture des généalogies familiales qui aurait conduit à l’usage de noms plus « lettrés $»^{122}$.

I2I. Voir à ce sujet Yang Yanjie 楊彥杰, 《Huanan minjian de zushen chongbai » 華南民間的 祖神崇拜, Faguo banxue 法國漢學, 5 (2000), p. 388-399; John Lagerwey, "Gods and Ancestors : Cases of Crossover », in Tam Wai Lun 譚偉倫, éd., Zhongguo difang zongiiao yishi lunji 中國地方 宗教儀式論集, Zongjiao yu Zhongguo shehui yanjiu congshu 宗教與中國社會研究叢書, vol. I4, Hong Kong, Xianggang zhongwen daxue Chongji xueyuan zongjiao yu Zhongguo shehui yanjiu zhongxin 香港中文大學崇基學院宗教與中國社會研究中心, 2011, p. 367-405.

I22. Voir Chan Winghoi 陳永海, «Ordination Names in Hakka Genealogies: A Religious Practice and Its Decline », in David Faure et Helen Siu, éd., Down to Earth: The Territorial Bond 
Nous pouvons bien sûr arguer à nouveau de l'hypothèse des ethnies non chinoises dans la région du Hunan pour expliquer le nombre considérable d'ancêtres ordonnés. Mais, outre le fait que le Hunan fut dès les Song du Nord (960-II27) placé sous la tutelle de l'administration chinoise, puis régulièrement le théâtre de rébellions entraînant l'envoi d'une soldatesque laissée sur place de plus en plus nombreuse, d'une migration massive en provenance en particulier de la province du Jiangxi à partir des Ming, qu'elle qu'ait pu être la force de la tradition, il est plus que vraisemblable qu'au bout de quelques générations, sous les coups de boutoir de la « civilisation » chinoise, les Hunanais auraient dû perdre, comme les Hakka et d'une manière générale les populations des régions méridionales de la Chine, leurs spécificités ${ }^{123}$. Non seulement le Hunan n'a pas oublié ces pratiques « hétérodoxes », mais il les a perpétuées jusqu’à nos jours, et ceci malgré le fait qu'il a succombé, comme ailleurs, à la mode des généalogies familiales " confucéennes ", offrant ainsi un contraste saisissant entre un culte dédié à des initiés et des généalogies n'y faisant aucune allusion, sauf dans quelques textes biographiques évoquant le charisme de grands ancêtres. En d'autres termes, si le clan a "confucianisé » les ancêtres, la famille restreinte est demeurée fidèle aux siens - hommes et femmes - ainsi qu'aux maitres divinisés, introduisant un hiatus, un point aveugle entre culte clanique et culte familial. Cet écart n'est attesté que grâce à la conservation d'une statuaire. On peut donc se demander si l' "uniformisation » observée ailleurs n'est pas due $a$ contrario à l'absence de témoignages tangibles et alternatifs aux généalogies.

Le paysage religieux qui ressort de ces cultes familiaux aux ancêtres et aux maitres résiste aux tentatives généralisatrices. Nous avons certes affaire à des initiés, mais l'éventail nous conduit des maittres exorcistes aux médecins, sculpteurs, chasseurs, médiums, sages-femmes, acteurs... Si la vocation caractéristique à Taiwan des maitres exorcistes, par rapport aux prêtres taoïstes héritiers d'une tradition familiale, est confortée dans le Hunan par une majorité d'enseignements extra-familiaux, la formation familiale n'en est pas pour autant exclue. Les revendications en termes de religion laissent peu de place aux grands ordres, qu'ils soient bouddhistes ou taoïstes. On préfère cumuler les spécialités en revendiquant une double, et parfois une triple ordination, le costume et les rituels changeant au gré des besoins, avec cependant une conscience assez claire des différences. Ce sont pourtant les maittres exorcistes qui prédominent dans la statuaire, se plaçant volontiers sous l'égide de l'ordre du souverain de l'Origine, dont l'histoire demeure opaque, ou se réclamant d'un lieu, le mont des Abricotiers, à la fois symbolique et réel. Ces ambiguïtés disparaissent toutefois quant à la nature des méthodes rituelles employées : méthodes talismaniques, proférations d'invocations, usage de l'eau charmée, etc., qui les situent du côté des performances martiales, de la lutte symbolique contre les puissances maléfiques. Ces spécialistes, et leurs confrères, s'appuient sur des « divinités monstrueuses » locales, tels que Zhang Wulang 張五郎, les frères Meng 孟, les Dames et les rois du mont des Abricotiers, les Furies. Les lignées dont ils

in South China, Stanford, Stanford University Press, 1995, p. 65-82.

I23. Voir David Faure, «La solution lignagère. La révolution rituelle au XVI ${ }^{\mathrm{e}}$ siècle et l'Etat impérial chinois », Annales, Histoire, Sciences sociales, 2006/6, p. I29I-1316. 
se réclament ne comptent au mieux que quinze ou vingt générations, mais elles restent ancrées dans le terroir, à peine tentent-ils parfois d'y introduire de manière artificielle quelques personnages ou lignées célèbres afin de redorer leur blason, ce qui ne trompe au final personne.

On explique habituellement ces pratiques comme étant simplement le résultat de leur absorption dans le giron du taoïsme. S'agissant des peuples du Sud, le taoïsme aurait en quelque sorte agi comme l'avant-garde de la colonisation Han, apportant non seulement une écriture mais aussi une liturgie ${ }^{124}$. Les différences ne sont cependant pas niées, et elles s'ordonnent notamment entre des rituels en langue classique pour les taoïstes, et en langue vernaculaire pour les maitres locaux ${ }^{125}$, ou encore respectivement entre les rituels dits « lettrés » (wen 文) et ceux qualifiés de martiaux ( $w u$ 武) ; mais ces écarts sont pensés en termes de fonction et non de statut, en termes de complémentarité, allant parfois jusqu’à la fusion dans le cas de spécialistes taoïstes pouvant jouer, en changeant de costume, les deux rôles. Il suffit d'ajouter aux dimensions historique de l'absorption et liturgique des structures rituelles celle théologique de la révélation continue — le phénomène des textes révélés se perpétuant tout au long de l'histoire - pour faire du taoïsme, religion par nature cumulative et englobante ${ }^{\mathrm{i26}}$, le cadre indépassable dans lequel se nichent les cultes locaux, la « religion sans nom », la religion populaire, etc. En somme, les pratiques religieuses dont nous sommes témoins, ainsi que la statuaire du Hunan, ne seraient qu'un succédané et un avatar du taoïsme.

Il est indéniable que l'implication historique du taoïsme au niveau local, la conversion des divinités locales en divinités taö̈stes, l'absorption dès les Song du Sud des rites martiaux du Tonnerre (Leifa 雷法) dans le corpus taoïste, l'émergence relativement tardive des traditions fashi aux alentours de la dynastie des Ming, plaident en faveur de la thèse du succédané. Mais nous pourrions tout aussi bien renverser la perspective, en nous plaçant du point de vue des pratiques locales. L'histoire de Zhang Wulang 張五郎, la divinité locale omniprésente dans le Hunan, est de ce point de vue édifiante. De nombreuses légendes racontent que Zhang Wulang se rendit auprès de Laojun 老君, ou Taishang laojun 太上老君, pour étudier les rituels exorcistes (xue fa 學法). L'étude se transforma en compétition (dou fa 鬥法) : Laojun soumet Zhang à des épreuves de plus en plus difficiles, qu'il ne peut surmonter que grâce à l'aide de la fille de Laojun, amoureuse de Zhang dès le premier regard et dotée de pouvoirs magiques remarquables, qui ne peuvent être que le fruit de l'initiation reçue de son père. Les deux amants finissent par s'enfuir, provoquant la colère meurtrière

I24. Michel Strickmann, «The Tao Among the Yao: Taoism and the Sinification of South China ", in Sakai Tadao sensei koki shukuga-kinen no kai 酒井忠夫先生古稀祝賀記念の會, éd., Rekishi ni okeru minshū to bunka : Sakai Tadao sensei koki shukuga kinen ronshū 歴史における民衆 と文化一一酒井忠夫先生古稀祝賀記念論集, Tōkyō, Kokusho kankōkai 國書刊行會, 1982, p. 22-30.

I25. Kristofer Schipper, "Vernacular and Classical Ritual in China », Journal of Asian Studies, 45-I (1985), p. 2I-57. Pour une approche historique du statut des fashi, on lira avec grand intérêt le livre de Edward L. Davis, Society and the supernatural in Song China, Honolulu, University of Hawai'i Press, 200I.

I26. Vincent Goossaert et Caroline Gyss, Le Taoisme. La révélation continue, Paris, Gallimard, Réunion des Musées nationaux, coll. « Découvertes Gallimard », 2010.

(C) École française d'Extrême-Orient, Paris, 2012 Do not circulate without permission of the editor / Ne pas diffuser sans autorisation de l'éditeur 
de Laojun, qui lance contre Zhang des « couteaux volants ». La fille, que certains documents nomme Jiji 姬姬, un homophone pour jiji ru lüling 急急如律令 (Vite, vite, obéissez aux ordres !), déjoue par différents stratagèmes les coups portés par son père, mais elle doit finalement se résoudre à recourir à l'ultime stratagème qui consiste à figer Zhang Wulang dans la position du poirier : pieds en haut, tête en bas, il n'a plus ni visage ni yeux, il devient alors « invisible $»^{127}$.

Tout est dit dans cette histoire : la compétition avec le futur gendre, le rapt de la fille, la lutte à mort, la survie au prix d'une gaudriole handicapante. Certains diront qu'il ne s'agit finalement que d'une histoire de famille, que malgré les luttes intestines Zhang Wulang fait bien partie de la famille, mais c'est oublier que parfois il faut aux enfants sortir de la famille pour pouvoir exister. Zhang Wulang n'est pas entièrement soumis, et il demeure, bien que son image soit placée en dessous des autels, vénéré et omniprésent. D'une certaine manière, il est le porte drapeau d'une revendication identitaire locale irréductible. Il incarne à sa façon une forme de résistance, une résistance qu'il n'est pas nécessaire de penser en termes d'opposition frontale : la collaboration entre spécialistes religieux est de mise, sans que l'identité locale soit pour autant diluée dans un grand tout. De même qu'une statuaire d'ancêtres et de maîtres divinisés se superpose aux généalogies, les pratiques religieuses locales coexistent avec les grandes institutions, qu'elles soient taö̈stes, bouddhistes ou confucéennes. Il est ainsi fort probable que nous ayons avec le Hunan l'image d'une société locale ouverte, polymorphe et multipolaire, avant que les institutions, l'idéologie, les discours politiques et académiques ne l'uniformisent. Pour combien de temps encore?

I27. Il serait très intéressant de comparer l'histoire de Zhang Wulang et Laojun, avec celle de ce dernier et Xu Jia : cela montrerait que les rapports taoïsme et religion locale peuvent prendre bien des formes. Au sujet de Laojun et Xu Jia, voir K. Schipper, op. cit., p. 37-46.

(C) École française d'Extrême-Orient, Paris, 2012

Do not circulate without permission of the editor / Ne pas diffuser sans autorisation de l'éditeur 


\section{Appendice}

Tableau des ordres religieux mentionnés dans les certificats de consécration

\begin{tabular}{|c|c|c|c|c|c|c|}
\hline Ordre religieux & Numéro & $\begin{array}{l}\text { Initiation intra- } \\
\text { familiale }\end{array}$ & $\begin{array}{c}\text { Initiation } \\
\text { extra-familiale }\end{array}$ & $\begin{array}{l}\text { Culte } \\
\text { à une } \\
\text { divinité }\end{array}$ & Adresse & Date \\
\hline $\begin{array}{l}\text { 五[雷]梅山[捧]退 } \\
\text { 開刀破骨 }\end{array}$ & Т0746 & $\mathrm{X}$ & $X$ & & $\begin{array}{l}\text { 寧邑三都六區 } \\
\text { 九崙保迴崙峰 }\end{array}$ & 1857 \\
\hline 元皇大教 & Т0327 & & $\mathrm{X}$ & & $\begin{array}{l}\text { 寧邑十都十二 } \\
\text { 區扶坪保 }\end{array}$ & 1914 \\
\hline 元皇五十三教 & Т0564 & & $\mathrm{X}^{*}$ & & $\begin{array}{l}\text { 益陽縣桂華鄉 } \\
十 七 \text { 七都上 } \\
\text { 餘保 }\end{array}$ & 1850 \\
\hline \multirow{11}{*}{$\begin{array}{l}\text { 元皇正教/元皇/元 } \\
\text { 皇之傳/元皇神教 }\end{array}$} & Т0799 & & $\mathrm{X}^{*}$ & & manque & 1870 \\
\hline & T0106 & & $\mathrm{X}$ & & manque & 1897 \\
\hline & Т0651 & & $X$ & & $\begin{array}{l}\text { 寧 鄉 縣 六 都 } \\
\text { 五區 }\end{array}$ & 1943 \\
\hline & Т0519 & & $\mathrm{X}$ & & $\begin{array}{l}\text { 寧鄉縣十都六 } \\
\text { 區崇德鄉仁義 } \\
\text { 里 祖 塔 保 梁 } \\
\text { 家冲 }\end{array}$ & 1940 \\
\hline & Т0823 & & & $\mathrm{X}$ & \begin{tabular}{|l} 
新化縣石馬二 \\
都鵝溪
\end{tabular} & 1798 \\
\hline & Т0482 & & $\mathrm{X}$ & & $\begin{array}{l}\text { 湘鄉縣云下冊 } \\
\text { 八都神童鄉成 } \\
\text { 仁里佩塘保 }\end{array}$ & 1885 \\
\hline & Т0230 & $\mathrm{X}$ & & & $\begin{array}{l}\text { 湘鄉縣興讓八 } \\
\text { 都萬 [金]鄉善 } \\
\text { 集里梅龍[保] }\end{array}$ & 1794 \\
\hline & Т0767 & & $\mathrm{X}$ & & $\begin{array}{l}\text { 湘鄉縣鶴山十 } \\
\text { 五都花桥 中 } \\
\text { [区] }\end{array}$ & 1931 \\
\hline & T0471 & $\mathrm{X}$ & & & 潭邑七都六甲 & 1946 \\
\hline & Т0350 & & $\mathrm{X}$ & & $\begin{array}{l}\text { 益阳專区大 }[ \\
\text { 福] 区木[孔]公 } \\
\text { 社永福大隊大 } \\
\text { 江口八八畧 }\end{array}$ & 1963 \\
\hline & Т0374 & & $\mathrm{X}^{*}$ & & $\begin{array}{l}\text { 益陽縣十一里 } \\
\text { 桂 華 鄉十七 } \\
\text { 八都上[餘]保 } \\
\text { 管界 }\end{array}$ & 清 \\
\hline $\begin{array}{l}\text { 元皇正教口水、 } \\
\text { 報犯]、[打]符變 } \\
\text { 宅符法秘訣一宗 }\end{array}$ & Y1121066 & & $\mathrm{X}$ & & $\begin{array}{l}\text { 寧鄉縣十都口 } \\
\text { 二區太[]保 }\end{array}$ & 1874 \\
\hline
\end{tabular}




\begin{tabular}{|c|c|c|c|c|c|c|}
\hline 元皇正教諸般符法 & Т0292 & & $\mathrm{X}$ & & \begin{tabular}{|l} 
寧邑六都十 \\
一區
\end{tabular} & 1873 \\
\hline \multirow{3}{*}{ 元皇法教 } & Т0147 & & $\mathrm{X}$ & & $\begin{array}{l}\text { 安化縣長安鄉 } \\
\text { 龍圤坪地名歐 } \\
\text { 家圫 }\end{array}$ & 1940 \\
\hline & T0164 & & $\mathrm{X}$ & & $\begin{array}{l}\text { 安化縣長安鄉 } \\
\text { 龍地坪地名歐 } \\
\text { 家圫 }\end{array}$ & 1940 \\
\hline & Т0149 & & $\mathrm{X}$ & & $\begin{array}{l}\text { 安化縣長安鄉 } \\
\text { 龍吅坪地名歐 } \\
\text { 家圫 }\end{array}$ & 1940 \\
\hline 元皇洪範大教 & Т0104 & $\mathrm{X}$ & & & $\begin{array}{l}\text { 寧鄉縣崇德鄉 } \\
\text { 仁義里十都六 } \\
\text { 區祖 塔保 茶 } \\
\text { 圤冲 }\end{array}$ & 1811 \\
\hline 元皇捧退法訣 & Т0569 & & $\mathrm{X}$ & & $\begin{array}{l}\text { 寧鄉縣十都五[ } \\
\text { 龍][...] }\end{array}$ & 1909 \\
\hline $\begin{array}{l}\text { 元皇梅山[收]猖諸 } \\
\text { 盤符法秘訣 }\end{array}$ & Т0590 & & $\mathrm{X}$ & & $\begin{array}{l}\text { 寧鄉縣二都二 } \\
\text { 區崇德鄉開通 } \\
\text { 里鳥山堡 }\end{array}$ & 1891 \\
\hline 元皇梅山符法 & Т0400 & & $\mathrm{X}^{*}$ & & $\begin{array}{l}\text { 寧邑七都十 } \\
\text { 一區 }\end{array}$ & 1916 \\
\hline 元皇蛇水秘訣 & T0067 & & $\mathrm{X}$ & & manque & manque \\
\hline $\begin{array}{l}\text { 元皇道法先天正教 } \\
\text { 符罡咒法書符咒水 } \\
\text { 治病驅邪和瘟遣送 } \\
\text { 掃邪歸正 }\end{array}$ & Т0258 & $\mathrm{X}$ & & & $\begin{array}{l}\text { 新化縣石馬三 } \\
\text { 都 陂 頭 村 麻 } \\
\text { 水塘 }\end{array}$ & $\begin{array}{c}\text { incom- } \\
\text { plet }\end{array}$ \\
\hline $\begin{array}{l}\text { 元皇道法先天符罡 } \\
\text { 口决(訣) }\end{array}$ & Т0166 & $\mathrm{X}$ & & & $\begin{array}{l}\text { 新化縣石馬三 } \\
\text { 都陂頭村麻水 } \\
\text { 塘口坪 }\end{array}$ & $\begin{array}{c}\text { incom- } \\
\text { plet }\end{array}$ \\
\hline 元皇護命法 & Y112008 & & $\mathrm{X}$ & & manque & 1907 \\
\hline 元皇正教/魯班 & Y 1121058 & ? & ? & ? & $\begin{array}{l}\text { 寧鄉縣十都六 } \\
\text { 區大潙 山三 } \\
\text { 塔保 }\end{array}$ & 大清國 \\
\hline 元皇魯班正教 & Т0361 & $\mathrm{X}$ & & & $\begin{array}{l}\text { 寧 鄉 縣 三 都 } \\
\text { 五區 } \\
\end{array}$ & 1953 \\
\hline $\begin{array}{l}\text { 元皇魯班正教 } \\
\text { 啟水法決拳宗 }\end{array}$ & Y 1122026 & & $\mathrm{X}$ & & $\begin{array}{l}\text { 湘鄉縣[噎]天 } \\
\text { 十八都常安鄉 } \\
\text { 豐樂里伯泥保 }\end{array}$ & $\begin{array}{c}\text { incom- } \\
\text { plet }\end{array}$ \\
\hline 元皇魯班正藝 & Т0458 & & & $\mathrm{X}$ & $\begin{array}{l}\text { 益陽縣十二里 } \\
\text { 政陽鄉十九都 } \\
\text { 梓下保 }\end{array}$ & 1926 \\
\hline 木匠正教 & T0618 & & & $\mathrm{X}$ & \begin{tabular}{|l} 
寧九都五區長 \\
冲保(楚)
\end{tabular} & 1983 \\
\hline $\begin{array}{l}\text { 先天元皇五雷雪山 } \\
\text { 梅山娘娘收家書符 } \\
\text { 諸般法訣一宗 }\end{array}$ & Т0045 & & $\mathrm{X}$ & & 寧邑六都十區 & 1927 \\
\hline
\end{tabular}

(C) École française d'Extrême-Orient, Paris, 2012

Do not circulate without permission of the editor / Ne pas diffuser sans autorisation de l'éditeur 


\begin{tabular}{|c|c|c|c|c|c|c|}
\hline 先天元皇正[教] & T0601 & & & $\mathrm{X}$ & $\begin{array}{l}\ldots . .][\text { 化] 縣[永] } \\
{[\ldots . .] \text { 地 }[. . .]}\end{array}$ & manque \\
\hline $\begin{array}{l}\text { 先天元皇佛巫二教 } \\
\text { 五雷雪山[ ]梅山 } \\
\text { 收家[ ] ]禁諸盤(般) } \\
\text { 符法決(訣)持印 } \\
\text { 信]一宗 }\end{array}$ & Т0042 & $\mathrm{X}$ & & & 六(都)八區 & 1987 \\
\hline 先天佛道元皇正教 & Т0009 & & $\mathrm{X}$ & & $\begin{array}{l}\text { 新化縣石馬三 } \\
\text { 都[ ]溪大江村 } \\
\text { [流]江[ ] }\end{array}$ & 1899 \\
\hline 先天法旨 & Y1122019 & & $\mathrm{X}$ & & $\begin{array}{l}\text { 安化縣西路常 } \\
\text { 豐鄉浮青保王 } \\
\text { 家坊 }\end{array}$ & 1808 \\
\hline 先祖元皇家教 & Т0148 & $\mathrm{X}$ & & & $\begin{array}{l}\text { 新化縣大陽上 } \\
\text { 八都下 維 山 } \\
\text { 青山 }\end{array}$ & 1915 \\
\hline 老君之教 & Т0544 & & $\mathrm{X}$ & & $\begin{array}{l}\text { 隆回縣中和鄉 } \\
\text { 第十七保大地 } \\
\text { 名水西小地名 } \\
\text { 皎碧山 }\end{array}$ & 1918 \\
\hline 佛教 & Т0237 & & $\mathrm{X}$ & & $\begin{array}{l}\text { 安邑[歸]化鄉 } \\
\text { 駆頭舖陳家崙 }\end{array}$ & 1930 \\
\hline 佛教 & Т0834 & & $\mathrm{X}$ & & $\begin{array}{l}\text { 邵陽縣隆回鄉 } \\
\text { 地名金潭村福 } \\
\text { 地知止庵 }\end{array}$ & 1946 \\
\hline 佛道兩教 & Т0452 & $\mathrm{X}$ & & & $\begin{array}{l}\text { 新化縣石馬三 } \\
\text { 都下廟村 }\end{array}$ & $\begin{array}{c}\text { incom- } \\
\text { plet }\end{array}$ \\
\hline 巫釋正教 & T0466-2-1 & & $\mathrm{X}$ & & 寧邑七都八區 & 1922 \\
\hline 花蒼[燒]手 & Y 15032 & & $\mathrm{X}^{*}$ & & $\begin{array}{l}{[\text { [...][] ] 都九區 }} \\
\text { 沙坪保 }\end{array}$ & 1914 \\
\hline 茅山小教各项秘旨 & $\mathrm{T} 0313$ & & $\mathrm{X}$ & & 益陽十二里 & 1947 \\
\hline 梅山正教 & Т0454 & & & & $\begin{array}{l}\text { 湘鄉縣壼天十 } \\
\text { 八都常安乡 [ ][ } \\
\text { 樂]里岩前保 }\end{array}$ & 1937 \\
\hline 梅山和山法度 & Т0771 & & $\mathrm{X}^{*}$ & & $\begin{array}{l}\text { 湘鄉縣鶴山鄉 } \\
\text { 十五都花研區 }\end{array}$ & 1939 \\
\hline 梅山教？ & T0794 & $\mathrm{X}$ & & & manque & 1888 \\
\hline 梅山教? & T0790 & $\mathrm{X}$ & & & manque & 1930 \\
\hline 梅王正教 & Y 1121062 & $?$ & $?$ & & $\begin{array}{l}\text { 湘鄉 縣雲下 } \\
\text { 三十八[都]景[ } \\
\text { 夏]鄉西陽里浪 } \\
\text { 石保 }\end{array}$ & 1901 \\
\hline 梅苑[㳖]正教 & Т0562 & $\mathrm{X}$ & & & $\begin{array}{l}\text { 湘鄉縣瑴天十 } \\
\text { 八常安鄉豐樂 } \\
\text { 里物使保 }\end{array}$ & 1944 \\
\hline
\end{tabular}




\begin{tabular}{|c|c|c|c|c|c|c|}
\hline $\begin{array}{l}\text { 淮南元皇雪山符秘 } \\
\text { 决(訣)一宗 }\end{array}$ & Т0303 & & $\mathrm{X}$ & & $\begin{array}{l}\text { 寧鄉縣(?)三都 } \\
\text { 六區 }\end{array}$ & 1932 \\
\hline 清微元皇 正教 & T 1042 & & $\mathrm{X}$ & & $\begin{array}{l}\text { 湘鄉縣本邑十 } \\
\text { 八都常安鄉永 } \\
\text { 樂里岩前保 }\end{array}$ & $\begin{array}{c}\text { incom- } \\
\text { plet }\end{array}$ \\
\hline 華佗捧退一宗 & Т0822 & & $\mathrm{X}$ & & 湘鄉縣白泥保 & 1997 \\
\hline 葛翁正教 & T0584 & $\mathrm{X}$ & & & manque & 1929 \\
\hline 魯[班]玄[]宗 & Т0464 & & & $\mathrm{X}$ & $\begin{array}{l}\text { 湘鄉卅八(都) } \\
\text { 神童鄉城仁里 } \\
\text { 佩塘保 }\end{array}$ & $\begin{array}{c}\text { incom- } \\
\text { plet }\end{array}$ \\
\hline \multirow{11}{*}{ 魯班正教 } & Т0680 & & & $\mathrm{X}$ & manque & $\begin{array}{l}\text { incom- } \\
\text { plet }\end{array}$ \\
\hline & Т0577 & & $\mathrm{X}^{*}$ & & manque & 1916 \\
\hline & Т0516 & & & $\mathrm{X}$ & $\begin{array}{l}\text { 安化縣常豐鄉 } \\
\text { 伏口保 }\end{array}$ & 1928 \\
\hline & Т0515 & & & $\mathrm{X}$ & $\begin{array}{l}\text { 寧邑三都四區 } \\
\text { 鳥王山 }\end{array}$ & 1938 \\
\hline & Т0777 & & $\mathrm{X}$ & & $\begin{array}{l}\text { 寧邑六都十 } \\
\text { 二區 }\end{array}$ & 1953 \\
\hline & Т0780 & & & $\mathrm{X}$ & $\begin{array}{l}\text { 寧邑十二區泉 } \\
\text { 中鄉原屬六都 } \\
\text { [十][九]區 }\end{array}$ & 1954 \\
\hline & Т0628 & & $\mathrm{X}$ & & $\begin{array}{l}\text { 寧鄉六都一區 } \\
\text { (T0628-2-1) } \\
\text { 富鄉縣六都 }\end{array}$ & 1946 \\
\hline & Т0513 & & $\mathrm{X}$ & & $\begin{array}{l}\text { 寧 鄉 縣六 都 } \\
\text { 六區 }\end{array}$ & 1948 \\
\hline & Y 113043 & & $\mathrm{X}^{*}$ & & $\begin{array}{l}\text { 寧 鄉 縣六 都 } \\
\text { 四區 }\end{array}$ & 1938 \\
\hline & Т0575 & & $\mathrm{X}$ & & $\begin{array}{l}\text { 湘鄉縣十八都 } \\
\text { 常安鄉豐樂里 } \\
\text { 白泥保 }\end{array}$ & 1940 \\
\hline & Y 113123 & & & $\mathrm{X}$ & $\begin{array}{l}\text { 漣源縣[ ][ ]市 } \\
\text { ]右公社 }\end{array}$ & 1963 \\
\hline 黎薗正教 & Т0685 & & $\mathrm{X}$ & & $\begin{array}{l}\text { 新化縣石馬三 } \\
\text { 都黃沙村 }\end{array}$ & 1877 \\
\hline 龍啟教 & Т0185 & & $\mathrm{X}$ & & manque & manque \\
\hline 靈寶先天元皇正教 & Т0168 & $\mathrm{X}$ & & & $\begin{array}{l}\text { 新化縣石馬三 } \\
\text { 都陂 頭 村 麻 } \\
\text { 水塘 }\end{array}$ & $\begin{array}{l}\text { incom- } \\
\text { plet }\end{array}$ \\
\hline & 70 & 15 & 43 & 10 & & \\
\hline
\end{tabular}

$\mathrm{X}^{*}$ : relation de maitrise sans expression de lien de parenté, mais le patronyme de la statuette et du commanditaire est identique.

(C) École française d'Extrême-Orient, Paris, 2012

Do not circulate without permission of the editor / Ne pas diffuser sans autorisation de l'éditeur 


\section{Bibliographie}

\section{Abréviations}

DZ Daozang 道藏. Les références suivent la numération donnée dans K. Schipper et F. Verellen, eds., 2004, The Taoist Canon: A Historical Companion to the Daozang, Chicago, Chicago University Press, 2004.

T. Taishō shinshou daizōkyō 大正新修大藏經, édité par Takakusu Junjirō 高楠 順次郎 et. al., Tōkyō, Taishō Issaikyō kankōkai, I924-1932, IOo vols.

ZZ Dai Nihon zoku zōkyō 大日本續藏經, Kyōto, Zōkyō shoin 藏經書院, 19021905, reprinted as Xu zangjing 續藏經, Taipei, Xinwenfeng chubanshe 新文豐出版社, 1968-1978, 150 vols.

\section{Éditions électroniques et banques de données}

Arrault, Alain, éd., en collaboration avec Michela Bussottr, Patrice Fava, Li Feng 李豐, ZHANG Yao 張瑤

2005 Les statuettes religieuses du Hunan. I. La collection Patrice Fava (banque de données, version de travail ; 909 pièces), http://www.shenxianghunan. com/bdd_web_barbara/index.html

Arrault, Alain, éd., en collaboration avec Michela Bussotti, Li Feng, Zhang Yao, DENG Zhaohui 鄧昭慧, SHEN Jinxian 沈晉賢

2006 Les statuettes religieuses du Hunan. 2. La collection du musée du Hunan (banque de données, version de travail ; 856 pièces), http://www. shenxianghunan.com/bdd_web_barbara/index.html

ARrault, Alain, éd., en collaboration avec Yan Xinyuan 顏新元 et Li Feng

2009 Les statuettes religieuses du Hunan. 3. La collection Yan Xinyuan (banque de données, version de travail ; 1367 pièces), http://www.shenxianghunan. com/xyx/index.html

\section{Sources}

Anshen ben 安神本, s. 1., s. d., s. p., copie de Long Songlin 龍松林, Guandu qiao cun 官渡橋村, Yangxi zhen 洋溪鎮, Xinhua xian 新化縣.

Daozang jiyao 道藏輯要, Taipei, Xinwenfeng chuban gongsi 新文豐出版公司, 1977.

Guang Hongming ji 廣弘明集, $T$. vol. 52, n ${ }^{\circ} 2103$.

Hunzu liupai quanzong 混祖流派全宗, copié par Qin Chuhu 秦楚湖, Yangxi zhen 洋溪鎮, Xinhua xian 新化縣, 1904.

Jiu Tang sbu 舊唐書, Beijing, Zhonghua shuju 中華書局.

Kaiguang ben quanji 開光本全集, s.l., s.d., s.p., copie de Zou Zuwen 鄒祖文, Yangxi zhen 洋溪鎮, Xinhua xian 新化縣.

Laojun shejiao 老君設教, s.l., s.d., s.p., copie de Feng Xiaoyuan 奉孝元, Fengjia shan 奉家山, Xinhua xian 新化縣.

Sifen lü xingshi chao jianzheng ji 四分律行事鈔簡正記, ZZ, vol. 43. 
Taishang Laojun kaitian jing 太上老君開天經, DZ I437, fasc. $\mathrm{n}^{\circ}$ 1059, Zhonghua Daozang 中華道藏, vol. 8, p. 160-162.

Wenchang yinghua yuanbuang dadao zhenjun shuo zhusheng yansi miaoying zhenjing 文昌應化元皇大道真君說注生延嗣妙應真經, Daozang jiyao 道藏輯要, xingji 星集 9, p. 26a-35a.

Wenjin daojiao sanxiu zongpu 文厅道教三修宗譜, s. 1., 1935.

Xieji bianfang sbu 協紀辨方書, édition de 1739, in Siku quanshu 四庫全書, vol. 8II, Taibei, Taiwan Shangwu yinshuguan, 1983-1986.

Xishan qunxian buizhen ji 西山群仙會真記, $D Z 246$, fasc. $\mathrm{n}^{\circ} \mathrm{I} 16$.

Xiudan miaoyong zbili lun 修丹妙用至理論, $D Z$ 234, fasc. $\mathrm{n}^{\circ}$ II3.

$X u$ zhenren Yuxia ji 許眞人玉匣記, $D Z_{\mathrm{I} 480}$, fasc. $\mathrm{n}^{\circ} \mathrm{II} 08$, préface ${ }^{4} 433$. Voir aussi Zengbu Yuxia ji tongshu 增補玉匣記通書.

Yuanhuang dadao zhenjun jiujie baojing 元皇大道真君救劫寶經, Daozang jiyao 道藏輯 要, xing $j i$ 星集 9 , p. $18 \mathrm{a}-25 \mathrm{~b}$

Yunji qiqian 雲笈七籤, $D Z$ IO32, fasc. n' 677-702, Zhonghua Daozang, vol. 29, p.I-962

Yuxia ji 玉匣記, attribué à l'immortel Xu 許真人 : voir Xu zhenren Yuxia ji 許眞人玉 匣記 et Zengbu Yuxia ji tongshu 增補玉匣記通書.

Zengbu Yuxia ji tongshu 增補玉匣記通書, s.l., Sanyi tang 三義堂, I9II.

Zhonghua Daozang 中華道藏, Pékin, Huaxia chubanshe 華夏出版社, 2004.

Zhongguo xiju yinyue jicheng 中國戲劇音樂集成, Hunan juan 湖南卷, 2 vol., Beijing, Wenhua yishu chuban she 文化藝術出版社, 1992.

\section{Études}

Arrault, Alain

2008 «Analytic Essay on the Domestic Statuary of Central Hunan: The Sult to Divinities, Parents and Masters ", Journal of Chinese Religions, 36, p. I- 53 .

Arrault, Alain et Bussotti, Michela

2008 "Statuettes religieuses et certificats de consécration en Chine du Sud », Arts asiatiques, 63, p. 36-6o.

Arrault, Alain et Martzloff, Jean-Claude

2003 «Les calendriers de Dunhuang », in Marc Kalinowski, éd., Divination et société dans la Chine médiévale, Paris, BNF, p. 85-2II.

CHAN Winghoi 陳永海

1995 «Ordination Names in Hakka Genealogies: A Religious Practice and Its Decline », in David Faure, Helen Siu, eds., Down to Earth: The Territorial Bond in South China, Stanford, Stanford University Press, p. 65-82.

Chen Zi'ai 陳子艾 et Hua Lan 華瀾 (Alain Arrault), éd.

[sous presse] “Xiangzhong zongjiao yu xiangtu shebui” diaocha baogao ji “湘中 宗教與鄉土社會”調査報告集, 2 vols., actes du colloque du même nom, Loudi 婁底 — Shuiche 水車, 24-29 juin 2006, Beijing, Zongjiao wenhua chubanshe 宗教文化出版社. 
[sous presse] «Taiyuan tong huapeng de xinyang wenhua neiwen he tong yu tongshen de yanbian ji yuanyin » 桃源峒花篷的信仰文化內蓝和峒與峒神的 演變及原因, dans Chen et Hua (Arrault), éd., “Xiangzhong zongjiao yu xiangtu shebui" diaocha baogao ji.

Davis, Edward L.

2001 Society and the supernatural in Song China, Honolulu, University of Hawai'i Press.

De Groot, J.J.M.

1886 Les fêtes annuellement célébrées à Emoui (Amoy), Paris, Ernest Leroux.

1967 Religious system of China, 6 vol., Leyden, Brill, I907-I9Io, réimpression Taipei, Cheng-wen Publishing 成文出版社.

FAURE, David

2006 «La solution lignagère. La révolution rituelle au $\mathrm{XVI}^{\mathrm{e}}$ siècle et l'Etat impérial chinois », Annales, Histoire, Sciences sociales, 2006/6, p. I291-1316.

FeNG Yunxing 奉雲星

[sous presse] 《Fengjia shan jumin shekan wenhua diaocha 》 奉家山居民神弇文 化調查, dans Chen et Hua (Arrault), éd., "Xiangzhong zongjiao yu xiangtu shebui" diaocha baogao ji.

Gamble, Sidney D.

1929 Peking Wages, ed. Maxwell S. Stewart, Peiping 北平, The Department of Sociology and Social work, Yenching University.

Goossaert, Vincent et Gyss, Caroline

2010 Le Taoïsme. La révélation continue, Paris, Gallimard, Réunion des Musées Nationaux, coll. « Découvertes Gallimard».

Hu Nenggai 胡能改

2001 Meishan kebu : Xinhua xingshi tanyuan 梅山客户: 新化姓氏探源, Xinhua 新 化, Guoji Yan Huang wenhua chubanshe 國際炎黄文化出版社.

Huang Zhen 黃鎮

[sous presse] 《Meishan shigong de fafu, faqi yu mianju» 梅山師公的法服, 法器 與面具, dans Chen et Hua (Arrault), éd., "Xiangzhong zongjiao yu xiangtu shebui" diaocha baogao ji.

HuANG Zhen 黄鎮 et Liu Qigui 劉期貴

[sous presse] «Longhui xian shigong de fashi, fafu, faqi ji you guan zhuanshuo » 隆回縣師公的法事, 法服, 法器及有關傳說, dans Chen et Hua (Arrault), éd., "Xiangzhong zongjiao yu xiangtu shebui" diaocha baogao ji.

Hunan tushu guan 湖南圖書館, éd.

2006 Hunan shizu yuanliu 湖南氏族源流, Changsha, Yuelu shushe 岳麓書社. 
Jun Hyeonggwon 田炣權

2004 «Qing mo zhi Minguo shiqi Hunan Rucheng xian de shangpin liutong he wujia biandong 》清末至民國時期湖南汝城縣的商品流通和物價變動, Qingshi yanjiu 清史研究, I, P. IO2-IIO.

LAGERWEY, John

2011 "Gods and Ancestors: Cases of Crossover ", in Tam Wai Lun 譚偉倫, ed., Zhongguo difang zongjiao yishi lunji 中國地方宗教儀式論集, Zongjiao yu Zhongguo shebui yanjiu congshu 宗教與中國社會研究叢書, vol. I4, Hong Kong, Xianggang zhongwen daxue Chongji xueyuan zongjiao yu Zhongguo shehui yanjiu zhongxin 香港中文大學崇基學院宗教與中國社會研究中心, p. 367-405.

LAU, D. C. (trad.)

1984 Mencius [Mengzi 孟子], Hong Kong, The Chinese University Press.

LI Guangdi 李光地 (1642-1718)

Rongcun yulu xuji 榕村語錄續集, dans Siku weishou jikan 四庫未收輯刊, siji 肆輯, vol. 2I, Beijing, Beijing chubanshe 北京出版社, 1997.

Li Kui 李魁

[sous presse] 《Meishan shuishi de ge'an diaocha yu yitong bijiao » 梅山水師的個 案調查與異同比教, dans Chen et Hua (Arrault), éd., “Xiangzhong zongjiao yu xiangtu shehui" diaocha baogao ji.

Li Xinwu 李新吾

[sous presse] «Lenhshui jiang Yangyuanzhang tan shigong yi daoshi de yitong bijiao » 冷水江楊源張壇師公與道士的異同比較, dans Chen et Hua (Arrault), éd., "Xiangzhong zongjiao yu xiangtu shebui" diaocha baogao ji.

Liu Weishun 劉偉順

[sous presse] 《Xinshao xian Wenxian guan diaochao baogao » 新郡縣文仙觀调 查報告, dans Chen et Hua (Arrault), éd., "Xiangzhong zongjiao yu xiangtu shebui" diaocha baogao ji.

MA Tieying 馬鐵鷹

[sous presse] 《Bei Longhui de minjian yisu » 北隆回的民間醫俗, dans Chen et Hua (Arrault), éd., "Xiangzhong zongjiao yu xiangtu shebui" diaocba baogao ji.

ŌFuCHI Ninji 大淵忍爾

1983 Cbūgokujin no shūkyō girei : Bukkyō, Dōkyō, minkan shinkō 中國人の宗教 禮儀一一佛教・道教・民間信仰, Tōkyō, Fukutake shoten 福武書店.

QIN Guorong 秦國榮

1998 Daopai banci 道派班次, mss, Yangxi zhen 洋溪鎮.

SCHIPPER, Kristofer

1985 "Vernacular and Classical Ritual in Taoism », Journal of Asian Studies, $45^{-\mathrm{I}}$, P. $2 \mathrm{I}^{-} 57$. 
Schipper, Kristofer and Verellen, Franciscus, eds.

2004 The Taoist Canon: A Historical Companion to the Daozang, Chicago, University of Chicago Press.

Strickmann, Michel

1982 "The Tao Among the Yao: Taoism and the Sinification of South China ", in Sakai Tadao sensei koki shukuga-kinen no kai 酒井忠夫先生古稀祝賀 記念の會, éd., Rekishi ni okeru minshū to bunka : Sakai Tadao sensei koki sbukuga kinen ronshü 歴史における民衆と文化一一酒井忠夫先生古稀祝賀記念 論集, Tōkyō, Kokusho kankōkai 國書刊行會, p. 22-30.

1996 "L'icône animée », dans Mantras et mandarins, Paris, NRF, Gallimard, p. I65-2II.

Su Qihuan 蘇其桓

[sous presse] «Xinshao xian Shirong Su jia de jiazhu taipo xinyang minsu diaocha » 新邵縣時榮蘇家的家主太婆信仰民俗調查, dans Chen et Hua (Arrault), éd., "Xiangzhong zongjiao yu xiangtu shehui" diaocha baogao ji.

Su Yejiang 蘇業江

[sous presse] 《Shang Meishan Manwang chongpai» 上梅山蠻王崇拜, dans Chen et Hua (Arrault), éd., "Xiangzhong zongjiao yu xiangtu shebui" diaocha baogao ji.

Su Zhengrong 蘇崢嵓

[sous presse] 《Xiang zhong Tuzhu shan qu de Niangniang xinyang 》 湘中土主 山區的娘娘信仰, dans Chen et Hua (Arrault), éd., “Xiangzhong zongjiao yu xiangtu shebui" diaocha baogao ji.

Su Zhuanfeng 蘇傳鳳 et Su Jianwen 蘇建文

[sous presse] 《Meishan Su Gan guju di renmen de taigong xinyang 》 梅山蘇 甘古居地人們的太公信仰, dans Chen et Hua (Arrault), éd., “Xiangzhong zongjiao yu xiangtu shebui" diaocha baogao ji.

WANG Xiaowu 王小悟

[sous presse] 《Anhua Huifei cun shenkan wenhua de diaocha yu yanjiu» 安化翬 飛村神弇文化的調查與研究, dans Chen et Hua (Arrault), éd., “Xiangzhong zongjiao yu xiangtu shebui" diaocha baogao ji.

YANG Dexiang 楊德湘

[sous presse] «Meishan shigong jiao 'He Niangniang' fashi ji qi yuanyuan yu wenhua neihan » 梅山師公教和娘娘法事及其淵源與文化內涵, dans Chen et Hua (Arrault), éd., "Xiangzhong zongjiao yu xiangtu shebui” diaocha baogao $j i$.

YANG Yanjie 楊彥杰

2000 《Huanan minjian de zushen chongbai » 華南民間的祖神崇拜, Faguo banxue 法國漢學, 5, p. 388-399. 


\section{ZENG Di 曾迪}

[sous presse] «Xinhua xian daojiao yuanliu ji Julan gong leijiao chanshi » 新化縣 道教源流暨聚嵐宮雷醮闢事, dans Chen et Hua (Arrault), éd., “Xiangzhong zongiiao yu xiangtu shebui" diaocha baogao ji.

[sous presse] 《Meishan nuoxi “He Meishan”》梅山儺戲“和梅山”, dans Chen et Hua (Arrault), éd., "Xiangzhong zongjiao yu xiangtu shebui" diaocha baogao ji.

ZENG Yufang 曾毓芳

"Wang Yan gong shulüe»王言公述略, dans Zeng shi wuxiu Xiang pu zhengbian 曾氏五修祥譜正編, “Wenlu fang 》 文祿房, juan 4, Duqin tang 篤親堂, I857, s. p.

ZHANG Shihong 張式弘

[sous presse] 《Anhua daojiao de diaocha baogao » 安化道教的調查報告, dans Chen et Hua (Arrault), éd., "Xiangzhong zongjiao yu xiangtu shebui" diaocha baogao ji.

ZHONG Yuru 鍾玉如

2004 《Yuanling de wunuo wenhua » 沅陵的巫儺文化, Huaibua xueyuan xuebao 懷化學院學報, 23, 3, p. 56-59.

Zou Shengyun 唃升雲

[sous presse] «Songcao. Miaotian guan chuan cheng de teshu chaodu fashi » 送曹 - 苗田觀傳承的特殊超度法事, dans Chen et Hua (Arrault), éd., "Xiangzhong zongjiao yu xiangtu shebui" diaocha baogao ji.

[sous presse] «Taiyuan tong huapeng de xinyang wenhua neiwen he tong yu tongshen de yanbian ji yuanyin » 桃源峒花篷的信仰文化內蘊和峒與峒神的 演變及原因, dans Chen et Hua (Arrault), éd., “Xiangzhong zongjiao yu xiangtu shebui" diaocha baogao ji. 